Portland State University

PDXScholar

$7-2013$

\title{
Evaluation of the Performance of the Sydney Coordinated Adaptive Traffic System (SCATS) on Powell Boulevard in Portland, OR
}

\author{
Miguel A. Figliozzi \\ Portland State University, figliozzi@pdx.edu \\ Christopher Monsere \\ Portland State University, monsere@pdx.edu
}

Follow this and additional works at: https://pdxscholar.library.pdx.edu/cengin_fac

Part of the Civil and Environmental Engineering Commons

Let us know how access to this document benefits you.

\section{Citation Details}

Figliozzi, Miguel A., and Christopher Monsere. "Evaluation of the Performance of the Sydney Coordinated Adaptive Traffic System (SCATS) on Powell Boulevard in Portland, OR." OTREC -RR-13-07. Portland, OR: Transportation Research and Education Center (TREC) 2013. https://dx.doi.org/10.15760/trec.104

This Report is brought to you for free and open access. It has been accepted for inclusion in Civil and Environmental Engineering Faculty Publications and Presentations by an authorized administrator of PDXScholar. Please contact us if we can make this document more accessible: pdxscholar@pdx.edu. 


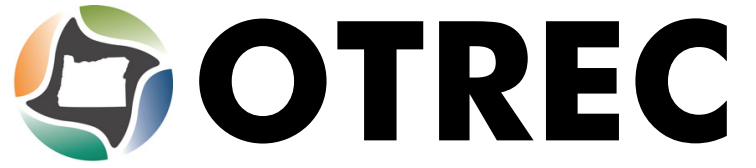

FINAL REPORT

\section{Evaluation of the Performance of the Sydney Adaptive \\ Traffic System (SCATS) on Powell Boulevard in Portland, OR}

OTREC-RR-13-07 July 2013 



\title{
EVALUATION OF THE PERFORMANCE OF THE SYDNEY COORDINATED ADAPTIVE TRAFFIC SYSTEM (SCATS) ON POWELL BOULEVARD IN PORTLAND, OR.
}

\section{Final Report}

\section{OTREC-RR-13-07}

by

Miguel Figliozzi, Ph.D.

Christopher Monsere, Ph.D

\author{
Research Assistants \\ Eric Albright \\ Wei Feng \\ Adam Moore \\ Courtney Slavin
}

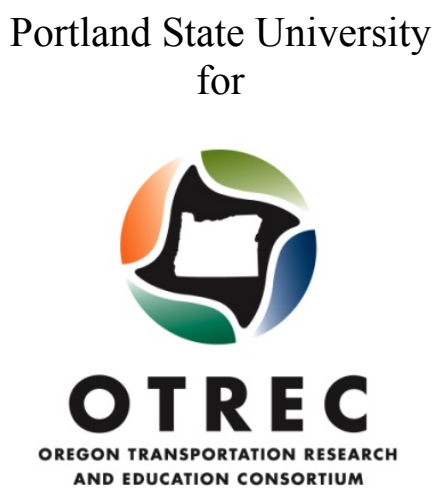

P.O. Box 751

Portland, OR 97207

\section{July 2013}





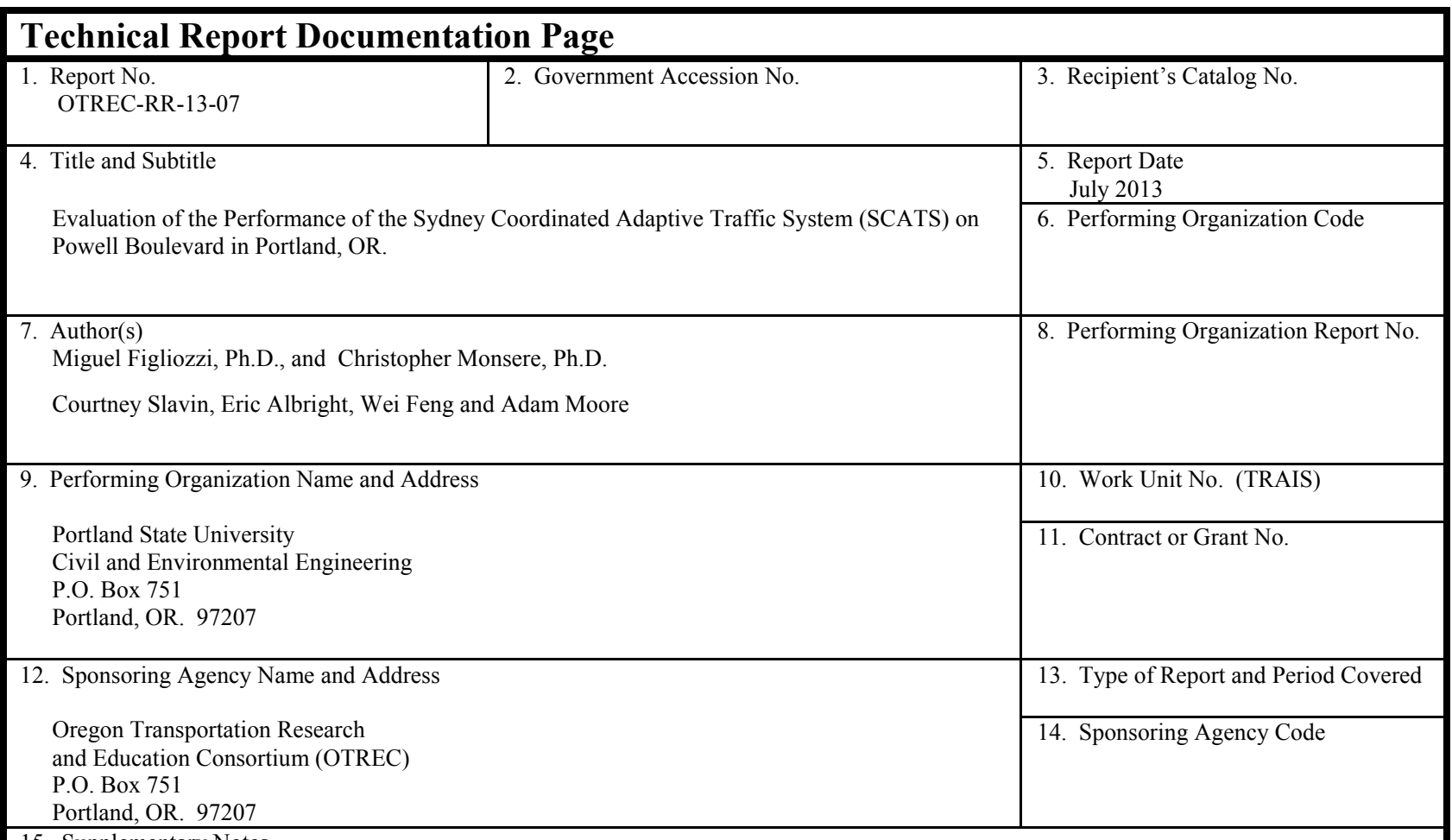

15. Supplementary Notes

\section{Abstract}

The Sydney Coordinated Adaptive Traffic System (SCATS) is used to mitigate traffic congestion along urban arterial corridors. Although there has been research on SCATS' performance, this report combines three different areas of research about SCATS that are not known to be represented in any research literature. These include: (a) the relationship between SCATS, traffic volumes, and Transit Signal Priority (TSP); (b) between TSP and traffic conditions; and (c) the correlation between signal timing and air quality; in particular, human exposure to the air pollutant $\mathrm{PM}_{2.5}$ at intersections. In addition, this research looked at the key factors affecting transit user exposure to traffic-related pollutants at bus shelters. All areas of study present the results of statistical tests and regressions to determine SCATS or traffic variables impacts.

SCATS did show statistically significant improvements regarding traffic speeds at one minor intersection, even when traffic volumes showed a statistically significant improvement. At a major intersection, results were mixed and not conclusive. Overall, it was determined that the improvements available through SCATS vary depending on the time of day and the direction of travel. TSP was not negatively affected by SCATS. In controlling for both priority and traffic conditions, each were shown to have a distinguished and significant impact on bus travel time. Non-priority signals had a much greater impact on travel time than priority signals (11.0 and 0.6 seconds for the corridor model, respectively). In controlling for both priority and traffic conditions, each were shown to have a distinguished and significant impact on travel time. Utilizing a regression model, results in an intuitive ranking of the intersections' delay was produced; major intersections with high traffic volumes on crossing streets are likely to not experience TSP benefits.

To a high degree, this research has shown that pedestrian exposure can be considered as an outcome of traffic-signal timing decisions made by cities and counties. The statistical results have shown the high impact that signal timing and queuing have on pedestrian level exposure. Heavy vehicle volume was a significant variable as well as the presence of buses. The reduction of bus idling time through more efficient operations and transit-signal priority is likely to reduce pedestrian and transit users' pollution exposure levels. Longer green times along the main corridor are able to significantly reduce particulate matter for transit users and pedestrians waiting at the sidewalk of the intersection, whereas time allocated to cross the street increases queuing and exposure along the main corridor. The impact of heavy-duty diesel engines is also clear. The reduction of bus idling time through more efficient operations and transit-signal priority is likely to reduce pedestrian and transit users' pollution exposure levels. Transit agencies can also reduce pollution significantly by improving the efficiency and cleanliness of their engines. TriMet (the local transit agency) initiatives to improve fuel efficiency by installing EMP engine-cooling devices not only improve fuel efficiency, but also air quality. Finally, significant reductions in transit users' exposure to traffic-related pollution can be made at bus stops by properly orienting the shelter and by reducing bus idling.

\begin{tabular}{|c|c|c|c|}
\hline \multicolumn{2}{|c|}{$\begin{array}{l}\text { 17. Key Words } \\
\text { Evaluation, SCATS, transit, performance, air quality, PM, UFP }\end{array}$} & \multicolumn{2}{|c|}{$\begin{array}{l}\text { 18. Distribution Statement } \\
\text { No restrictions. Copies available from OTREC: } \\
\text { www.otrec.us }\end{array}$} \\
\hline $\begin{array}{l}\text { 19. Security Classification (of this report) } \\
\text { Unclassified }\end{array}$ & $\begin{array}{l}\text { 20. Security Classification (of this page) } \\
\text { Unclassified }\end{array}$ & $\begin{array}{l}\text { 21. No. of Pages } \\
80\end{array}$ & 22. Price \\
\hline
\end{tabular}





\section{ACKNOWLEDGEMENTS}

The authors gratefully acknowledge the Oregon Transportation Research and Education Consortium (OTREC) for sponsoring this project. The authors are thankful to Peter Koonce and Willie Rotich from the City of Portland Bureau of Transportation, and to Steve Callas and David Crout from TriMet for providing data and helpful comments. Any errors or omissions are the sole responsibility of the authors.

\section{DISCLAIMER}

The contents of this report reflect the views of the authors, who is solely responsible for the facts and the accuracy of the material and information presented herein. This document is disseminated under the sponsorship of the U.S. Department of Transportation University Transportation Centers Program in the interest of information exchange. The U.S. Government assumes no liability for the contents or use thereof. The contents do not necessarily reflect the official views of the U.S. Government. This report does not constitute a standard, specification, or regulation. 


\section{TABLE OF CONTENTS}

\begin{tabular}{|c|c|}
\hline & SUMMA \\
\hline 0 & 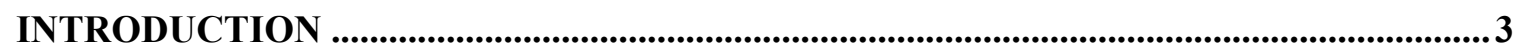 \\
\hline 1.1 & \\
\hline 1.2 & 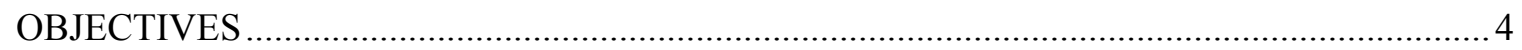 \\
\hline 1.3 & EPORT ORGANIZATION.. \\
\hline 2.0 & LITERATURE REVIEW ......... \\
\hline 2.1 & VALUATION OF SCATS .......... \\
\hline 2.2 & RANSIT SIGNAL PRIORITY. \\
\hline 2.3 & TRAFFIC AND AIR QUALITY. \\
\hline $\mathbf{0}$ & STUDY AREA....... \\
\hline $\mathbf{0}$ & A STATISTICAL STUDY OF THE IMPACTS OF SCATS ADAPTIVE TRAFFIC \\
\hline IGNA & IL CONTROL ON TRAFFIC AND TRANSIT PERRFORMANCE.. \\
\hline 4.1 & 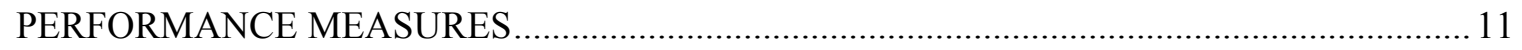 \\
\hline 4.2 & EVALUATION RESULTS ......... \\
\hline 4.3 & 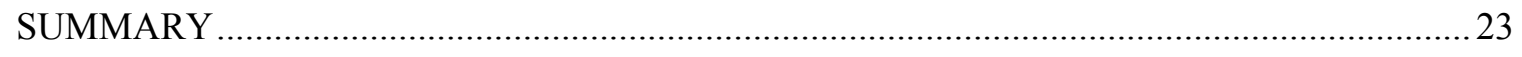 \\
\hline & SCHEDULE RECOVERY FOR LATE BUSES: WHAT ARE THE INDIVID \\
\hline & CONTRIB \\
\hline 5.1 & STUDY DESIGN \\
\hline 5.2 & CAPTURING TSP AND TRAFFIC CONDITI \\
\hline 5.3 & GENERIC STOP SEGMENT RESULTS . \\
\hline 5.4 & INTERSECTION LEVEL RESULTS ... \\
\hline 5.5 & (1) \\
\hline 0 & THE IMPACT OF TRAFFIC SIGNAL TIMING ON PEDESTRIAN PARTICULTE \\
\hline IAT T & ER EXPOSUR \\
\hline 6.1 & STUD \\
\hline 6.2 & DATA COLLECTION AND PROCESSING ... \\
\hline 6.3 & STATISTICAL ANALYSIS .. \\
\hline 6.4 & SUMMARY .... \\
\hline 7.0 & AN EMPIRICAL ANALYSIS OF EXPOSURE TO PARTICULATE MATTER AT BUS \\
\hline CTO 2 - & SHELTERS.. \\
\hline 7.1 & STUDY LO \\
\hline 7.2 & DATA COLLECTION A \\
\hline 7.3 & STATISTICAL ANALYSIS . \\
\hline 7.4 & SUMMARY ...... \\
\hline .0 & ND RECOMMENDATIONS. \\
\hline & וטים תחת \\
\hline
\end{tabular}




\section{LIST OF TABLES}

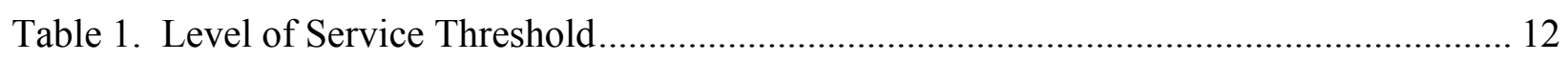

Table 2. Models for Daily Traffic on Powell Boulevard ............................................................. 13

Table 3. Travel Speed and Volume Before-After Comparison and Significance Test.................. 14

Table 4. Time-Points, Off-Peak-Hour Reliability Performance …………………….................. 17

Table 5. Idling Time Before-and-After Comparison ...................................................................... 18

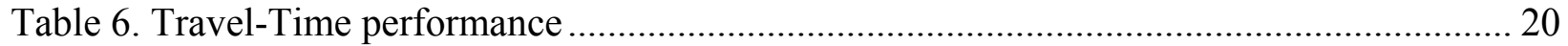

Table 7. Explanatory Variables in Regression Model .............................................................. 21

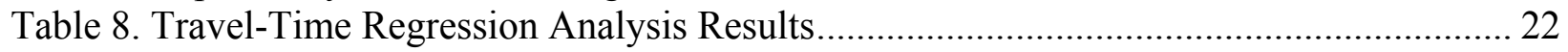

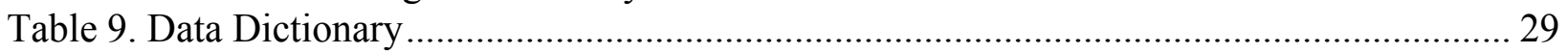

Table 10. Stop-to-Stop Travel Time Base Models ………………………………………............ 31

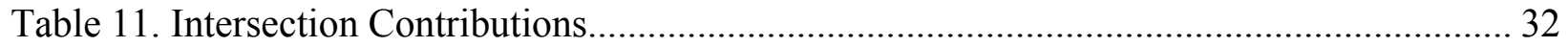

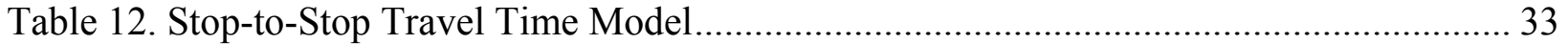

Table 13. Signalized Intersection's Contribution to Travel Time ..................................................... 34

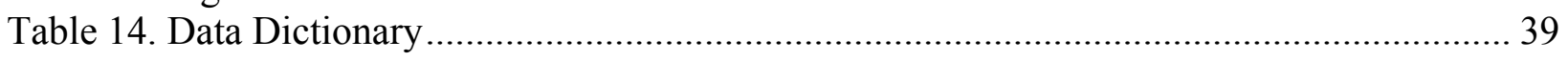

Table 15. $\mathrm{PM}_{2.5}$ Log Linear \& AR1 Models........................................................................... 41

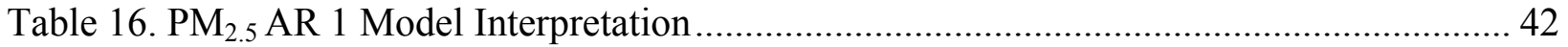

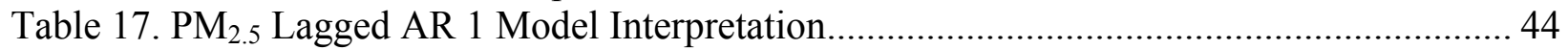

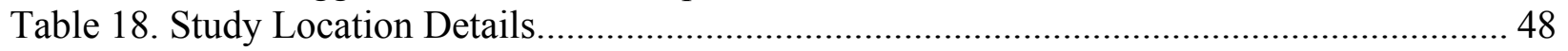

Table 19. Variable Definitions................................................................................................ 51

Table 20. Summary Statistics for Each Shelter Location ......................................................... 52

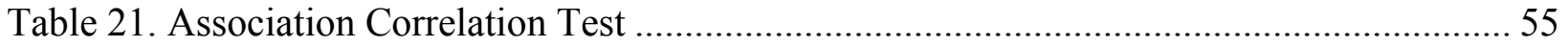

Table 22. Log-Linear UFP Regression Model............................................................................ 57

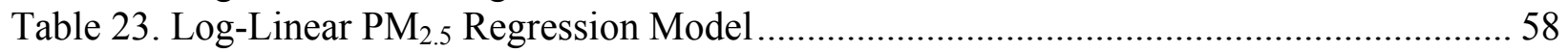

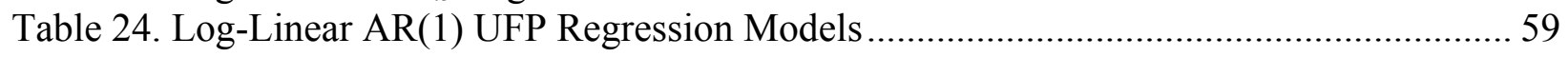

Table 25. Log-Linear AR(1) $\mathrm{PM}_{2.5}$ Regression Models .............................................................. 60 


\section{LIST OF FIGURES}

Figure 1. Overview of Study Area ..................................................................................... 10

Figure 2. Speed and Volume (Before-After) Comparisons at Powell and 26th Avenue............. 15

Figure 3. Peak Hours and Idling time before and after Comparison. ....................................... 19

Figure 4. Map of the SE Powell Blvd corridor in South East Portland. Source: Google Maps ${ }^{\text {TM }} 26$

Figure 5. Stop Location Geometry................................................................................. 27

Figure 6. Intersection Contribution and Recovery at signalized intersections ......................... 35

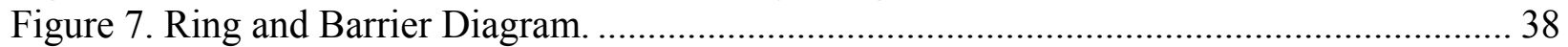

Figure 8. $\mathrm{PM}_{2.5}$ Concentration, Wind, and Volume Scatterplots ........................................... 40

Figure 9. Cross Correlation Plots ................................................................................... 43

Figure 10. Shelter orientation (a) towards roadway and (b) away from roadway..................... 47

Figure 11. Morning (a) UFP and (b) $\mathrm{PM}_{2.5}$ concentrations inside and outside the bus shelter ... 53

Figure 12. Bivariate polar plots illustrating wind speed and direction effects on UFP and $\mathrm{PM}_{2.5} 54$ 


\section{EXECUTIVE SUMMARY}

Mitigating traffic congestion along urban arterial corridors has become a challenge in the United States. Unlike freeways, arterial corridors are part of the urban landscape, intersecting with neighborhood streets and business and shopping districts. Arterials are also used as commuter routes and usually provide public transportation amenities such as buses. Traffic along arterial corridors is usually mitigated using a system of traffic signals at intersections. Conventional, pre-timed signal systems are unable to mitigate unexpected traffic patterns that occur, especially during heavy commuting periods. In order to improve mobility on congested corridors with variable demand, the Sydney Coordinated Adaptive Traffic System (SCATS) was developed. In October 2011, a SCATS system was installed along Powell Boulevard, a major arterial in Portland, OR., known to exhibit congestion at peak travel times.

Although there has been research on SCATS' performance, this report combines three different areas of research not known to be represented in any research literature. This includes the relationship between SCATS and Transit Signal Priority (TSP); between TSP and bus driver behavior; and the correlation between signal timing and air quality, specifically human exposure to the air pollutant $\mathrm{PM}_{2.5}$ along transit corridors. The analysis in this report is based on traffic and transit data collected before and after the installation of SCATS along Powell Boulevard. Although SCATS was not designed as a tool to improve transit performance, it is important to determine how SCATS affects transit performance on congested corridors. This work presents the results of statistical tests and regressions to determine SCATS' impacts. Statistically significant differences were observed in terms of travel times and SCATS-related regression parameters. Overall, travel time changes or improvements related to SCATS seem to depend greatly on the direction of travel and the time of day.

Previous research has shown that TSP can improve the quality of service of late transit buses. However, in most cases, these studies fail to incorporate traffic conditions or how drivers can drive more aggressively to make up lost time. Failing to control for traffic conditions or bus driver behavior may then overestimate the effectiveness of TSP; maximum bus travel speed was used as a proxy variable to account for traffic conditions and driver behavior. This study attempted to quantify the impacts of both TSP and traffic conditions on travel time by controlling for bus-stop and intersection characteristics. In addition to signal-priority requests and maximum speed, time of day, stop-location type, signalized intersection and bus-bay data were used to study and predict travel time. Regression analysis was used to model travel time from the departure at one stop to the arrival at the next stop. Both priority requests and traffic conditions were found to be significant predictors of travel-time reduction. Also, signalized intersections with priority were shown to have significantly less travel-time penalties when compared to those intersections without TSP available. The model coefficients for individual intersections along the corridor were then used to create a ranking of intersection transit performance and the results were compared to a previous study of late-bus recovery.

Compared to motor vehicle drivers, pedestrians and transit users are greatly exposed to vehicle emissions. However, pedestrian exposure to traffic emissions is typically not a consideration when traffic-signal timing decisions are made. The relationship between exposure to air pollution and traffic-signal timing has not yet been fully explored or modeled. This research quantifies the factors that contribute to pedestrian and transit-user exposure to fine particulate matter $\left(\mathrm{PM}_{2.5}\right)$ at a busy intersection along an urban arterial. This study is the first research effort to combine real-world, detailed, traffic-signal timing data (at five-second intervals) and air-pollutant exposure data. Several types of variables are included in the statistical analysis: traffic signal timing variables, weather-related variables, traffic volumes and composition variables, and variables associated to bus presence and characteristics. Statistical results show the importance of signal-timing variables, traffic volumes and queuing. In addition, to better understand transit users' exposure to traffic pollution this research looked at transit-user exposure to 
PM2.5 and ultrafine particulate matter (UFP) at bus-stop shelter design. Statistical analysis showed a significant difference in PM2.5 and UFP levels inside and outside shelters. Shelters facing towards the roadway exhibited greater PM2.5 and UFP concentrations inside the shelter, while shelters facing away from the roadway exhibited lower concentrations. These results highlight the importance of shelter design considerations from a transit user's air pollution exposure perspective. 


\subsection{INTRODUCTION}

\subsection{BACKGROUND}

Traffic congestion in urban areas is a concern in the United States. Over the past 20 years traffic congestion has increased in cities, peak traffic periods have lengthened, and travel-time reliability has decreased (Federal Highway Administration). Conventional traffic-signal timing is unresponsive to actual traffic conditions, controlled by pre-timed plans that are updated every couple of years. Pre-timed traffic control systems are unable to mitigate unexpected traffic patterns that occur, especially during heavy commuting periods. As an alternative to conventional signal-timing regimens, adaptive traffic-signal control systems have been developed. These systems use detection and algorithms to adapt the trafficsignal timing parameters to optimize the traffic operations. There are various types of adaptive systems available, which operate in slightly different manners. One adaptive traffic-control system that is widely used is the Sydney Coordinated Adaptive Traffic System (SCATS).

SCATS was developed in Australia in the early 1970s and has been used successfully to alleviate traffic congestion. SCATS uses loop detection and video cameras to operate in real-time conditions. The system optimizes cycle lengths, phase splits and offsets on a cycle-by-cycle basis. The degree of saturation is used to adjust the cycle length. The phase splits are timed by giving each approach an equal degree of saturation, or higher priority can be given to the main road. SCATS selects offsets based on free-flow travel time and degree of saturation, which provides minimum stops for the vehicles on the main roadway. Its popularity has grown over time, and it has expanded to other countries and within the United States (TransCore).

Efficient and reliable public transportation systems are imperative to the successful operation of transportation networks in congested urban areas. Public transportation can provide more affordable options and is able to transport more passengers per vehicle than private vehicles. Of all public transportation modes, buses make up the largest percentage in the United States with $52.5 \%$ of the number of passenger trips and $38.9 \%$ of the passenger miles. Ttransit use has been increasing over the last two decades (Dickens and Neff, 2011).

One of the challenges of a bus-transit system is that it is directly affected by roadway congestion wherever they share the right-of-way with general traffic. Hence, the performance of public transit in congested corridors is affected by traffic volumes and signal timing at intersections. A tool that can be used to help buses to stay on schedule is TSP. A late bus communicates to the trafficsignal controller that it is requesting priority, and the controller adjusts the settings to allow for additional green time for the bus or shorten the red time if the bus is waiting at the intersection. Efficient TSP systems are able to help the bus stay on schedule and improve its travel time and reliability (Smith, Hemily and Ivanovic, 2005).

Traffic conditions and late bus drivers can reduce or increase running time by allowing faster speeds or driving more or less aggressively. TSP, traffic conditions and operator behavior have the potential to affect bus travel time and schedule adherence, and thus keep buses on schedule. Hence, schedule recovery can be related to TSP interventions, traffic conditions, driver behavior or all of them simultaneously.

Air pollution is also a concern along transportation corridors. In urban areas, the main contributor to a population's exposure to air pollution is vehicle emissions on or around transportation facilities. Many urban arterials are multimodal in nature, facilitating travel by private vehicles, transit buses, bicycles, and 
walking. Transportation system users are exposed to air pollution in urban areas regardless of their mode choice. For example, transit users waiting for the bus are within close proximity to vehicle emissions for extended periods of time, despite contributing very little to roadway pollution levels themselves.

Mitigating their exposure may be accomplished through relatively simple measures, such as carefully considering the placement of bus-stop shelters, though little research has been dedicated to exploring this possibility. The efficiency of traffic operations on arterial roadways can greatly impact bus emissions in terms of the number of stops and the delay. The relationship between traffic-signal timing and pedestrian exposure to emissions has not yet been fully explored. If this relationship can be more clearly understood, future traffic-signal timing efforts will be able to reduce pedestrian exposure level to emissions.

\subsection{OBJECTIVES}

The objectives of this study are to:

1) Evaluate whether the implementation of adaptive traffic systems positively impact traffic speeds, bus transit performance, and TSP.

2) Regarding TSP and traffic, the report attempts to answer the following questions:

a. Does TSP provide significant benefits to bus travel time?

b. Are the effects of TSP and traffic conditions measurable and distinguishable?

3) To assess if there are correlations between pedestrian and transit-user, air-pollution exposure levels along an urban arterial with traffic variables, In addition, this research analyzes whether bus-shelter design impacts transit-user exposure levels to traffic-related air pollution.

\subsection{REPORT ORGANIZATION}

The report is organized as follows: A literature review is provided for each of the three studies in Section 2. A general description of the study area is given in Section 3. Section 4 covers the relationship and performance of TSP and SCATS along the study area in addition to results for both general vehicle traffic and transit traffic. Section 5 covers the research of TSP and its influence on bus-driver behavior. Section 6 will present the impact of traffic-signal timing on pedestrian particulate matter exposure. Section 7 presents results regarding the impact of bus-shelter design on transit user's exposure levels. Conclusions and recommendations will be given in Section 8. 


\subsection{LITERATURE REVIEW}

\subsection{EVALUATION OF SCATS}

SCATS has been installed in various cities across the United States with mixed results. Various beforeand-after studies have been conducted in order to test the improvements of adaptive traffic-signal control compared to existing pre-timed or time-of-day plans. Many claims are made about performance improvements; however, the results vary on a case-by-case basis. There are differences in performance improvements that partly have to do with how the evaluation was conducted in addition to other potential site-specific reasons.

The evaluation of an adaptive traffic-signal control is not a trivial exercise and requires certain conditions to ensure fairness and accuracy. One condition is related to the reference system or the existing timing plans that constitute the evaluation baseline. The more optimized and responsive to traffic conditions the existing timing plans already are, the more difficult it is to see improvements with the implementation of an adaptive system. Clearly defining the baseline system performance is crucial when reporting improvements (Soyke, Bollock and Gettman, 2006).

Other factors that affect the evaluation of an adaptive traffic-signal control system are roadway specific, such as changes in traffic volumes and geometry of the intersections. Geometric changes or not controlling for traffic volumes between the before-and-after periods can be another common flaw in the evaluation. Relevant data should be collected within a narrow time window to avoid big changes in the demand patterns. None of the previous SCATS case studies evaluated transit in detail. Most of the studies did not use permanent data collection stations and instead focused their evaluation on peak and off-peak periods. This is insufficient due to the fact that traffic volumes fluctuate greatly throughout the day.

Very few SCATS evaluations have been conducted in the United States, and no evaluation has closely examined the relationship between SCATS and TSP. The City of Beaverton, OR., implemented SCATS on Farmington Road in 2011. However, only six of the intersections are operating under adaptive signal control. The segment, which is 0.7 miles in length, carries heavy traffic in the eastbound and westbound directions. The corridor has two travel lanes in each direction and a speed limit of 30 miles per hour. The before-and-after study conducted by DKS Associates (Peters, O'Brien and Pachman.) examined three performance measures: side-street delay, travel time, and recovery from signal preemption. Side-street delay was obtained from a Synchro model, the travel time from Bluetooth MAC reader devices, and the recovery from signal preemption was found with preemption logs. The results indicated that the largest improvement was a faster recovery time after preemption from the TriMet WES commuter train. Before SCATS was implemented, recovery from preemption took up to six minutes; afterwards, the recovery was reduced to less than two minutes. With preemption triggered every 10-15 minutes during peak periods, this reduction in recovery has made a significant impact on traffic performance. However, side-street delay was reduced only when traffic arrived randomly and not in a platoon. The greatest travel-time improvements occurred during off-peak periods. There were no statistical tests conducted. Previous

research has also simulated SCATS and its impact on emissions using VISSIM, but TSP was not included (Kergaye, Stevanovic and Martin, 2010; Stevanovic, Stevanovic and Kergaye, 2012). 


\subsection{TRANSIT SIGNAL PRIORITY}

TSP is the process of detecting transit vehicles approaching signalized intersections and adjusting the phasing of the signal in real time to reduce the delay experienced by the transit vehicle. The literature surrounding TSP can generally be divided into two categories: simulations and empirical studies.

The installation of a TSP system represents an expensive and possibly unrewarding decision for the agencies managing transit and signalized intersection lighting. Often simulations are used to better understand the potential benefits of TSP on bus run time and schedule adherence without the high installation costs and risk associated with a new system. Simulations showing the potential benefits of TSP are well documented in the literature. An arterial corridor in Arlington, VA., was simulated by Dion et al. This study found that buses benefited from TSP while other vehicle traffic was not significantly impacted (2004). Byrne et al. simulated TSP at one intersection and found that far-side stop locations are preferable to near-side stops (2005). Janos and Furth used VISSIM, a transportation and traffic modeling software, to simulate a signal control strategy on an arterial in San Juan with intersections that would respond more quickly to bus-priority effects (2002). In Vancouver, BC, Ngan et al. used VISSIM to simulate TSP on a corridor where results lead to the recommendation for an installation of TSP on the corridor (2004).

In contrast to simulations of TSP, empirical studies are performed on existing TSP installations in order to assess the operation of the new system. Skabardonis evaluated the effects of passive and active TSP on a real-life arterial (2000). Conditional priority has been shown to strongly influence schedule adherence (Furth and Muller, 2000). Empirical analysis of TSP in Portland has been performed previously at the route level (Kimpel et al., 2005; Kloos, Danaher and Hunter-Zaworski, 1995), with mixed reviews on the performance across routes and corridors. Additionally, the authors of this paper have conducted previous analysis of this particular corridor that suggested TSP performance was varied among different intersections (i.e., median recovery in seconds was greater at intersections with less demand on the minor crossing streets) (Albright and Figliozzi, 2012).

While a number of papers in the literature acknowledge the potential for operator behavior and actions to have significant effects on running time and schedule adherence, no TSP performance studies control for traffic conditions or driver behavior. Most studies tend to only consider geometric factors, such as distance and stop location or environmental factors, such as passenger movement and intersection delay. Some studies have considered the operator as a source of running-time variation, but they have focused on driver characteristics such as years of experience and route familiarity and not on the individual actions that may make up time or affect schedule recovery. For instance, Strathman et al. studied AVL and APC bus data, and found bus operators are an important source of running-time variation (2002); this study utilized experience, complaints and shift type, but TSP and driver variables were not jointly studied.

\subsection{TRAFFIC AND AIR QUALITY}

\subsubsection{Air Pollutants, Regulations, and Health Effects}

The U.S. Environmental Protection Agency (EPA) defines air pollution as "the presence of contaminants or pollutant substances in the air that interfere with human health or welfare, or produce other harmful environmental effects." Since the EPA was established in 19070, the number of laws concerning the regulation of air pollution has grown substantially. The EPA created the National Ambient Air Quality Standards (NAAQS), which includes regulations for six pollutants: carbon monoxide, particulate 
matter, nitrogen oxide, sulfur oxide, smog and lead (Vallero, D., 2008). This research will focus on particulate matter.

Particulate matter (PM) is a mixture of solid particles and liquid droplets found in the air that is defined by the particle size. It is made up of acids (such as nitrates and sulfates), organic chemicals, metals, and soil or dust particles. $\mathrm{PM}_{2.5}$ is between $1.0 \mu \mathrm{m}$ and $2.5 \mu \mathrm{m}$, and is measured by mass, in micrograms per cubic meter $\left(\mu \mathrm{g} / \mathrm{m}^{3}\right)$. Under the NAAQS, the standards for $\mathrm{PM}_{2.5}$ are $15 \mu \mathrm{g} / \mathrm{m}^{3}$ annually and $35 \mu \mathrm{g} / \mathrm{m}^{3}$ for 24 hours (EPA, 2011). On June 29, 2012, the EPA proposed a reduction in the annual $\mathrm{PM}_{2.5}$ standard to $12-13 \mu \mathrm{g} / \mathrm{m}^{3}$, which would result in a $13-20 \%$ reduction (EPA, 2012). Ambient $\mathrm{PM}_{2.5}$ background concentrations are generally below $16 \mu \mathrm{g} / \mathrm{m}^{3}$ (Bedada, et al., 2007).

The negative health impacts of PM are widely documented. The anatomy of the human lung enables smaller particles to travel deeper into the lung and can allow some particles to reach a person's bloodstream. Because of this, finer particles pose a greater health risk than coarse ones (EPA). There are several health effects that are related to the respiratory system from exposure to particulate matter, such as wheezing and exacerbation of asthma, respiratory infections, cardiovascular disease, chronic bronchitis and chronic obstructive pulmonary disease (COPD) (Vallero, 2008).

\subsubsection{Traffic Signals and Emissions Models}

The most common type of traffic-signal timing is time-of-day plans (i.e., to best meet changes in traffic demands, a different signal plan is implemented at predetermined times of the day). This is the least expensive type of plan and requires less hardware to operate. As traffic conditions change over time, time-of-day plans must be updated to meet new traffic conditions. The process of updating traffic-signal plans is called signal retiming. Signal retiming re-optimizes the operation of signalized intersections by adjusting parameters such as cycle length, split times, and offsets. According to the Federal Highway Administration's (FHWA) Signal Timing Manual, signal timing should be reviewed every three to five years to check for changes in traffic patterns and re-optimize timing plans (Kittleson \& Associates, Inc., 2008). It has also been suggested that retiming should be done at least once a year to keep up with changes in traffic patterns (Sunkari, 2004). Adaptive systems can be used to automatically adjust the timing plans to respond to the real traffic conditions. Although more expensive to operate, it is estimated that signal timing can reduce harmful emissions by 5-10\% (Peters, McCourt, Hurtado, 2009).

Quantifying the effect of traffic-signal timing on air quality can be done indirectly through modeling emissions and dispersions or through field measurements. In the USA, the EPA leads air-quality modeling efforts, and has developed the Motor Vehicle Emission Simulator (MOVES) and emission dispersion models such as AERMOD.

Utilizing MOVES, Papson, Hartley and Kuo analyzed emissions, including $\mathrm{NO}_{\mathrm{x}}$ and $\mathrm{PM}$, at congested and uncongested signalized intersections; emission factors from MOVES for each activity mode, including cruising, deceleration, idling, and acceleration, in grams per vehicle-second and time-in-mode were used to calculate total emissions under different traffic conditions; time-in-mode was obtained from the control delay, queue length, and cycle length outputs from a Synchro model (Papson, Hartley, Kou, 2011). Li, Wu and Zou examined the impacts of signal timing on vehicle emissions at an isolated intersection by using three models with pre-timed signalization. The three models were optimized by minimizing: (a) delay, (b) stops, and (c) delay by limiting stops to a set value or constraint. Some of the inputs are: traffic volume, green time, lost time, cycle length, speed, deceleration rate, acceleration rate, and roadway grade. The model results were used to calculate the emissions. The modeling results showed that reducing the number of stops can reduce $\mathrm{CO}$ at the expense of slight increases in $\mathrm{CO}_{2}, \mathrm{HC}$, and $\mathrm{NO}_{\mathrm{x}}$ (Li et al., 2004). Li, Li, Pang, Yang and Tian created a model for a signalized intersection that optimizes cycle length and green time by minimizing a weighted sum of delay, fuel consumption, and emissions. 
The model was applied to an intersection in Nanjing City in China. Modeling results show that the optimized signal timing yields reductions in delay and emissions (Li et al., 2004).

The studies cited in the previous paragraph have examined the impacts of traffic-signal timing on emissions using models; the modeling results have not been verified against field data. Some studies have collected field data related to signalization and emissions, but these studies have specifically focused on in-vehicle exposure as detailed next.

\subsubsection{Traffic Signals and In-Vehicle Exposure}

Given the complexity of air-quality modeling, another line of research has focused on linking in-vehicle exposure and traffic signals. Unal et. al. examined the effect of signalization on in-vehicle emissions in Cary, N.C., by collecting emissions and traffic data before and after signalization of the corridors. The results indicated that in cases where the traffic flow significantly improved, emissions followed the same trend. Additionally, the highest emission rates were during acceleration, with idling being the lowest; the impact of signalization was measured along the main corridor and the effect on the side street was not examined (Unal, Rouphail, Frey, 2003).

Parikh studied the effect of signal coordination on emissions in the Dallas/Fort Worth area by collecting real-world emissions data during morning and afternoon peak and off-peak periods every second including $\mathrm{CO}_{2}, \mathrm{NO}_{\mathrm{x}}, \mathrm{HC}, \mathrm{CO}$, engine rpm, vehicle speeds, temperature, and position data using GPS. Data was collected before the signal retiming and a year later during the same months. The results showed that there was a reduction in $\mathrm{NO}_{\mathrm{x}}$ and an increase in $\mathrm{CO}_{2}$ after signal coordination (Parikh, 2006). The impact from atmospheric factors, such as temperature and relative humidity, was not included.

Tao et. al. collected real-world emissions data including $\mathrm{CO}_{2}, \mathrm{NO}_{\mathrm{x}}, \mathrm{HC}$, and $\mathrm{CO}$ during peak and off-peak periods to check for differences in emissions depending on traffic conditions. Coordinated timing was used in the field while a second car was driven according to a set of rules to emulate non-coordinated conditions. The results showed that coordinated timing reduced emissions, but the effect was weakened during the peak periods where the average speed decreased (Tao, Shi, Yu, 2011). This study compared coordinated to non-coordinated conditions without actually changing the timing in the field; the results may have been different if data was collected with a true non-coordinated timing scheme.

The case studies examined in this literature review had a different goal than this research does. These studies focused on exposure for drivers, but they do not help to explain exposure for other modes, such as walking or waiting for transit. Drivers have much more control over their environment than pedestrians and transit users do. Empirical research has clearly shown that drivers can significantly reduce their exposure, by $83-90 \%$, to in-vehicle PM exposure by closing the vehicle vents or running the air conditioning system (Bigazzi and Figloizzi, 2005)

Pedestrians, outdoor business customers and employees, and transit users do not have an option to protect themselves from poor air quality. The goal of this research is to examine exposure for pedestrians and transit users by measuring air quality at a stationary location on the sidewalk where transportation users walk or wait. Additionally, previous research efforts have not examined the effect of signal timing on emissions by simultaneously incorporating the effect of weather, heavy vehicles, transit vehicles, volume, and signal timing into their data collection and analysis. 


\subsection{STUDY AREA}

Powell Boulevard is an urban arterial corridor located in Portland, OR., that connects the downtown core to the City of Gresham. Powell Boulevard, also known as Highway US-26, has two lanes of traffic in each direction and a variety of land uses. The route runs in the eastbound and westbound direction and includes the Ross Island Bridge, which crosses over the Willamette River. The study area is shown below in Figure 1 Figure 1(a), where downtown Portland is shown to the west of Powell Boulevard. In the map, points "A" and "D" are the start and end points of the study corridor.

The SCATS implementation is shown in Figure 1 (b); SCATS is implemented in the segment between point "A" (SE Milwaukie Avenue - close to $11^{\text {th }}$ and Powell) and "D" (SE 72 ${ }^{\text {nd }}$ Avenue and Powell). The intersections of particular interest are highlighted below with either a triangle or a circle. The triangles represent transit time points, which are bus stops where holding and schedule recovery can take place if the bus operator is ahead of schedule. The two intersections that are circled are the locations of traffic counters. This was the first SCATS implementation to integrate transit system priority in the United States (City of Portland, 2011).

In 2009, the average annual daily traffic ranged from 56,500 vehicles right off the Ross Island Bridge, to 41,000 vehicles at the intersection of Powell and Milwaukie, and 34,100 vehicles at the intersection of Powell and $39^{\text {th }}$ (ODOT, 2009). For example, following the Highway Capacity Manual procedures for signalized intersection level of service, it was found that the intersection Powell and $39^{\text {th }}$ has a low level of service during the peak periods, ranging from $\mathrm{C}$ to $\mathrm{F}$. For the morning peak period, from 8-9 a.m., one of the movements operates at a level of service $\mathrm{F}$ and the westbound through movements are at level of service E. For the afternoon peak period, from 5-6 p.m., four of the movements operate at level of service F, with two of them being left turns and the other two being the eastbound through movements. The level of service by movement for Powell and $39^{\text {th }}$ Avenue is shown in Figure 1(c) for both peak periods. The intersection level of service was calculated based on delay per movement (Kittelson \& Associates, Quality Counts, Portland State University).

A high-frequency bus route, Route 9, runs along Powell Boulevard. Route 9 is within the top 10 TriMet routes in terms of productivity and passenger demand. In 2011, Route 9 served 37.9 passengers per vehicle hour (TriMet, 2012). The peak periods for Route 9 coincide with general vehicle traffic peaks, and occur in the morning for the westbound direction and in the afternoon for the eastbound direction. 


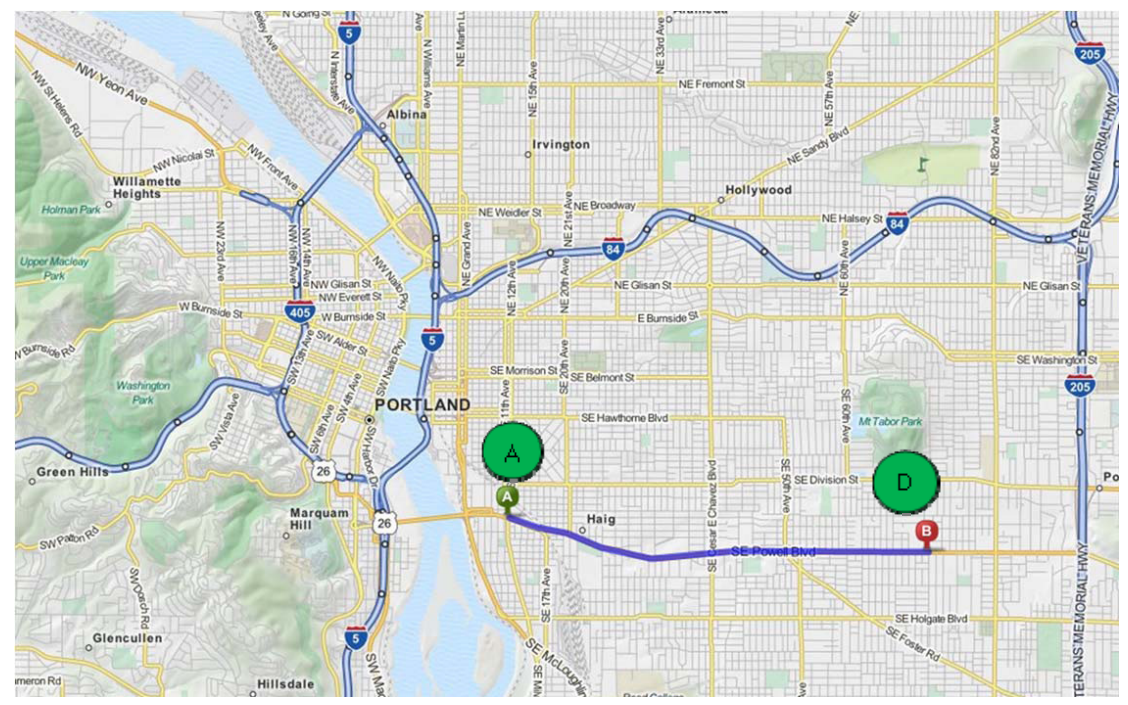

(a) Segment Location

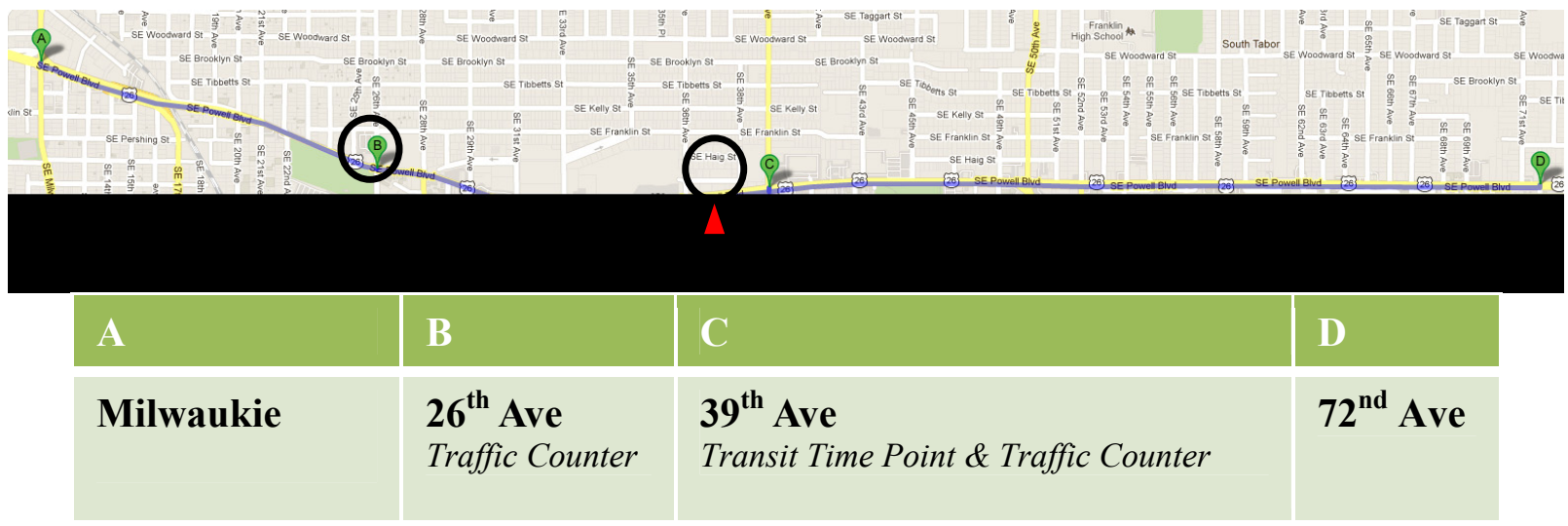

(b) Powell Boulevard Study Segment Configuration
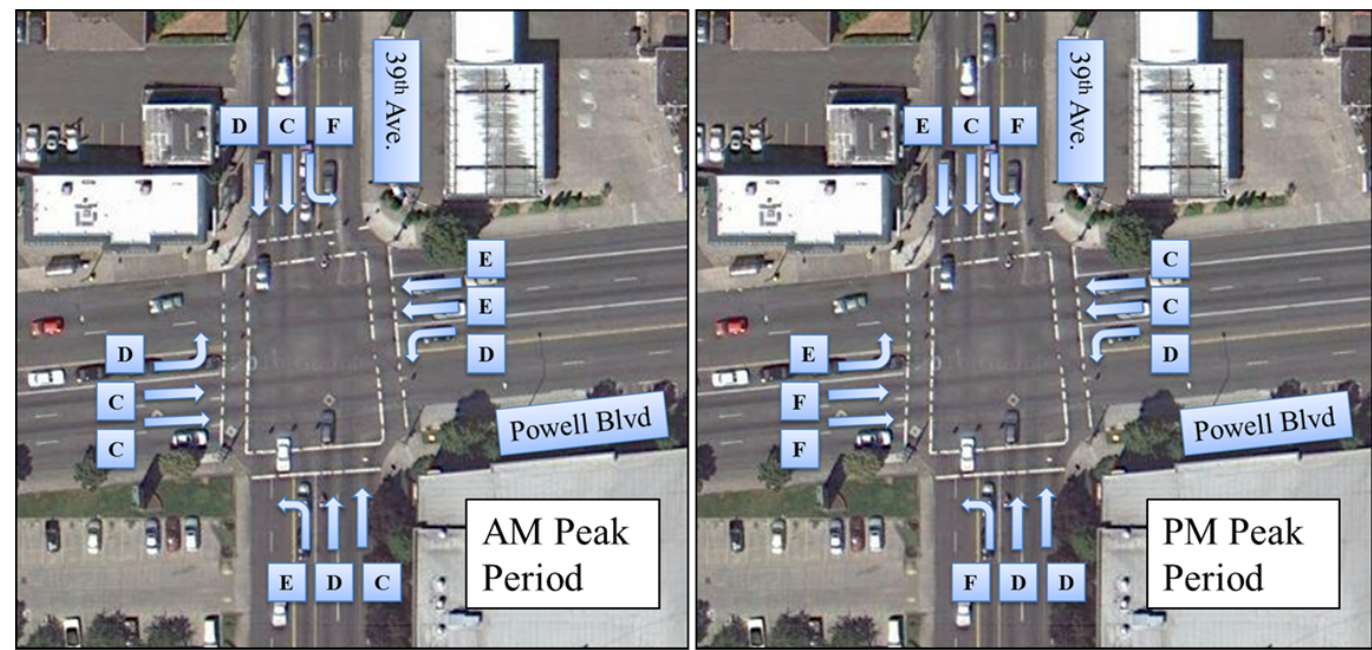

(c) Level of service for Powell and $39^{\text {th }}$ Avenue intersection.

Figure 1. Overview of Study Area 


\subsection{A STATISTICAL STUDY OF THE IMPACTS OF SCATS ADAPTIVE TRAFFIC SIGNAL CONTROL ON TRAFFIC AND TRANSIT PERRFORMANCE}

\subsection{PERFORMANCE MEASURES}

Traffic volumes and speeds were used to control for changes in travel patterns. The source of traffic volume data were two Wavetronix units that were installed by the City of Portland. The units digitally generate a radar signal in order to collect vehicle counts, speeds and classifications. The Wavetronix units were installed close to Powell and $26^{\text {th }}$ and Powell and $39^{\text {th }}$, with enough setback from the intersection to assure free-flow traffic conditions (no queuing) during the peak periods.

Transit performance measures are also used to compare before-and-after SCATS conditions. Data provided by TriMet included Route 9 automatic vehicle location (AVL) and passenger counts. The performance measures include schedule delay, headway delay, idling time, and travel time. Passenger boarding activities were used to control for differences between the before-and-after periods. Bus performance is greatly affected by traffic; traffic was measured to control for this factor in the analysis.

On-time performance and headway adherence are the two most popular reliability measures used in the transit industry for low- and high-frequency service, respectively. High-frequency service is defined by bus headways shorter than 10 minutes (Kittelson and Associates Inc., KFH Group Inc., Parsons Brinkerhoff Quade and Douglas Inc., and Hunter-Zaworski). These performance measures are paired with schedule and headway delay. On-time performance represents the percentage of on-time departures at a stop level. The Transit Capacity and Quality of Service Manual (TCQSM) $2^{\text {nd }}$ edition defines on-time performance as being zero to five minutes late; TriMet defines on-time performance as being no more than one minute early to no later than five minutes past scheduled departure time. Therefore, the index for on-time performance percentage is calculated using TriMet's version:

1 - (early depart records / all depart records) - (late depart records / all depart records)

Headway adherence represents how regular bus headways. The formula (Kittelson and Associates Inc., KFH Group Inc., Parsons Brinkerhoff Quade and Douglas Inc., and Hunter-Zaworski) for calculating headway adherence is shown below:

$c_{v h}=$ standard deviation of headway deviations / mean scheduled headway

Where $c_{v h}$ is the coefficient of variation of headways and headway deviation is the difference between the actual departure headway and the scheduled departure headway at a stop. TCQSM $2^{\text {nd }}$ edition (14) also suggests a level of service threshold for each reliability index. See Table 1. 
Table 1. Level of Service Threshold

\begin{tabular}{lll}
\hline LOS & On-time performance & Headway adherence \\
\hline $\mathrm{A}$ & $0.95-1.00$ & $0.00-0.21$ \\
$\mathrm{~B}$ & $0.90-0.949$ & $0.22-0.30$ \\
$\mathrm{C}$ & $0.85-0.899$ & $0.31-0.39$ \\
$\mathrm{D}$ & $0.80-0.849$ & $0.40-0.52$ \\
$\mathrm{E}$ & $0.75-0.799$ & $0.53-0.74$ \\
$\mathrm{~F}$ & $<0.75$ & $>=0.75$ \\
\hline
\end{tabular}

The greater the on-time performance ratio, or the lower the headway adherence index, the more reliable the transit service.

Idling time is defined as the difference between actual departure time and actual arrival time at a stop minus dwell time at that stop. This represents extra time that a bus is waiting at a stop. For example, if the bus stop is at a near side stop (i.e., a stop placed right before the bus enters an intersection) then idling time can be partially attributed to time waiting at a red light and without including passenger service time. Idling time can be used as a proxy to measure the amount of traffic blocking the bus exit after serving passengers at a stop.

Ideally all variables that can affect travel time both before and after SCATS should be controlled for. We examine before-and-after transit performance conditions during the same month, though a year apart, to account for seasonal variation. Since the traffic data was not available for the year before the SCATS system was installed, traffic and transit performance measures were calculated for different time periods. For traffic data, the "before" time period is a week before the SCATS system was installed, whereas the "after" time period is two months after SCATS. A two-month period is used because there was a SCATS calibration period. Transit data for the whole month of November was used. Additionally, traffic flow was evaluated close to the $26^{\text {th }}$ and $39^{\text {th }}$ intersections (see intersections circled on the map). A transit time point, denoted by a triangle in Figure 1(b), was used for transit performance evaluation of scheduled stops.

An investigation of environmental factors that might affect traffic patterns was also conducted. Variables that may affect travel speeds and volumes include days of the week, weather and wind variables, and holidays. Precipitation can be a significant factor in effecting travel speeds (Kyte, Khatib, Shannon, and Kitchener, 2000). Precipitation, cloudiness and wind speed can reduce travel intensity, while hail and high temperatures may increase travel intensity (Cools, Moons, and Wets, 2009).

Linear regression analysis was performed on a number of variables, including air temperature, precipitation, wind speed and holidays. Sources included weather data from Weather Underground (www.wunderground.com) and were compared to weather data from the National Oceanic and Atmospheric Administration (www.noaa.gov). School holidays were considered because of the location of a high school at $26^{\text {th }}$ and Powell. Federal holidays were considered as well. Table 2 is a list of models that best represented the traffic and volumes along Powell Boulevard. 
Table 2. Models for Daily Traffic on Powell Boulevard

\begin{tabular}{|c|c|c|c|c|c|c|}
\hline & \multicolumn{6}{|c|}{ Speed } \\
\hline & \multicolumn{3}{|c|}{ Eastbound } & \multicolumn{3}{|c|}{ Westbound } \\
\hline & \multicolumn{6}{|c|}{ 26th and Powell } \\
\hline Observations $(\mathrm{N})$ & \multicolumn{3}{|r|}{144} & \multicolumn{3}{|r|}{144} \\
\hline \multirow[t]{2}{*}{ Adjusted R-Square } & \multicolumn{3}{|r|}{0.862} & \multicolumn{3}{|r|}{0.039} \\
\hline & coef. & Std. Error & $\mathrm{p}$ value & coef. & Std. Error & $\mathrm{p}$ value \\
\hline (Intercept) & 39.670 & 0.441 & $2.00 \mathrm{E}-16$ & 37.050 & 0.647 & $2.00 \mathrm{E}-16$ \\
\hline Volume & 0.000 & 0.000 & $2.00 \mathrm{E}-16$ & 0.000 & 0.000 & 0.044951 \\
\hline Weekday & -1.435 & 0.177 & $2.10 \mathrm{E}-13$ & -1.017 & 0.222 & $1.02 \mathrm{E}-05$ \\
\hline \multirow[t]{3}{*}{ School Holiday } & 0.862 & 0.154 & $1.12 \mathrm{E}-07$ & 0.713 & 0.208 & 0.000785 \\
\hline & \multicolumn{6}{|c|}{ 39th and Powell } \\
\hline & \multicolumn{3}{|r|}{152} & \multicolumn{3}{|r|}{152} \\
\hline \multirow{2}{*}{ Adjusted R-Square } & \multirow{2}{*}{\multicolumn{3}{|c|}{$\begin{array}{c}0.778 \\
p \text { value }\end{array}$}} & \multicolumn{3}{|r|}{0.560} \\
\hline & & & & coef. & Std. Error & $\mathrm{p}$ value \\
\hline (Intercept) & 42.710 & 0.812 & $2 \mathrm{E}-16$ & 36.970 & 0.260 & $2.00 \mathrm{E}-16$ \\
\hline Volume & 0.000 & 0.000 & $1.36 \mathrm{E}-14$ & 0.000 & 0.000 & $1.77 \mathrm{E}-07$ \\
\hline Weekday & -2.497 & 0.276 & $8.29 \mathrm{E}-16$ & -0.482 & 0.100 & $3.59 \mathrm{E}-06$ \\
\hline \multirow{4}{*}{ School Holiday } & \multicolumn{3}{|c|}{ Not significant } & 0.363 & 0.089 & $7.30 \mathrm{E}-05$ \\
\hline & \multicolumn{6}{|c|}{ Volume } \\
\hline & \multicolumn{3}{|c|}{ Eastbound } & \multicolumn{3}{|c|}{ Westbound } \\
\hline & \multicolumn{6}{|c|}{ 26th and Powell } \\
\hline Observations $(\mathrm{N})$ & & & 144 & & & 144 \\
\hline \multirow[t]{2}{*}{ Adjusted R-Square } & & & 0.792 & & & 0.811 \\
\hline & coef. & Std. Error & $\mathrm{p}$ value & coef. & Std. Error & $\mathrm{p}$ value \\
\hline (Intercept) & 12971.3 & 286.2 & $2.00 \mathrm{E}-16$ & 14632.8 & 262.3 & $2.00 \mathrm{E}-16$ \\
\hline Monday or Tuesday & 5286.6 & 357.4 & $2.00 \mathrm{E}-16$ & 5102.0 & 327.6 & $2.00 \mathrm{E}-16$ \\
\hline Wednesday or Thursday & 6212.2 & 365.4 & $2.00 \mathrm{E}-16$ & 6063.5 & 335.0 & $2.00 \mathrm{E}-16$ \\
\hline Friday & 6917.1 & 420.0 & $2.00 \mathrm{E}-16$ & 7004.8 & 385.0 & $2.00 \mathrm{E}-16$ \\
\hline Saturday & 2872.8 & 401.1 & $7.35 \mathrm{E}-11$ & 3420.4 & 367.7 & $8.94 \mathrm{E}-16$ \\
\hline School Holiday & -1127.8 & 355.5 & 0.00193 & -1054.2 & 325.8 & 0.00158 \\
\hline Federal Holiday & -2602.8 & 639.1 & $8.45 \mathrm{E}-05$ & -2681.6 & 585.8 & $1.17 \mathrm{E}-05$ \\
\hline & \multicolumn{6}{|c|}{ 39th and Powell } \\
\hline Observations $(\mathrm{N})$ & \multicolumn{3}{|r|}{152} & & & 152 \\
\hline Adjusted R-Square & & & 0.828 & & & 0.765 \\
\hline & coef. & Std. Error & $\mathrm{p}$ value & coef. & Std. Error & $\mathrm{p}$ value \\
\hline (Intercept) & 12850.1 & 216.8 & $2.00 \mathrm{E}-16$ & 14352.4 & 306.4 & $2.00 \mathrm{E}-16$ \\
\hline Monday or Tuesday & 4553.4 & 272.0 & $2.00 \mathrm{E}-16$ & 5177.3 & 384.5 & $2.00 \mathrm{E}-16$ \\
\hline Wednesday or Thursday & 5184.6 & 274.5 & $2.00 \mathrm{E}-16$ & 6144.0 & 387.9 & $2.00 \mathrm{E}-16$ \\
\hline Friday & 5788.9 & 318.9 & $2.00 \mathrm{E}-16$ & 6821.6 & 450.7 & $2.00 \mathrm{E}-16$ \\
\hline Saturday & 2621.7 & 303.9 & $2.31 \mathrm{E}-14$ & 3125.4 & 429.5 & $3.23 \mathrm{E}-11$ \\
\hline School Holiday & -917.1 & 240.4 & 0.000213 & -902.5 & 339.8 & 0.00893 \\
\hline Federal Holiday & -3481.7 & 401.8 & $1.86 \mathrm{E}-14$ & -3944.4 & 567.8 & $1.78 \mathrm{E}-10$ \\
\hline
\end{tabular}


Weather variables were not significant in this model. Days of the week, national holidays and school holidays were significant factors in volume and speed modeling. Days of the week increase the volume, with Wednesday, Thursday and Friday having the highest volumes.

During the weeks that were evaluated before and after the implementation of SCATS, environmental factors were not significant. The before-and-after studies were conducted in the same season, autumn. There were no extreme changes or major weather events before or after the study. Also, there were no federal or school holidays in the evaluation period.

\subsection{EVALUATION RESULTS}

\subsubsection{Traffic Evaluation}

The traffic comparison was performed for the morning (7-9 a.m.) and afternoon (4-6 p.m.) weekday peak periods. Only the peak period corresponding to commuter traffic was used, morning westbound traffic and afternoon eastbound traffic. To account for daily variation in traffic, data for each weekday was averaged. The "before" time period includes Monday, Oct.3 to Friday, Oct. 7, 2011; the "after" time period includes Monday, Nov. 28 to Friday, Dec.2, 2011. Figure 2 shows the westbound average speed and volume before and after the SCATS implementation at the Powell and $26^{\text {th }}$ morning peak hours.

Figure 2 (a) shows that after SCATS the speeds were able to increase and get closer to the speed limit of 35 miles per hour.

Table 3. Travel Speed and Volume Before-After Comparison and Significance Test

\begin{tabular}{|c|c|c|c|c|c|c|}
\hline \multirow{2}{*}{$\begin{array}{l}\text { Difference } \\
\text { (After - Before) }\end{array}$} & \multicolumn{2}{|c|}{ Speed } & \multirow{2}{*}{$\begin{array}{l}\text { One-side t-test } \\
\text { p-value }\end{array}$} & \multicolumn{2}{|c|}{ Volume } & \multirow{2}{*}{$\begin{array}{l}\text { One-side t-test } \\
\text { p-value }\end{array}$} \\
\hline & mph & $\%$ & & vehs & $\%$ & \\
\hline $26^{\text {th }}$ AM WB & 4 & $21 \%$ & 0.000 & 7 & $7 \%$ & 0.003 \\
\hline $26^{\text {th }}$ PM EB & 2 & $7 \%$ & 0.001 & 7 & $5 \%$ & 0.000 \\
\hline $39^{\text {th }}$ AM WB & 2 & $7 \%$ & 0.000 & 4 & $3 \%$ & 0.016 \\
\hline $39^{\text {th }}$ PM EB & -6 & $-22 \%$ & 1.000 & -1 & $0 \%$ & 0.693 \\
\hline
\end{tabular}




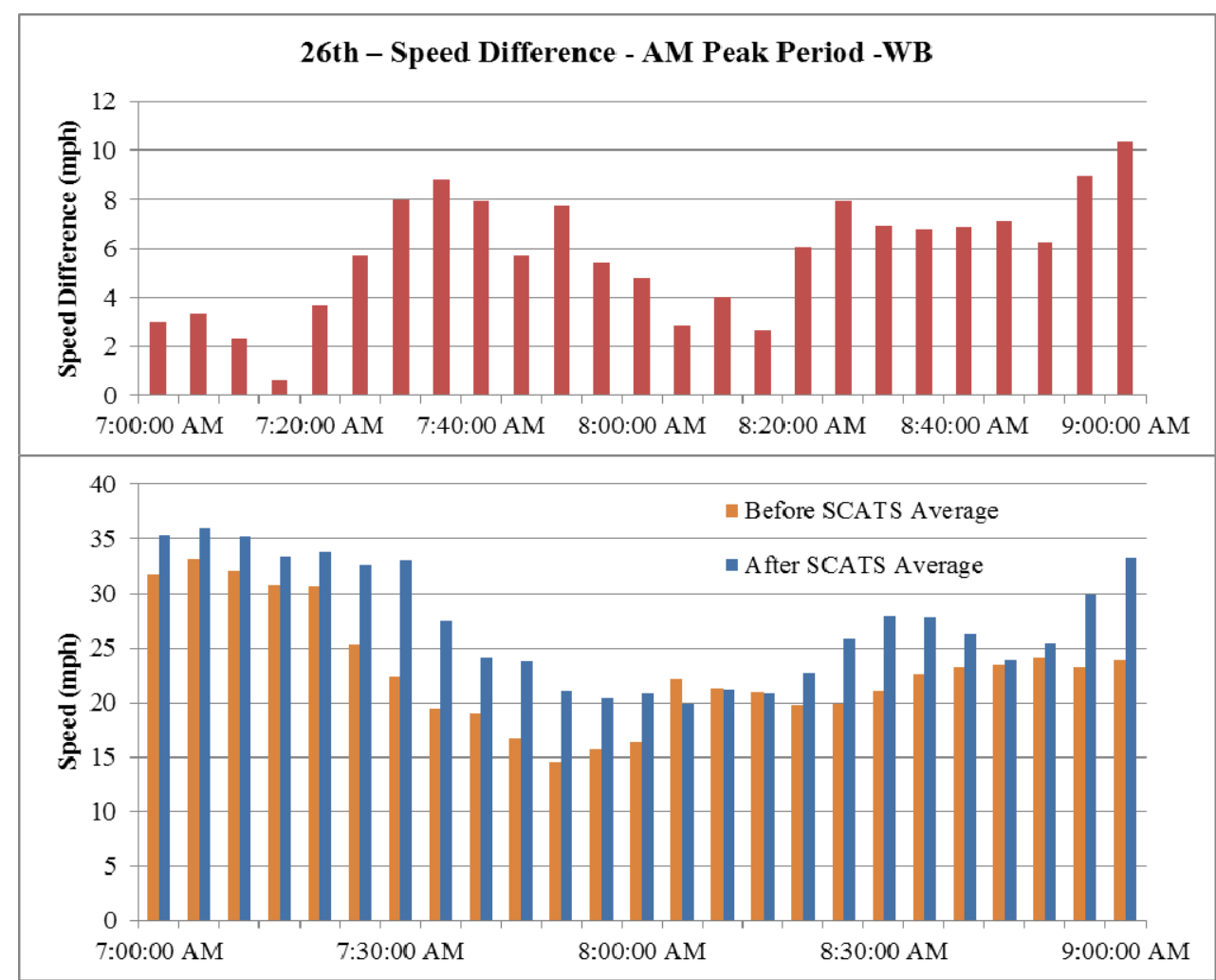

(a) Speed (mph)

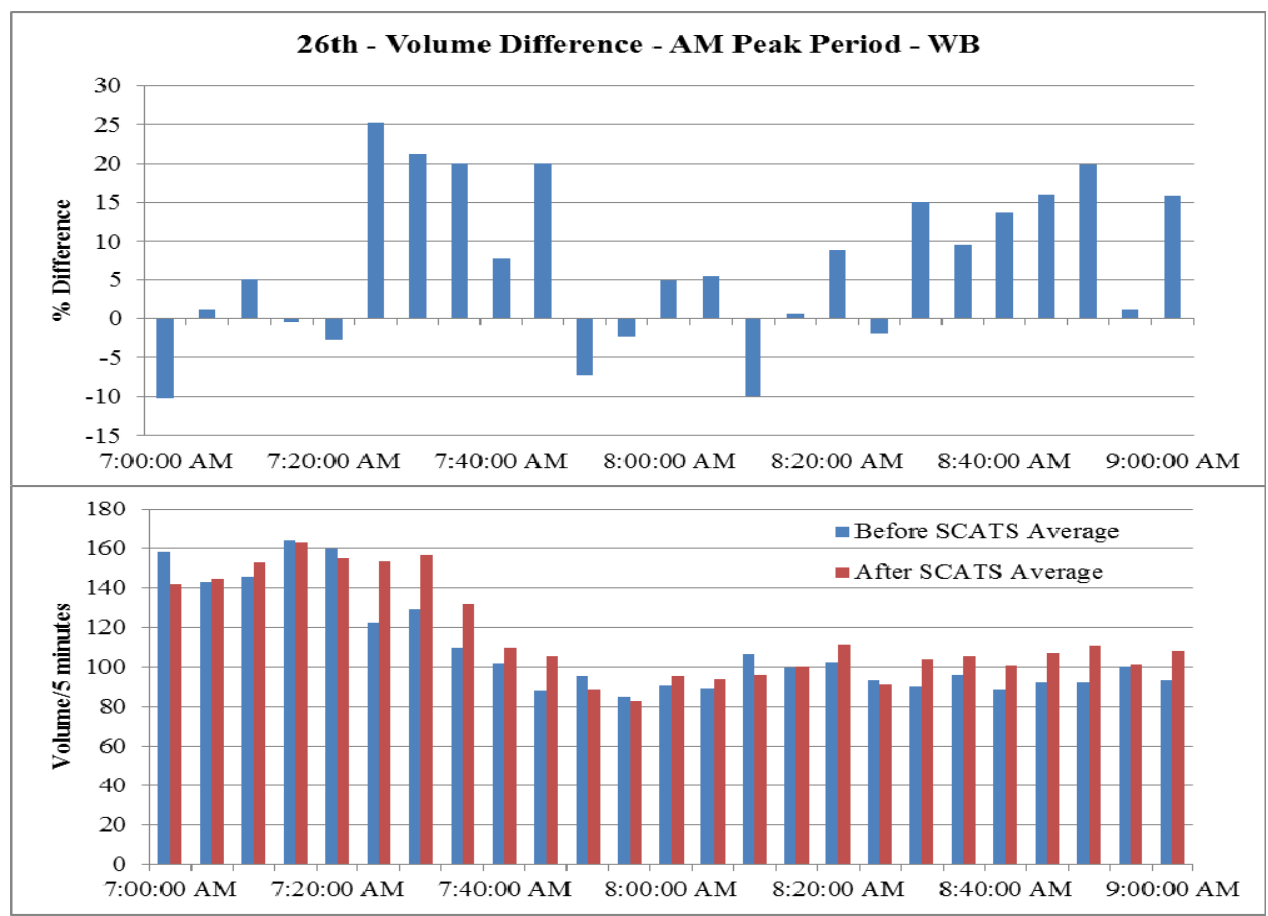

(b) Volume (number of vehicles per five minutes)

Figure 2. Speed and Volume (Before-After) Comparisons at Powell and 26th Avenue 
The volume changes for the morning peak period are shown at Powell and $26^{\text {th }}$ in Figure 2 (b). It can be seen that during most of the morning peak period, a significantly higher volume of vehicles was present after SCATS was implemented. Figure 2 shows the average differences in travel speed (miles per hour) and volume (number of vehicle per five minutes) and the level of significance. The results show that at Powell and $26^{\text {th }}$ there were both significant speed improvements and higher traffic volumes after SCATS was installed.

Powell and $39^{\text {th }}$ yielded more mixed results. For the morning peak period, there were significant speed and volume improvements. However, during the afternoon peak period, there were speed decreases and the volume remained fairly constant. It is possible that the mixed results are because $26^{\text {th }}$ is a more minor cross street with smaller volume, whereas $39^{\text {th }}$ is a large arterial with high volume. The SCATS system favors or gives more priority to the main arterial (Powell) when there is less demand at the secondary street; the green time on Powell increased and it was reduced at $26^{\text {th }}$. This improvement or higher efficiency in the allocation of green time was not possible at $39^{\text {th }}$ due to its higher traffic volume.

\subsubsection{Transit Evaluation}

One month of detailed bus-stop event data in November 2010 and November 2011 were used to evaluate the transit performance before and after SCATS was implemented. Passenger activity was examined to control for possible changes in transit activity; statistical tests indicate that there are no significant differences in passenger boarding per hour and passenger load per bus at any time point or segment.

\section{Time Point Reliability}

Time-point reliability evaluation was collected at Powell and $39^{\text {th }}$ and was compared using different performance measures for peak and off-peak periods in both directions.

The high-frequency periods occur between 4-6 p.m. (pm peak) in the eastbound direction, and between 78 a.m. (am peak) in the westbound direction. All other times are low-frequency service or off-peak. For the off-peak periods, schedule delay and on-time performance are the suggested performance measures, whereas for peak periods headway delay and headway adherence are the performance measures suggested by TCQSM $2^{\text {nd }}$ edition.

Mean schedule delay was compared utilizing a one sided t-test; if $\mu_{1}=$ population mean of group 1 (before SCATS) and $\mu_{2}=$ population mean of group 2 (after SCATS), the null and alternative hypotheses can be stated as:

$\mathrm{H}_{0}: \mu_{1} \leq \mu_{2}$

$\mathrm{H}_{1}: \mu_{1}>\mu_{2}$

Mean headway delay (i.e., actual headway minus the scheduled headway) was compared utilizing one sided F-test; if $\sigma^{2}{ }_{1}=$ population variance of group 1 (before SCATS) and $\sigma_{2}{ }_{2}=$ population variance of group 2 (after SCATS), given that for headway adherence the deviation is relevant then the hypotheses are:

$\mathrm{H}_{0}: \sigma_{1}^{2} / \sigma_{2}^{2} \leq 1$

$\mathrm{H}_{1}: \sigma^{2}{ }_{1} / \sigma_{2}^{2}>1$

Statistical results are shown in Table 4. Time-Points, Off-Peak-Hour Reliability Performance, including the mean, standard deviation, number of observations and significance of the statistical results for both schedule delay and headway delay. Additionally, the on-time performance and level of service 
are shown for the off-peak periods, while the headway adherence and level of service are shown for the peak periods.

Schedule delay is not significantly improved in the eastbound or westbound direction during the off-peak period. The time-point schedule delay is better in the westbound off-peak hours compared to the eastbound direction. There are no major changes in on-time performance in either direction of travel. The level of service is low both before and after SCATS was implemented: an F in the eastbound direction and a slightly better $\mathrm{D}$ in the westbound direction.

The mean headway delay is close to zero seconds but the standard deviations range from four to five minutes. There were no significant improvements in the deviation of headway delay after SCATS was implemented. The headway adherence remained the same or became slightly worse after the SCATS implementation. The level of service remained in the same category.

Table 4. Time-Points, Off-Peak-Hour Reliability Performance

\begin{tabular}{|c|c|c|c|c|c|c|c|c|}
\hline \multirow[t]{3}{*}{ Powell \& 39th } & \multicolumn{4}{|c|}{ Schedule Delay } & \multicolumn{4}{|c|}{ Headway Delay } \\
\hline & \multicolumn{2}{|c|}{$\begin{array}{l}\text { Eastbound } \\
\text { Off-Peak }\end{array}$} & \multicolumn{2}{|c|}{$\begin{array}{l}\text { Westbound } \\
\text { Off-Peak }\end{array}$} & \multicolumn{2}{|c|}{$\begin{array}{l}\text { EB PM Peak } \\
\text { (4-6 p.m.) }\end{array}$} & \multicolumn{2}{|c|}{$\begin{array}{l}\text { WB AM Peak } \\
\text { (7-8 a.m.) }\end{array}$} \\
\hline & Before & After & Before & After & Before & After & Before & After \\
\hline Mean (seconds) & 168 & 172 & 138 & 109 & 0 & -10 & 7 & 2 \\
\hline Std. (seconds) & 238 & 227 & 222 & 210 & 270 & 295 & 205 & 234 \\
\hline Observations & 1,557 & 1,578 & 1,643 & 1,679 & 354 & 377 & 255 & 270 \\
\hline P-value & 0.685 & & $0.000 *$ & & 0.954 & & 0.983 & \\
\hline On-time performance & 0.74 & 0.74 & 0.83 & 0.84 & & & & \\
\hline Headway adherence & & & & & 0.42 & 0.47 & 0.31 & 0.38 \\
\hline LOS & $\mathrm{F}$ & $\mathrm{F}$ & $\mathrm{D}$ & $\mathrm{D}$ & $\mathrm{C}$ & $\mathrm{C}$ & $\mathrm{C}$ & $\mathrm{C}$ \\
\hline
\end{tabular}

In general, the implementation of SCATS did not significantly improve or worsen transit performance at Powell and $39^{\text {th }}$. The only exception is the reduction in schedule delay in the westbound direction after SCATS. 


\section{Idling Time}

Idling time, which is the extra time spent at a bus stop after serving passengers, was calculated at every stop in the segment where SCATS has been implemented. The idling time was summed and averaged over all the stops in each direction.

The results, shown in Table 5, indicate no major changes in idling time over the corridor, from Powell and Milwaukie to Powell and $72^{\text {nd }}$. Mean idling times during the peak periods are shown in the eastbound direction; at the majority of the stops, the idling time was similar before and after SCATS. However, the largest percentage increases in idling time were observed at $24^{\text {th }}$ and $26^{\text {th }}$. In the westbound direction, the stops with the largest percentage increases in idling time were observed at $24^{\text {th }}$ and $21^{\text {st }}$. These increases in transit idling may be due to longer queues at these intersections. However, at the more important or congested intersections, Milwaukee and $39^{\text {th }}$, the amount of idling time did not change consistently or significantly.

Table 5. Idling Time Before-and-After Comparison

\begin{tabular}{lllll}
\hline & \multicolumn{2}{l}{ Total Idling Time (seconds) } & \multicolumn{2}{l}{ Average Idling Time (seconds) } \\
\hline Eastbound & Before & After & Before & After \\
\hline PM peak (4-6 p.m.) & 384 & 388 & 18.3 & 18.5 \\
Off-peak & 315 & 320 & 15.0 & 15.3 \\
All day & 328 & 333 & 15.6 & 15.9 \\
\hline Westbound & & & 18.1 & \\
\hline AM Peak (7-8 a.m.) & 380 & 390 & 15.4 & 15.6 \\
Off-peak & 324 & 328 & 15.8 & 16.0 \\
All day & 331 & 337 & & \\
\hline
\end{tabular}




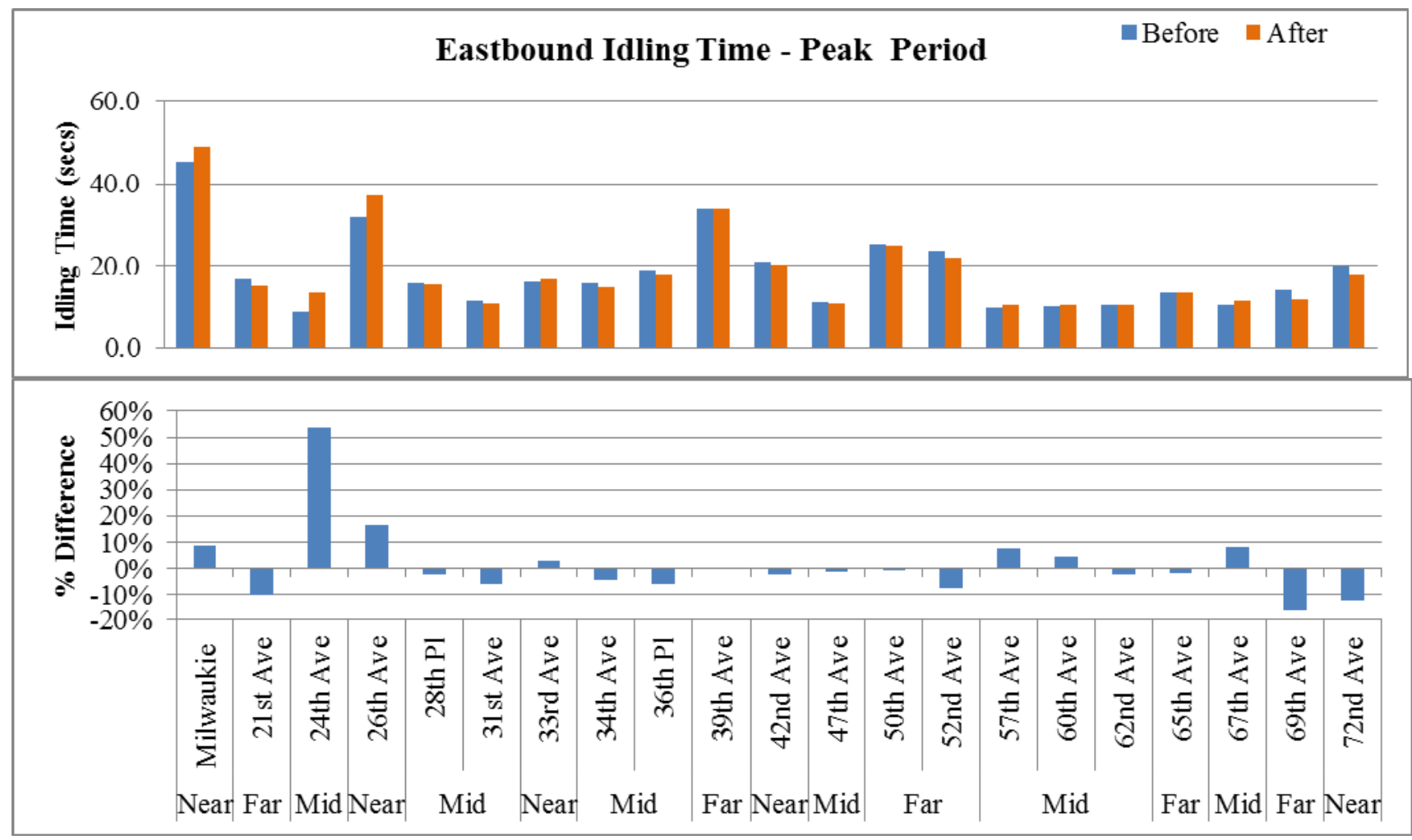

(a) Eastbound pm peak

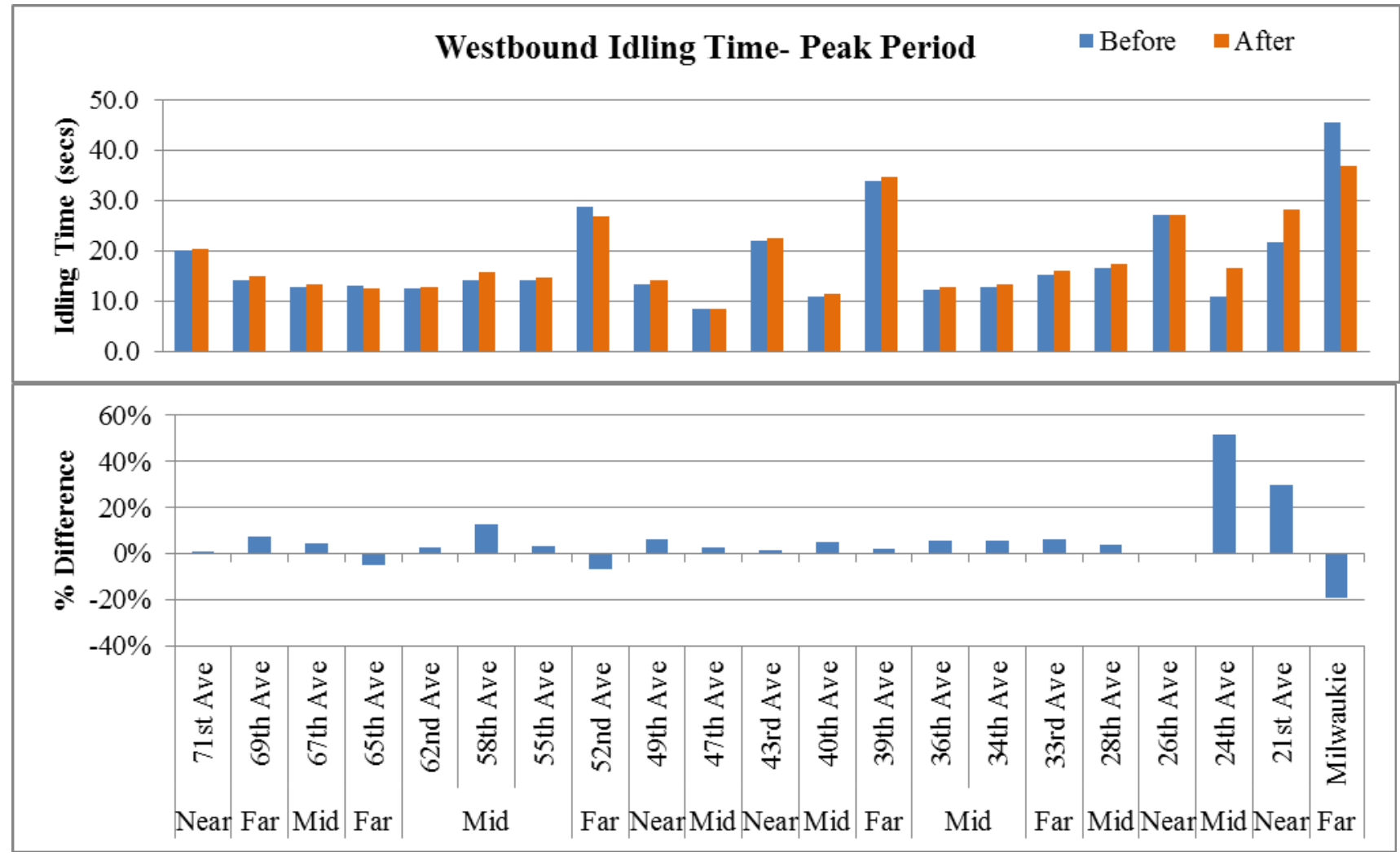

(b) Westbound am peak

Figure 3. Peak Hours and Idling Time Before-and-After Comparison 


\section{Travel Time}

Up to this point, the transit performance measures analyzed are at the stop level. Bus travel time was calculated between Powell and Milwaukie and Powell and $72^{\text {nd }}$ (shown as the study segment Figure 1 (b) to understand how the implementation of SCATS affected the entire corridor. One-sided t-tests were used to compare travel times; if $\mu_{1}=$ population mean of group 1 (before SCATS) and $\mu_{2}=$ population mean of group 2 (after SCATS) then hypotheses are:

$\mathrm{H}_{0}: \mu_{1} \leq \mu_{2}$

$\mathrm{H}_{1}: \mu_{1}>\mu_{2}$

In addition, to determine if the deviations of travel time have changed before and after SCATS to after SCATS, one-sided f-tests were conducted; if: $\sigma^{2}{ }_{1}=$ population variance of group 1 (before SCATS) and $\sigma_{2}^{2}=$ population variance of group 2 (after SCATS), then the null and alternative hypotheses are:

$\mathrm{H}_{0}: \sigma_{1}^{2} / \sigma^{2}{ }_{2} \leq 1$

$\mathrm{H}_{1}: \sigma^{2}{ }_{1} / \sigma_{2}^{2}>1$

Results (see Table 6) indicate that in the eastbound direction the mean travel times are significantly improved throughout the day after SCATS was implemented. In the westbound direction, the mean travel times were not improved. The deviation of travel time after the implementation of SCATS was not significantly improved in either direction. The bus scheduled travel time was constant over the two time periods.

Table 6. Travel-Time Performance

\begin{tabular}{|c|c|c|c|c|c|c|}
\hline \multirow[t]{2}{*}{ Eastbound } & \multicolumn{6}{|c|}{ PM Peak (4-6p.m.) Off-Peak } \\
\hline & Before & After & Before & After & Before & eAfter \\
\hline \multicolumn{2}{|c|}{ Mean (seconds) 897} & 879 & 755 & 739 & 782 & 765 \\
\hline Std. (seconds) & 131 & 134 & 144 & 156 & & 162 \\
\hline Observations & 382 & 376 & 1,578 & 1,592 & 21,960 & 1,968 \\
\hline P-value (t-test) & \multicolumn{2}{|l|}{$0.031 *$} & \multicolumn{2}{|c|}{$0.001 *$} & \multicolumn{2}{|c|}{$0.000 *$} \\
\hline P-value (f-test) & 0.670 & & 0.999 & & 0.994 & \\
\hline \multirow[t]{2}{*}{ Westbound } & \multicolumn{4}{|c|}{ AM Peak (7-8a.m.) Off-Peak } & \multicolumn{2}{|c|}{ All Day } \\
\hline & Before & After & Before & Afte & Before & eAfter \\
\hline \multicolumn{2}{|c|}{ Mean (seconds) 953} & 1,070 & 808 & 801 & 827 & 839 \\
\hline Std. (seconds) & 202 & 351 & 146 & 172 & 163 & 226 \\
\hline Observations & 256 & 272 & 1,641 & $1,6^{6}$ & 71,897 & 1,949 \\
\hline P-value (t-test) & 1.000 & & 0.103 & & 0.971 & \\
\hline P-value (f-test) & 1.000 & & 1.000 & & 1.000 & \\
\hline
\end{tabular}


Table 7. Explanatory Variables in Regression Model

\begin{tabular}{lllr}
\hline Name & Description & Range & Mean \\
\hline Ons & Number of passenger boardings for trip & $0-110$ & 16.45 \\
Offs & Number of passenger alightings for trip & $0-70$ & 15.35 \\
Lift & Number of times the lift was used during trip & $0-4$ & 0.10 \\
Stops & Number of stops during trip & $0-21$ & 11.74 \\
Priority & 1 if transit signal priority was requested, 0 otherwise & 0,1 & 0.61 \\
Peak & 1 if trip was during peak period, 0 otherwise & 0,1 & 0.16 \\
WB & 1 if trip was in westbound direction, 0 otherwise & 0,1 & 0.50 \\
SCATS & 1 if SCATS was implemented, 0 otherwise & 0,1 & 0.50 \\
\hline
\end{tabular}

Travel-time Regression Models

To control for all the potential differences in bus operations before and after SCATS, several regression models were estimated. The variables names, descriptions and ranges of values are listed in Table 7. The base model is shown Table 8 . The first model, including all eight parameters, indicated that all variables were significant except SCATS. To examine the impact of SCATS on the other variables, interaction variables were included in the model.

Interactions between SCATS and priority, SCATS and offs, and SCATS and lifts were not significant. The interactions were significant between SCATS and ons, SCATS and stops, SCATS and peak, and SCATS and direction. After further analysis, it was found that the interaction with SCATS and stops was more significant than SCATS and ons, and when used in the same regression model, forced the SCATS and ons to become insignificant 
Table 8. Travel-Time Regression Analysis Results

\begin{tabular}{|c|c|c|c|c|c|c|}
\hline & \multicolumn{3}{|c|}{ Base Model } & \multicolumn{3}{|c|}{ Final Model } \\
\hline R Square & \multicolumn{3}{|l|}{0.534} & \multicolumn{3}{|l|}{0.545} \\
\hline$F$ & \multicolumn{3}{|l|}{1258.326} & \multicolumn{3}{|l|}{767.483} \\
\hline \multirow[t]{2}{*}{$N$} & \multicolumn{3}{|l|}{7687} & \multicolumn{3}{|l|}{7687} \\
\hline & $B$ & $S E_{B}$ & P-Value & $B$ & $S E_{B}$ & P-Value \\
\hline Constant & 476.286 & 5.415 & 0.000 & 494.587 & 5.348 & 0.000 \\
\hline Ons & 3.973 & 0.156 & 0.000 & 3.961 & 0.156 & 0.000 \\
\hline Offs & 0.416 & 0.193 & 0.031 & 0.45 & 0.191 & 0.019 \\
\hline Lift & 31.04 & 3.92 & 0.000 & 30.997 & 3.875 & 0.000 \\
\hline Stops & 19.528 & 0.556 & 0.000 & 18.663 & 0.594 & 0.000 \\
\hline Priority & -24.745 & 2.929 & 0.000 & -23.994 & 2.897 & 0.000 \\
\hline Peak & 139.605 & 3.963 & 0.000 & & & \\
\hline WB Direction & 32.971 & 3.348 & 0.000 & & & \\
\hline After Scats Stops & & & & 1.685 & 0.357 & 0.000 \\
\hline After Scats Peak WB & & & & 221.087 & 8.076 & 0.000 \\
\hline After Scats Peak EB & & & & 87.736 & 7.648 & 0.000 \\
\hline After Scats Off-Peak EB & & & & -33.226 & 4.357 & 0.000 \\
\hline Before Scats Peak WB & & & & 112.052 & 8.754 & 0.000 \\
\hline Before Scats Peak EB & & & & 130.395 & 7.442 & 0.000 \\
\hline Before Scats Off-Peak WB & & & & 24.259 & 4.511 & 0.000 \\
\hline
\end{tabular}

*Note: After Scats Off Peak West was insignificant and was excluded

Baseline: Before SCATS/off peak/EB

The final regression analysis is shown in Table 8 next to the base model. In order to determine if the final model is better than the base model, an incremental $\mathrm{F}$ test was conducted to test the hypothesis that the coefficients of the additional variables are equal to zero. In this case, the unconstrained model has 12 predictors, and the constrained model has seven, so there are five additional variables. The incremental $\mathrm{F}$ value is 37.105 , with a corresponding p-value of 0.000 , indicating that the final model is a significant improvement upon the base model.

The results are very stable when comparing both models, which highlights the robustness and quality of the model. The factors related to passengers yield similar results, indicating that each passenger boarding takes on average of about four seconds, each passenger alighting takes an average less than half a second, and each lift usage takes an average 31 additional seconds. For each stop that the bus must make during a trip, it takes an average 19 additional seconds.

Trips that have transit signal priority (TSP) are reduced by approximately 24 seconds on average; the value of this parameter is stable and shows that the impact of transit priority is not affected by SCATS. This is an important result because a priori it was not possible to predict if the interaction between SCATS and TSP would be beneficial. 
From the base model, it is possible to see that trips made during the peak period have higher travel time than trips during the off-peak period, about 140 seconds more on average. Trips made in the westbound direction have higher travel time than trips in the eastbound direction, about 30 seconds more on average.

The results of the regression analysis make it possible to compare before and after SCATS for each peak period and direction. The variable for SCATS during off-peak in the westbound direction was not significant in the model, meaning that the coefficient was zero or equal to the baseline "Before SCATS/off peak/eastbound." Looking at the other variables it can be seen that on average:

- $\quad$ After SCATS, eastbound off-peak period travel time decreased 33 seconds.

- $\quad$ After SCATS, westbound off-peak period travel time decreased 24 seconds.

- $\quad$ After SCATS, eastbound peak period travel time decreased 42 seconds.

- $\quad$ After SCATS, westbound peak period travel time increased 110 seconds.

SCATS is helping to significantly reduce travel times in both directions and times, except for the westbound peak period. These regression results are consistent with the results already observed in Table 6, where the mean westbound peak period increased 117 seconds. Clearly, these travel times are not due to changes in passenger demands or boarding/alighting patterns.

\subsection{SUMMARY}

In order to evaluate traffic and transit performance before and after SCATS implementation, this research compared changes in traffic volumes and speeds and studied changes in transit performance such as schedule delay, headway delay, idling time and travel time.

Overall, the traffic conditions before and after SCATS were significantly different in terms of speed and volume. SCATS did show statistically significant improvements regarding traffic speeds at one minor intersection, even when traffic volumes showed a statistically significant improvement. At a major intersection results were mixed and not conclusive.

This is the first study to examine the joint performance of SCATS and TSP. Statistical tests and regression analysis were used to determine that SCATS did not negatively affect transit performance on Powell Boulevard. In particular, TSP was not affected by SCATS. Overall, it was determined that the improvements available through SCATS vary depending on the time of day and the direction of travel. Travel times were reduced in both directions during the off-peak period, which covers most of the day. However, the peak periods are when bus demand is the highest. During the peak periods, improvements in travel time for the entire study corridor segment were observed in the eastbound direction, while there were no improvements in the westbound direction.

From the traffic evaluation it seems that after SCATS transit buses may be dealing with the same congested conditions at major intersections, but with improved conditions at minor intersections. The transit evaluation accounted for passenger ridership, which did not change significantly between the two time periods. 


\subsection{SCHEDULE RECOVERY FOR LATE BUSES: WHAT ARE THE INDIVIDUAL AND JOINT CONTRIBUTIONS OF TRANSIT SIGNAL PRIORITY AND BUS BEHAVIOR?}

\subsection{STUDY DESIGN}

In order to investigate these questions an empirical study of bus AVL and APC data was performed, where TSP was approximated by bus priority requests and traffic conditions; maximum bus speed was used as a proxy variable for traffic conditions. The maximum speed reached between consecutive bus stops provided a data field to approximate the decisions and behavior of the bus operator. It was expected that the operator of a late bus would attempt to reach a higher speed between stops than the operator of a bus on time. Higher maximum speeds then approximated a bus operator's attempt to reduce travel time.

This study focused on a section of TriMet's Bus Route 9 that runs on S.E. Powell Boulevard in Portland, OR. Powell Boulevard is a major arterial corridor that connects Gresham and downtown Portland. The studied corridor measures approximately five miles and contains 14 signalized intersections and 54 bus stops, as shown in Figure 4. Figure 4 divides the corridor into sections, and provides an inset map of the S.E. Milwaukie to S.E. 21st segment. Along this corridor, TSP is available at each signalized intersection except S.E. 82nd Avenue and S.E. 86th Avenue. In Portland, Conditional TSP is used to insure only late buses are given priority. A detailed description of this system, including bus conditions and possible priority actions, can be found in Albright and Figliozzi (2012). Note that a controlled access section

existed for the segment in Figure 4, Part C; there are no entry or exit access points along the majority of this stop-to-stop segment and there is less bus-stop density. This will have an impact on the results, as described later in this section. 


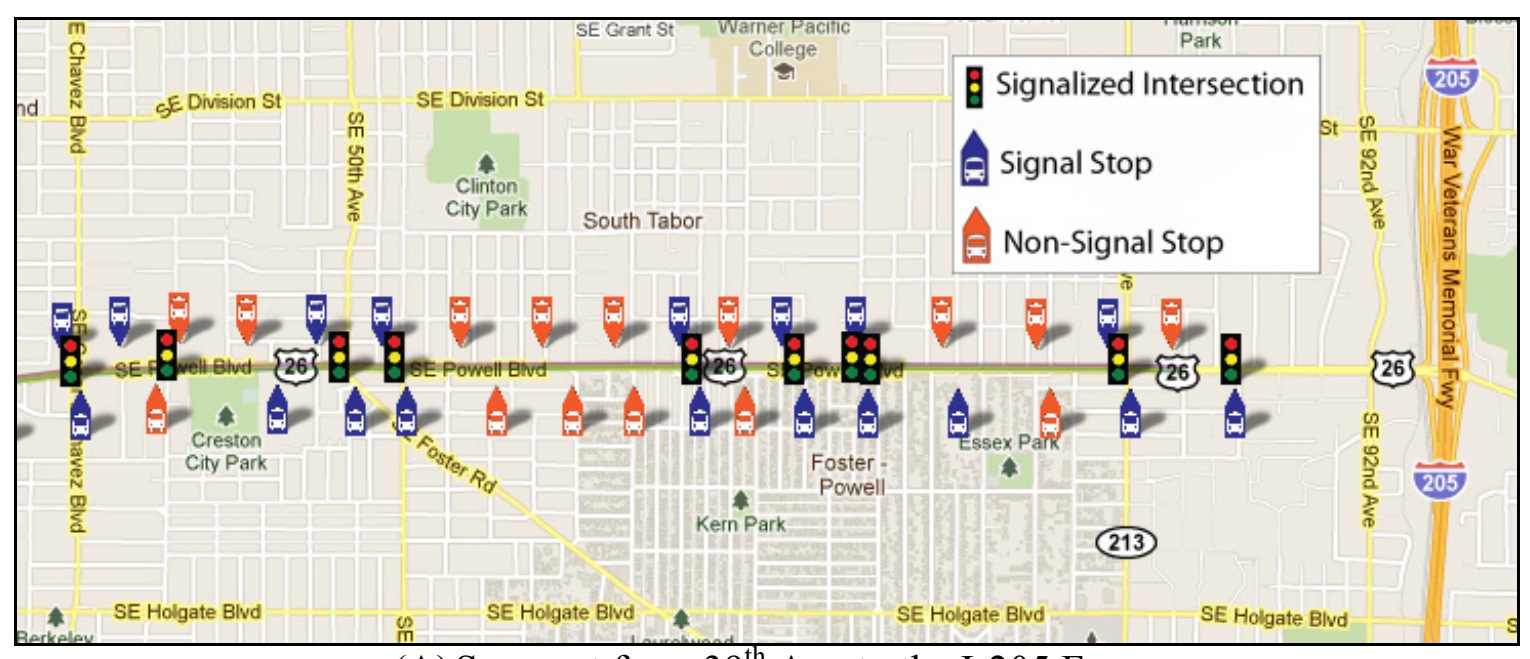

(A) Segment from $39^{\text {th }}$ Ave to the I-205 Freeway

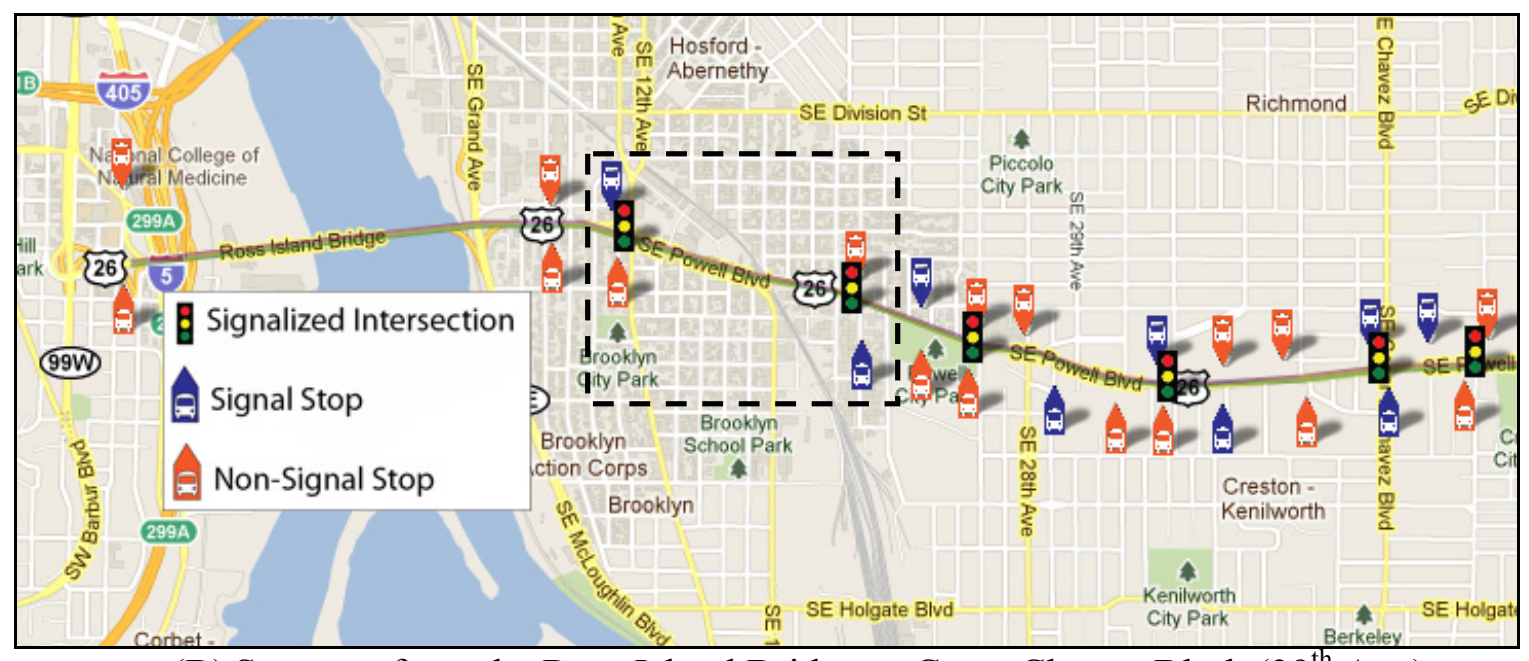

(B) Segment from the Ross Island Bridge to Cesar Chavez Blvd. ( $\left(39^{\text {th }} \mathrm{Ave}\right)$

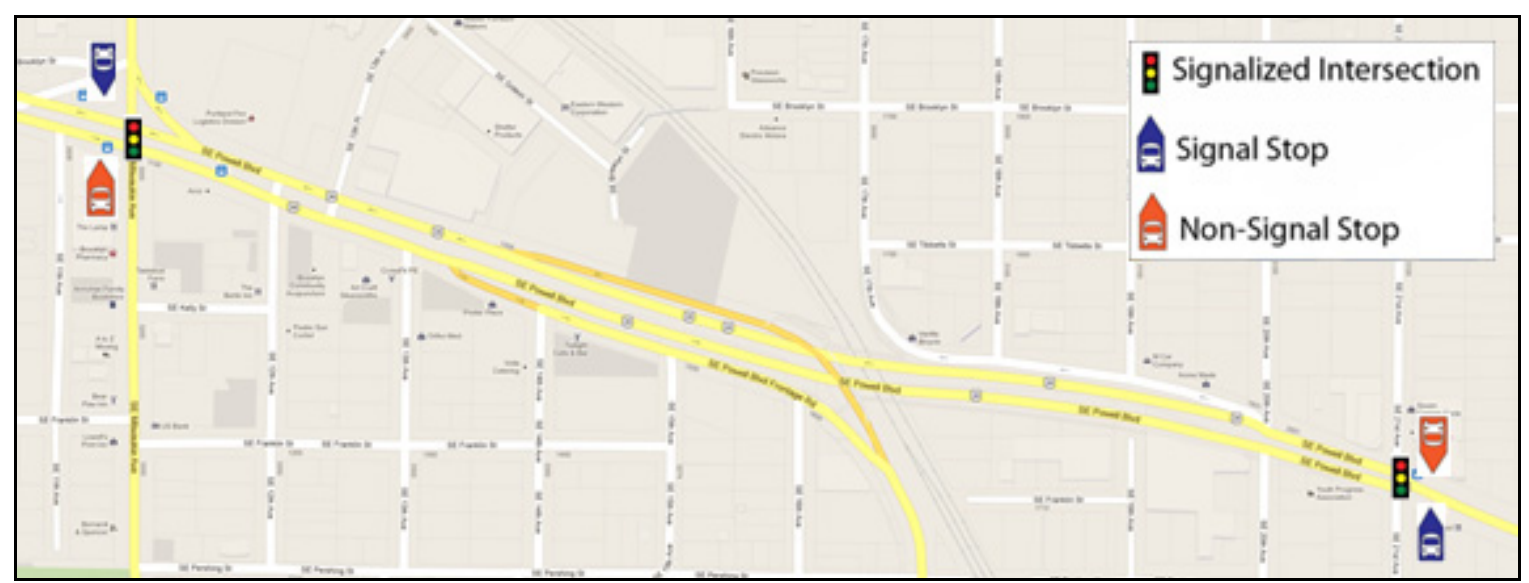

(C) Inset Segment from Milwaukie to $21^{\text {st }}$ (controlled access)

Figure 4. Map of the SE Powell Blvd Corridor in Southeast Portland. Source: Google Maps ${ }^{\mathrm{TM}}$. 
Bus AVL and APC data was collected from TriMet for the month of November 2010. This data was aggregated at the stop event level (i.e., a single record was created for every instance of a scheduled bus stop). For the particular study area, 97,187 stop events were observed. This AVL and APC data described the state of the bus as it made a stop and included fields such as arrival, actual and scheduled departure times, passenger boardings and alightings, location information and maximum speed reached during the previous travel segment. The maximum speed reached on the travel segment was determined by the onboard GPS connected to the AVL, APC and Bus Dispatch System. From this data, travel times were derived by comparing consecutive stop events for the same bus, and priority requests were determined by comparing the current bus state with the conditional priority requirements.

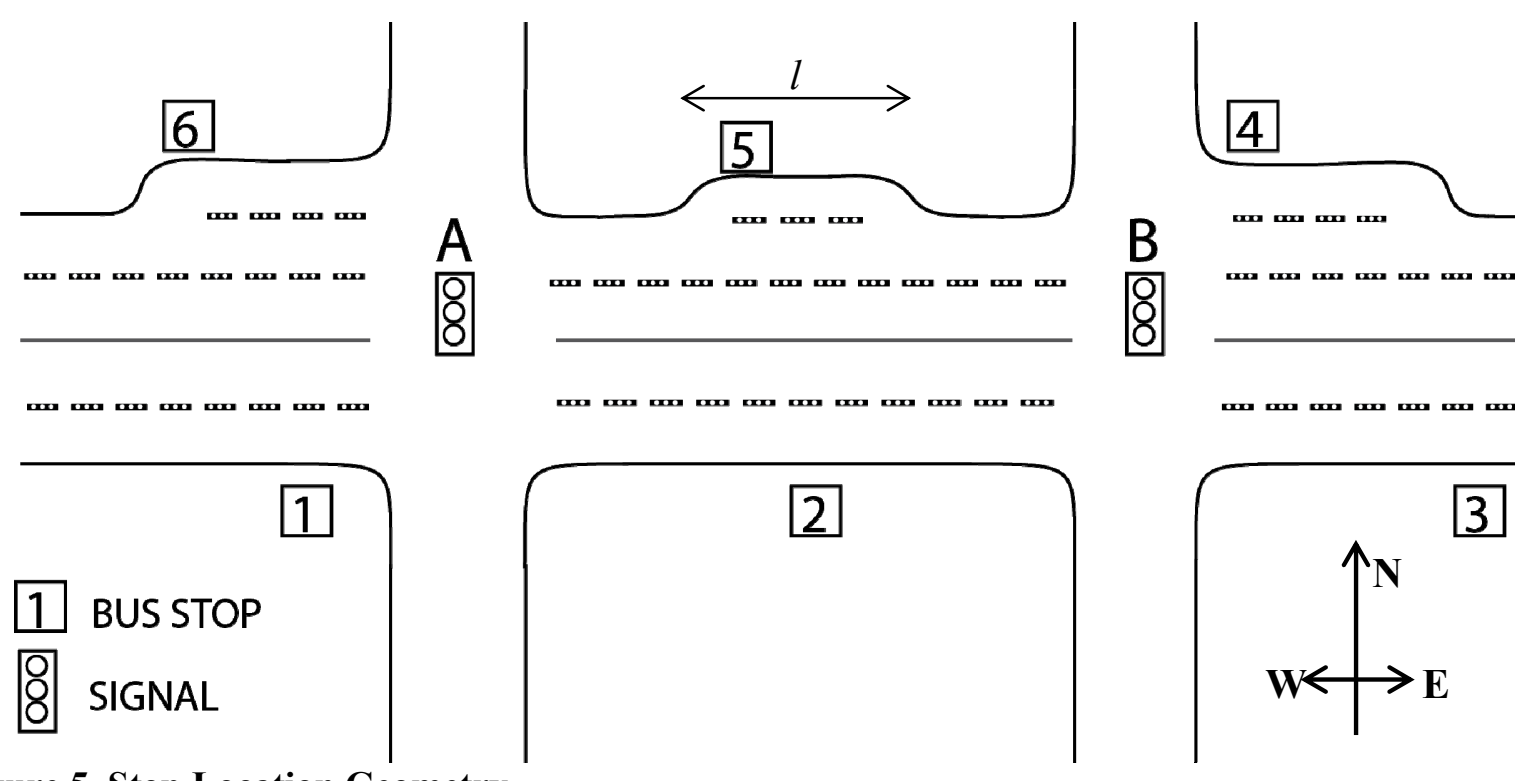

Figure 5. Stop Location Geometry

As each stop event was related to a specific stop location, the stop locations were then classified by certain geometric characteristics. Stops were assigned location types of near side, far side or mid-block to specify the spatial relationship between stop locations and signalized intersections. In Figure 5, for eastbound buses, stop 1 is a near-side stop, stop 2 is a mid-block stop and stop 3 is a far-side stop. Next, bus-bay locations and lengths were included in the models to understand what advantages or disadvantages due to merging delay they might enact on travel time. If a bus bay was present at the stop, the bus-bay length, in feet, of the bay (see $l$ in Figure 5) was assigned to the stop respective to its location. For westbound buses, stop 4 has a near-side bay and stop 6 has a far-side bay. Where a stop did not have a bay the length is assigned as 0 feet. Note that in some cases along the corridor a stop may have a bus bay on both the near and far side of the intersection. In that case the stop was assigned lengths for both near-side and far-side bus bays. Finally, in order to identify the stops most likely to demonstrate priority effects of signalized intersections, the stops directly downstream from a signal were classified as signal stops. These stops are easily identified in the case of far-side stops (i.e., stop 3 is the signal stops for eastbound buses passing signal B). In the case of near-side stops, the next downstream stop is the signal stop. For instance, Stop 1 is located on the near side of signal A; however, the eastbound signal stop for signal A is stop 2. Signal stops and non-signal stops along the study corridor are distinguished in the map in Figure 4. 


\subsection{CAPTURING TSP AND TRAFFIC CONDITIONS}

After the stop event and stop description data were joined, a set of lag and dummy variables were added to the data to facilitate regression analysis. While priority requests and lateness were available for the current stop, these did not necessarily affect how the operator would drive from the previous stop to the current stop. Therefore, the priority request and lateness were lagged in order to estimate the conditions the driver would be faced with when leaving the previous stop. Then sets of dummy variables were created to control for different times of day, direction, maximum speed of the bus, skipped stops and specific intersections.

As this study attempted to approximate TSP effects and operator behavior from AVL and APC data, some limitations exist. Traffic conditions and operator behavior were estimated by the maximum speed determined by the on-board GPS unit on the bus. A review of these speeds revealed many outliers, or unrealistic speeds, that were removed from the data set. More accurate and robust equipment on transit buses, coupled with proper storage and organization of data could lead to more accurate models of bus performance. Also, TSP events were approximated by buses meeting the criteria for priority requests. In this case, TSP events such as green extension and red truncation were not guaranteed, but only granted if green time was available. Unfortunately, at the time of this study, the logging of TSP events was not available.

Next, regression analysis was performed on the set of stop events where stop-to-stop travel time was the dependent variable. Stop-to-stop travel times were determined by the arrival time at the current stop minus the departure time at the previous stop. This departure-to-arrival travel time was chosen to eliminate the variability at the stop due to passenger boardings and alightings, dwell time and possible operator holding found when modeling departure-to-departure travel time. The set of independent variables considered in the regression model are shown in Table 9 and are broken up into the following categories: time of day, distance, lateness and priority, stop-location type, bus-bay type, and operator behavior. In the case of time of day and stop-location type variables, early morning (5-7 a.m.) and midblock represent the respective base cases. The maximum speed base case was the $1^{\text {st }}$ quartile of speeds, or $0-25 \mathrm{mph}$. 
Table 9. Data Dictionary

\begin{tabular}{|c|c|c|c|}
\hline Category & Independent Variable & Type & Description \\
\hline $\begin{array}{l}\text { Time of } \\
\text { Day }\end{array}$ & $\begin{array}{l}\text { AM Peak Period (7-9 A.M.) } \\
\text { Midday (9A.M.-4 P.M.) } \\
\text { PM Peak Period (4-6 P.M.) } \\
\text { Evening (>6 P.M.) } \\
\text { Eastbound Direction }\end{array}$ & $\begin{array}{l}\text { Dummy } \\
\text { Dummy } \\
\text { Dummy } \\
\text { Dummy } \\
\text { Dummy }\end{array}$ & $\begin{array}{l}\text { True (1) if arrival at current stop is between } 7 \\
\text { and } 9 \text { A.M. } \\
\text { True (1) if arrival between } 9 \text { A.M. and } 4 \text { P.M. } \\
\text { True (1) if arrival between } 4 \text { and } 6 \text { P.M. } \\
\text { True (1) if arrival later than } 6 \text { P.M. } \\
\text { True (1) if bus travel direction is eastbound }\end{array}$ \\
\hline Distance & Stop-to-Stop Travel Distance & $\begin{array}{l}\text { Distance } \\
\text { (miles) }\end{array}$ & $\begin{array}{l}\text { The travel distance from pervious to current } \\
\text { stop }\end{array}$ \\
\hline $\begin{array}{l}\text { Lateness } \\
\text { and } \\
\text { Priority }\end{array}$ & $\begin{array}{l}\text { Previous Stop Lateness } \\
\text { Previous Stop Priority } \\
\text { Requested }\end{array}$ & $\begin{array}{l}\text { Time (seconds) } \\
\text { Dummy }\end{array}$ & $\begin{array}{l}\text { The actual departure minus scheduled departure } \\
\text { at previous stop } \\
\text { True if bus meets priority request conditions at } \\
\text { previous stop }\end{array}$ \\
\hline Signals & $\begin{array}{l}\text { Non-Priority Signals } \\
\text { Priority Signals }\end{array}$ & $\begin{array}{l}\text { Number } \\
\text { (signals) } \\
\text { Number } \\
\text { (signals) }\end{array}$ & $\begin{array}{l}\text { Number of non-priority signals passed between } \\
\text { current and previous stop } \\
\text { Number of priority signals passed between } \\
\text { current and previous stop }\end{array}$ \\
\hline & $\begin{array}{l}\text { Near-Side Stop } \\
\text { Far-Side Stop } \\
\end{array}$ & $\begin{array}{l}\text { Dummy } \\
\text { Dummy }\end{array}$ & $\begin{array}{l}\text { True (1) if bus stop is located on the near side of } \\
\text { an intersection } \\
\text { True (1) if bus stop is located on the far side of } \\
\text { an intersection }\end{array}$ \\
\hline Stop Type & $\begin{array}{l}\text { Near-Side Bus-Bay Length } \\
\text { Far-Side Bus-Bay Length } \\
\text { Mid-Block Bus-Bay Length }\end{array}$ & $\begin{array}{l}\text { Length (feet) } \\
\text { Length (feet) } \\
\text { Length (feet) }\end{array}$ & $\begin{array}{l}\text { The length of bus bay if it exists on the near } \\
\text { side on an intersection } \\
\text { The length of bus bay if it exists on the far side } \\
\text { on an intersection } \\
\text { The length of bus bay if it exists mid-block }\end{array}$ \\
\hline \multirow[t]{2}{*}{$\begin{array}{l}\text { Operator } \\
\text { Behavior }\end{array}$} & $\begin{array}{l}\text { Max Speed Bin } 2 \text { (25-28 mph) } \\
\text { Max Speed Bin } 3 \text { (29-32 mph) } \\
\text { Max Speed Bin } 4 \text { (> } 32 \mathrm{mph})\end{array}$ & $\begin{array}{l}\text { Dummy } \\
\text { Dummy } \\
\text { Dummy }\end{array}$ & $\begin{array}{l}\text { True (1) if the maximum travel speed between } \\
\text { stops is between } 25 \text { and } 28 \mathrm{mph}\left(2^{\text {nd }} \text { quartile) }\right. \\
\text { True (1) if the maximum travel speed between } \\
\text { stops is between } 29 \text { and } 32 \mathrm{mph}\left(3^{\text {rd }} \text { quartile }\right) \\
\text { True (1) if the maximum travel speed between } \\
\text { stops is greater than } 32 \mathrm{mph}\left(4^{\text {th }} \text { quartile) }\right.\end{array}$ \\
\hline & $\begin{array}{l}\text { Previous Stop skipped } \\
\text { Current Stop skipped }\end{array}$ & $\begin{array}{l}\text { Dummy } \\
\text { Dummy }\end{array}$ & $\begin{array}{l}\text { True (1) if operator does not stop at previous } \\
\text { bus stop } \\
\text { True (1) if operator does not stop at current bus } \\
\text { stop }\end{array}$ \\
\hline
\end{tabular}




\subsection{GENERIC STOP SEGMENT RESULTS}

First a set of generic stop segment regression models were created to predict stop-to-stop travel time given the set of predictors in Table 1. Two models are presented in Table 2: a corridor model for bus-stop event data in both directions, and an eastbound direction model for stop event data occurring in the eastbound direction of the route. Note that these models took into account different characteristics of the ending stop in each stop-to-stop segment, but did not control for specific intersections. For each model, observations (n) and adjusted R-square values are shown along with the betas (coefficients), standard errors and P-values for each significant variable.

Maximum speeds were found to have intuitive effects for both models. Each higher speed bin, corresponding to the next quartile of observed maximum speeds, reduces the travel time significantly. Hence, a driver choosing to drive faster along the corridor had a significant effect on the schedule adherence. Lateness at the previous stop was significant for the eastbound model but not for the corridor model. Meeting priority request conditions at the previous stop, however, was significant in both models. Also both models showed non-priority and priority signals to be significant in predicting travel time. Note that there is a difference between the magnitudes of beta value of signals for both models. Non-priority signals contribute, on average, 11.0 and 10.7 seconds to travel time while priority signals contribute just 0.7 and 1.6 seconds for both directions and the eastbound direction, respectively. Considering the coefficients of priority requests, priority signals and non-priority signals, it can be assumed requesting priority along segments with priority signals provides an important travel-time savings over non-priority signals.

Each of the time-of-day variables showed intuitive results, though in both models the evening time period was not significant. The reference case for time periods was the early morning from 5-7 a.m. The corridor model showed significant increases in travel time throughout the day until after the PM peak period. The eastbound model displayed the eastbound peak period rush hour effects. In the eastbound direction, there is very little traffic moving away from downtown in the AM periods, and more traffic during the PM period. Distance was also significant and produced the largest positive contributing factor to travel time.

Several other predictors were found to be significant as well. Stops on the near side of an intersection were found to decrease travel time and stops on the far side increased travel time in both models. Bus-bay lengths had mixed effects between the two models. The corridor model showed near-side and far-side bay lengths increase travel time and mid-block bay lengths decrease travel time. In the eastbound model near-side bay length increased travel time, far-side bay length decreased travel time and mid-block length was not significant. Both models show that skipping stops provides some reduction in travel time, though in the eastbound direction skipping the current stop was not significant. 
Table 10. Stop-to-Stop Travel Time Base Models

\begin{tabular}{|c|c|c|c|c|c|c|}
\hline & \multicolumn{3}{|c|}{ Corridor (Both Directions) } & \multicolumn{3}{|c|}{ Eastbound Direction } \\
\hline Observations $(\mathrm{N})$ & & & 97187 & & & 48813 \\
\hline Adjusted R-Square & & & 0.589 & & & 0.678 \\
\hline Significant Variables & Beta & $\begin{array}{r}\text { Std } \\
\text { Error }\end{array}$ & P-Value & Beta & $\begin{array}{r}\text { Std } \\
\text { Error }\end{array}$ & P-Value \\
\hline (Intercept) & 3.929 & 0.190 & 0.000 & 2.734 & 0.212 & 0.000 \\
\hline AM Peak Period (7-9 A.M.) & 1.819 & 0.145 & 0.000 & \multicolumn{3}{|c|}{ Not Significant } \\
\hline Midday (9 A.M.-4 P.M.) & 1.319 & 0.109 & 0.000 & 1.577 & 0.137 & 0.000 \\
\hline PM Peak Period (4-6 P.M.) & 2.694 & 0.143 & 0.000 & 4.381 & 0.172 & 0.000 \\
\hline Eastbound Direction & -1.642 & 0.094 & 0.000 & \multicolumn{3}{|c|}{ Not Included } \\
\hline Stop-to-Stop Travel Distance & 130.064 & 0.423 & 0.000 & 122.053 & 0.439 & 0.000 \\
\hline Previous Stop Lateness & \multicolumn{3}{|c|}{ Not Significant } & 0.001 & 0.000 & 0.000 \\
\hline Previous Stop Priority Requested & -0.414 & 0.096 & 0.000 & \multicolumn{3}{|c|}{ Not Significant } \\
\hline Non-Priority Signals & 11.025 & 0.198 & 0.000 & 10.705 & 0.300 & 0.000 \\
\hline Priority Signals & 0.660 & 0.106 & 0.000 & 1.636 & 0.136 & 0.000 \\
\hline Near-Side Stop & -1.689 & 0.152 & 0.000 & -5.781 & 0.222 & 0.000 \\
\hline Far-Side Stop & 6.240 & 0.151 & 0.000 & 5.702 & 0.198 & 0.000 \\
\hline Near-Side Bus-Bay Length & 0.015 & 0.001 & 0.000 & 0.047 & 0.001 & 0.000 \\
\hline Far-Side Bus-Bay Length & 0.010 & 0.001 & 0.000 & -0.014 & 0.001 & 0.000 \\
\hline Mid-Block Bus-Bay Length & -0.004 & 0.001 & 0.000 & \multicolumn{3}{|c|}{ Not Significant } \\
\hline Max Speed Bin 2 (25-28 mph) & -6.622 & 0.142 & 0.000 & -6.081 & 0.195 & 0.000 \\
\hline Max Speed Bin 3 (29-32 mph) & -8.796 & 0.137 & 0.000 & -8.354 & 0.186 & 0.000 \\
\hline Max Speed Bin 4 (> $32 \mathrm{mph})$ & -11.889 & 0.151 & 0.000 & -12.031 & 0.199 & 0.000 \\
\hline Previous Stop Drive By & -0.732 & 0.095 & 0.000 & -0.421 & 0.128 & 0.001 \\
\hline Current Stop Drive By & -0.846 & 0.099 & 0.000 & \multicolumn{3}{|c|}{ Not Significant } \\
\hline
\end{tabular}

In Table 11 below, the median values and subsequent contributions of variables are shown using the results from Table 10. These contributions represent the travel-time effects caused by the median values of these variables. The median stop-to-stop travel times are reported in the last row. In both models travel distance was the largest positive contributor to travel time, while maximum speed was the largest negative contributor. It is important to note that both traffic conditions (using maximum speed as a proxy) and priority provided significant reductions in travel time in both models. While priority requests provided only a slight travel-time reduction, when combined with the signal type (non-priority or priority) the priority signals stood out as significantly smaller travel-time penalties when compared to those signals without priority. 
Table 11. Intersection Contributions

\begin{tabular}{|c|c|c|c|c|c|c|}
\hline \multirow[b]{2}{*}{ Variable } & \multicolumn{3}{|c|}{ Corridor (Both Directions) } & \multicolumn{3}{|c|}{ Eastbound Direction } \\
\hline & Median & Beta & $\begin{array}{r}\text { Contribution } \\
\text { (seconds) }\end{array}$ & Median & Beta & $\begin{array}{r}\text { Contribution } \\
\text { (seconds) }\end{array}$ \\
\hline Stop-to-Stop Travel Distance (mi) & 0.14 & 130.06 & 18.21 & 0.15 & 122.053 & 18.31 \\
\hline Previous Stop Priority Requested (T/F) & 1 & -0.41 & -0.41 & 1 & NA & NA \\
\hline Previous Stop Lateness (s) & 61 & NA & NA & 79 & 0.001 & 0.08 \\
\hline Near-Side Bus-Bay Length (ft) & 220 & 0.02 & 3.30 & 220 & 0.047 & 10.34 \\
\hline Far-Side Bus-Bay Length (ft) & 130 & 0.01 & 1.30 & 140 & -0.014 & -1.96 \\
\hline Mid-Block Bus-Bay Length (ft) & 140 & 0.00 & -0.56 & 160 & NA & NA \\
\hline Maximum Speed (mph) & 28 & -6.62 & -6.62 & 29 & -6.081 & -6.081 \\
\hline Stop-to-Stop Travel Time (s) & 14 & & & 16 & & \\
\hline
\end{tabular}

\subsection{INTERSECTION LEVEL RESULTS}

Final intersection specific regression models were then created that added a new set of dummy variables as predictors. These predictors indicated the presence of specific signalized intersections along the previous stop-to-stop segment. The introduction of these variables was intended to identify any signalized intersection characteristics that might not be correctly controlled for in the previous models. With this new set of predictors Adjusted R-Square values increased, suggesting better fitting models. The new models, both for the whole corridor (both directions) and the eastbound direction, are shown in Table 12. 
Table 12. Stop-to-Stop Travel Time Model

\begin{tabular}{|c|c|c|c|c|c|c|}
\hline & \multicolumn{3}{|c|}{ Corridor (Both Directions) } & \multicolumn{3}{|c|}{ Eastbound Direction } \\
\hline Observations $(\mathrm{N})$ & & & 97187 & & & 48813 \\
\hline Adjusted R-Square & & & 0.614 & & & 0.692 \\
\hline Significant Variables & Beta & $\begin{array}{r}\text { Std } \\
\text { Error }\end{array}$ & P-Value & Beta & $\begin{array}{r}\text { Std } \\
\text { Error }\end{array}$ & P-Value \\
\hline (Intercept) & 3.266 & 0.190 & 0.000 & 1.399 & 0.252 & 0.000 \\
\hline AM Peak Period (7-9 A.M.) & 1.994 & 0.141 & 0.000 & \multicolumn{3}{|c|}{ Not Significant } \\
\hline Midday (9A.M.-4 P.M.) & 1.507 & 0.105 & 0.000 & 1.621 & 0.135 & 0.000 \\
\hline PM Peak Period (4-6 P.M.) & 3.041 & 0.139 & 0.000 & 4.585 & 0.169 & 0.000 \\
\hline Eastbound Direction & -1.025 & 0.092 & 0.000 & \multicolumn{3}{|c|}{ Not Included } \\
\hline Stop-to-Stop Travel Distance & 125.184 & 0.466 & 0.000 & 123.849 & 0.465 & 0.000 \\
\hline Previous Stop Lateness & 0.001 & 0.000 & 0.002 & 0.001 & 0.000 & 0.000 \\
\hline Previous Stop Priority Requested* & -0.504 & 0.113 & 0.000 & -0.402 & 0.159 & 0.012 \\
\hline Priority Signals & 9.588 & 0.360 & 0.000 & 10.084 & 0.645 & 0.000 \\
\hline Near-Side Stop & -0.885 & 0.159 & 0.000 & -1.083 & 0.313 & 0.001 \\
\hline Far-Side Stop & 2.854 & 0.234 & 0.000 & 4.344 & 0.326 & 0.000 \\
\hline Near-Side Bus-Bay Length & \multicolumn{3}{|c|}{ Not Significant } & 0.008 & 0.001 & 0.000 \\
\hline Far-Side Bus-Bay Length & 2.854 & 0.234 & 0.000 & \multicolumn{3}{|c|}{ Not Significant } \\
\hline Mid-Block Bus-Bay Length & 0.010 & 0.001 & 0.000 & \multicolumn{3}{|c|}{ Not Significant } \\
\hline Max Speed Bin 2 (25-28 mph) & -0.004 & 0.001 & 0.000 & -5.026 & 0.194 & 0.000 \\
\hline Max Speed Bin 3 (29-32 mph) & -5.372 & 0.139 & 0.000 & -6.887 & 0.188 & 0.000 \\
\hline Max Speed Bin 4 (>32 mph) & -7.358 & 0.135 & 0.000 & -10.422 & 0.208 & 0.000 \\
\hline Previous Stop Drive By & -10.853 & 0.148 & 0.000 & -1.171 & 0.133 & 0.000 \\
\hline Current Stop Drive By & \multicolumn{3}{|c|}{ Not Significant } & 0.365 & 0.137 & 0.008 \\
\hline Passes $86^{\text {th }}$ & -20.801 & 0.346 & 0.000 & 4.162 & 0.428 & 0.000 \\
\hline Passes $82^{\text {nd }}$ & 24.842 & 0.333 & 0.000 & 25.804 & 0.519 & 0.000 \\
\hline Passes $72^{\text {nd }}$ & -7.752 & 0.437 & 0.000 & -8.607 & 0.721 & 0.000 \\
\hline Passes $71^{\text {st }}$ & -6.812 & 0.459 & 0.000 & -5.956 & 0.763 & 0.000 \\
\hline Passes $69^{\text {th }}$ & -10.516 & 0.353 & 0.000 & -9.429 & 0.639 & 0.000 \\
\hline Passes $65^{\text {th }}$ & -12.126 & 0.343 & 0.000 & -12.306 & 0.641 & 0.000 \\
\hline Passes $52^{\text {nd }}$ & -4.593 & 0.327 & 0.000 & -3.854 & 0.643 & 0.000 \\
\hline Passes $50^{\text {th }}$ & 1.923 & 0.338 & 0.000 & -3.505 & 0.641 & 0.000 \\
\hline Passes $43 \mathrm{rd}$ and $42^{\text {nd }}$ & -9.129 & 0.426 & 0.000 & -6.924 & 0.721 & 0.000 \\
\hline Passes $33^{\text {rd }}$ & -11.421 & 0.375 & 0.000 & -9.850 & 0.721 & 0.000 \\
\hline Passes $26^{\text {th }}$ & -9.761 & 0.428 & 0.000 & -9.072 & 0.725 & 0.000 \\
\hline Passes $21^{\text {st }}$ & -9.793 & 0.646 & 0.000 & -18.429 & 1.243 & 0.000 \\
\hline
\end{tabular}


These new models showed consistency with the base models across coefficients for time-of-day variables, distance, stop location and maximum speed. However, some coefficients have changed as the effects have been moved to specific intersection dummy variables. In these models previous stop lateness was positive and significant for both corridor and eastbound models, and previous stop priority requested was negative and significant in both directions. While skipping the previous stop significantly decreased travel time, skipping the current stop increased travel time and was only significant in the eastbound model. Also, the non-priority signals dummy variable was removed from the model, as only two signals did not have TSP available. This allowed all signals to be accounted for in the model except the base case (SE $39^{\text {th }}$ ).

Given the coefficients for the specific signals along the corridor and the coefficients describing stops at those locations, it was possible to determine the contribution of each signalized intersection to travel time. The results of this calculation are shown in Table 13 and intersections are ranked from smallest to largest travel-time contribution. The results are intuitive as intersections with less traffic volume on crossing minor streets, and therefore more available green time to be used for TSP actions, show considerably less travel-time contributions than those with high volumes on the crossing streets. Additionally, the two intersections without TSP available, SE $82^{\text {nd }}$ Ave and SE $86^{\text {th }}$ Ave make up the highest and fifth highest travel time. Note that $21^{\text {st }}$ and Milwaukie share a combined 6.1 second contribution as both intersections lie between two consecutive stops, and the effects of both intersections are found at the downstream stop.

Table 13. Signalized Intersection's Contribution to Travel Time

\begin{tabular}{|c|c|c|c|c|c|}
\hline Intersection & Contribution(s) & $\begin{array}{c}\text { Median } \\
\text { Recovery (s) }\end{array}$ & $\begin{array}{l}\text { TSP Not } \\
\text { Available }\end{array}$ & $\begin{array}{c}\text { Major Cross } \\
\text { Street }\end{array}$ & $\begin{array}{c}\text { Controlled } \\
\text { Access }\end{array}$ \\
\hline $33^{\text {rd }}$ & 0.3 & 0.0 & & & \\
\hline $26^{\text {th }}$ & 1.1 & -1.0 & & & \\
\hline $72^{\text {nd }}$ & 1.6 & 18.0 & & & \\
\hline $65^{\text {th }}$ & 2.2 & 8.0 & & & \\
\hline $43 \mathrm{rd}$ and $42 \mathrm{nd}$ & 3.2 & 26.0 & & & \\
\hline $71^{\text {st }}$ & 4.2 & -5.0 & & & \\
\hline $69^{\text {th }}$ & 5.1 & 4.0 & & & \\
\hline $21 \mathrm{st} *$ & 6.1 & 42.0 & & & Yes \\
\hline Milwaukie* & 6.1 & 42.0 & & Yes & Yes \\
\hline $86^{\text {th }}$ & 8.6 & 20.0 & Yes & & \\
\hline $52^{\text {nd }}$ & 10.6 & -19.0 & & & \\
\hline $50^{\text {th }}$ & 11.0 & -8.0 & & & \\
\hline $39^{\text {th }}$ & 17.4 & -39.0 & & Yes & \\
\hline $82^{\text {nd }}$ & 32.0 & -66.0 & Yes & Yes & \\
\hline
\end{tabular}

Using the previous methodology presented to calculate recovery by Albright and Figliozzi (2012), median lateness and recovery were calculated. Figure 6 shows the median recovery in seconds at each intersection plotted against the intersection contribution. In this graph, intersections with TSP available are distinguished from those without TSP by point shape. Clear and intuitive trends were seen as intersections with low median recovery tend to exhibit the highest contribution of travel time. The presence of TSP also tended to increase median recovery and decrease intersection travel time contribution. The worst intersection contribution and recovery performance was detected at SE $82^{\text {nd }}$ where TSP is not enabled. The best recovery performance was seen at $21^{\text {st }}$ Avenue, where a controlled access section exists before the signalized intersection and bus stop that prevents vehicles from exiting or entering the segment. The best intersection contribution was at $33^{\text {rd }}$ Avenue, where a combination of TSP and low traffic volumes in the minor direction reduces any extra delay on buses. 


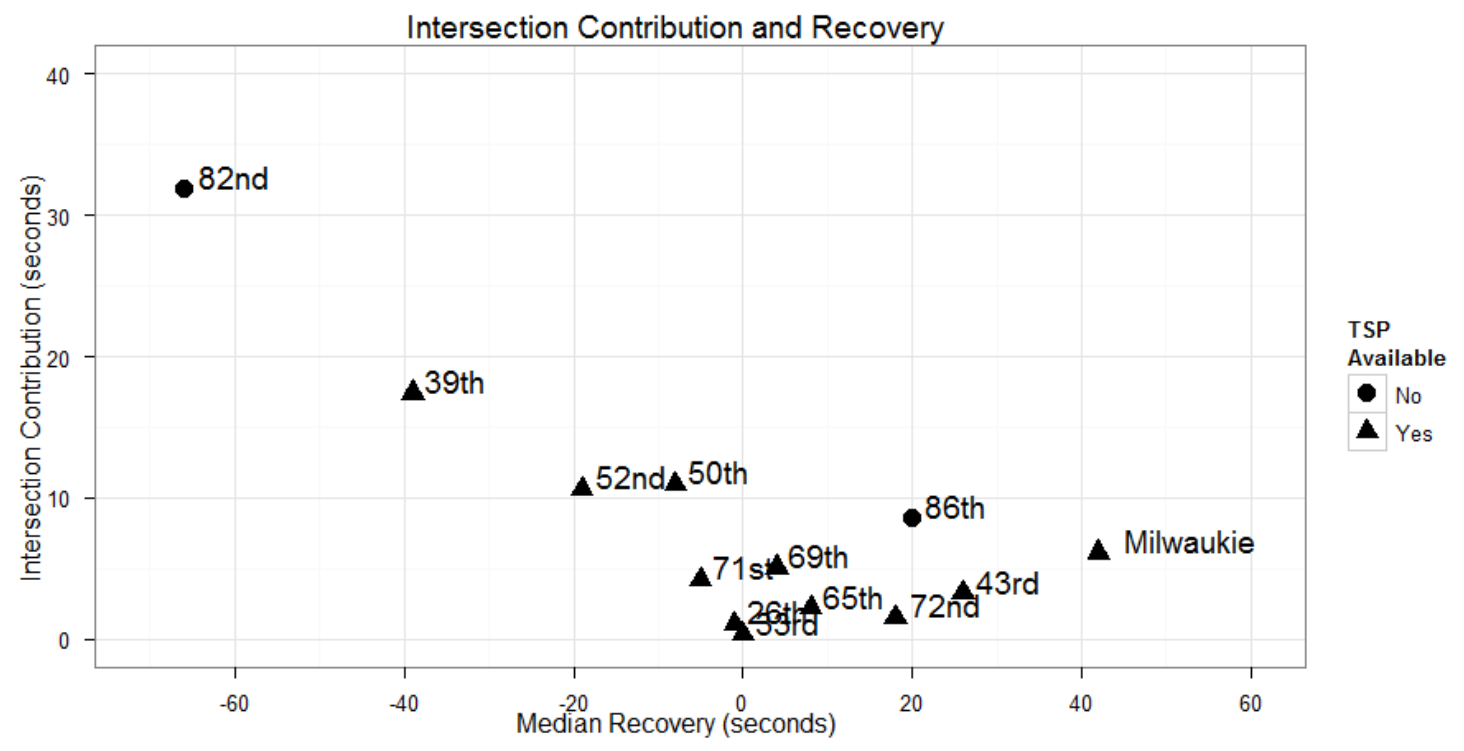

Figure 6. Intersection Contribution and Recovery at Signalized Intersections

\subsection{SUMMARY}

In this study an empirical analysis of TriMet's Route 9 in Southeast Portland was performed to determine the joint effects TSP, traffic and operator behavior have on travel time and if those effects could be distinguished from each other. Previous studies of TSP have been focused at the route and corridor level and found mixed results regarding TSP performance. This study focused on the stop-to-stop travel segment in order to determine if TSP benefits at certain locations may be masked by poor performance at the corridor or route level.

Regression analysis was used to model stop-to-stop travel time considering the effects of predictor variables such as: time of day, lateness, priority requests, operator behavior and bus-stop characteristics. The set of generic stop-to-stop segment models showed intuitive coefficients for time of day, distance and stop type. In these models driver behavior was approximated by maximum speed, and predicted traveltime reductions as much as nine and 12 seconds when maximum speeds were in the upper $3^{\text {rd }}$ and $4^{\text {th }}$ quartile, respectively. Priority requests at the previous stop were shown to have only slight reductions in travel (less than one second), but the coefficients of the signalized-intersection type variables proved the advantages of priority enabled signals. Non-priority signals had a much greater impact on travel time than priority signals (11.0 and 0.6 seconds for the corridor model, respectively). In controlling for both priority and operator behavior, each were shown to have distinguished and significant impact on travel time.

A second set of regression models was presented that attempted to control for each signalized intersection along the corridor. All signals provided significant effects on travel time. When these coefficients were combined with the other variable coefficients describing the characteristics of the stop, contributions to travel time for each intersection were calculated. This produced an intuitive ranking of the intersections that meets expectations of Albright and Figliozzi (2012), where major intersections with high traffic volumes on crossing streets are likely to not experience TSP benefits. This verification of the previous study is especially reassuring as different approaches were used for each study. This study employed regression analysis of travel time and the previous study used schedule adherence and recovery. The final results of this study were presented to the agencies responsible for transit and signalized-intersection lighting, and were determined to match the expectations of both of these groups. 


\subsection{THE IMPACT OF TRAFFIC-SIGNAL TIMING ON PEDESTRIAN PARTICULTE MATTER EXPOSURE}

\subsection{STUDY LOCATION}

The study area is located at Powell Boulevard and 26th Avenue, which is an ideal location for an air quality study for various reasons. The land use surrounding this intersection provides compelling reasons to measure the air pollution. Cleveland High School, which serves students from grades 9-12, is located at the northeast corner of the intersection. The school has high pedestrian, biking and transit activity during school start and release times. At the southwest corner of the intersection is the eight-acre Powell Park (City of Portland, 2008). Businesses are located on the other two corners of the intersection. In addition, this intersection is multimodal in nature. Powell is a heavily traveled corridor for private vehicles, especially during peak commuting periods, in addition to being a key bus route. Southeast 26th Street is a two-lane cross street (with auxiliary turn lanes at the intersection) and also an important north-south bike route.

\subsection{DATA COLLECTION AND PROCESSING}

Data was collected by a team of three to five people at Powell and 26th simultaneously measuring air quality, atmospheric factors, and traffic-related data. Data was collected on Wednesday, October 26th, 2011 from 7-9 a.m. The data collection consisted of a two-hour temporary setup of a variety of equipment owned by Portland State University. A Dusttrak DRX 8533 Monitor $^{1}$ was used to take measurements of the concentration levels of PM2.5 every second. This equipment is able to measure a concentration range of 0.001 to 150 milligrams per cubic meter $(\mathrm{mg} / \mathrm{m} 3)$; an anemometer was used to take measurements of wind speed and direction every five seconds. The equipment was set up at the northeast corner of the intersection on a cart located three feet from the side of the bus shelter and 12 feet from the curb (measurements were taken from the center of the cart). There was a tripod set up behind the cart to attach the tubing at a five-foot height; five feet is a typically assumed in the literature as the breathing height for most people.

Both bus presence and heavy vehicle presence were recorded by keeping track of the arrival time and departure times of these vehicles to one second accuracy. For bus presence, there were two departure times, including the time the bus closed its doors and the time the bus actually left the stop, route number, bus number, and the angle of the tailpipe on the back of the bus. Heavy vehicles within the first 50 feet of the queue in relation to the location of the air quality equipment were included. If a heavy vehicle was visibly emitting or had a smell associated with it, it was recorded as well, even if it was not in the queue. Bus and heavy vehicle presence was converted into binary variables with a one being present and a zero otherwise.

Detailed traffic-signal operation data was recorded, including the start and end time for each phase and the detector volumes. There are a total of five phases, as detailed in Table 14. The movements follow the

\footnotetext{
${ }^{1}$ http://www.tsi.com/DUSTTRAK-DRX-Aerosol-Monitor-8533
} 
standard numbering system, where 2 and 6 movements correspond to through/permitted right movements on Powell Boulevard; phase A for the main street; and 4 for through/right/permitted left movements on 26th Avenue (phase D). Figure 7 shows the ring and barrier diagram at the intersection (no pedestrian movement included); numbers do not correspond with the letters in Table 14 because the SCATS system utilizes letters. There are three left-turning options and associated phases depending on the detected demand (see phases C, E, and F in Table 14).

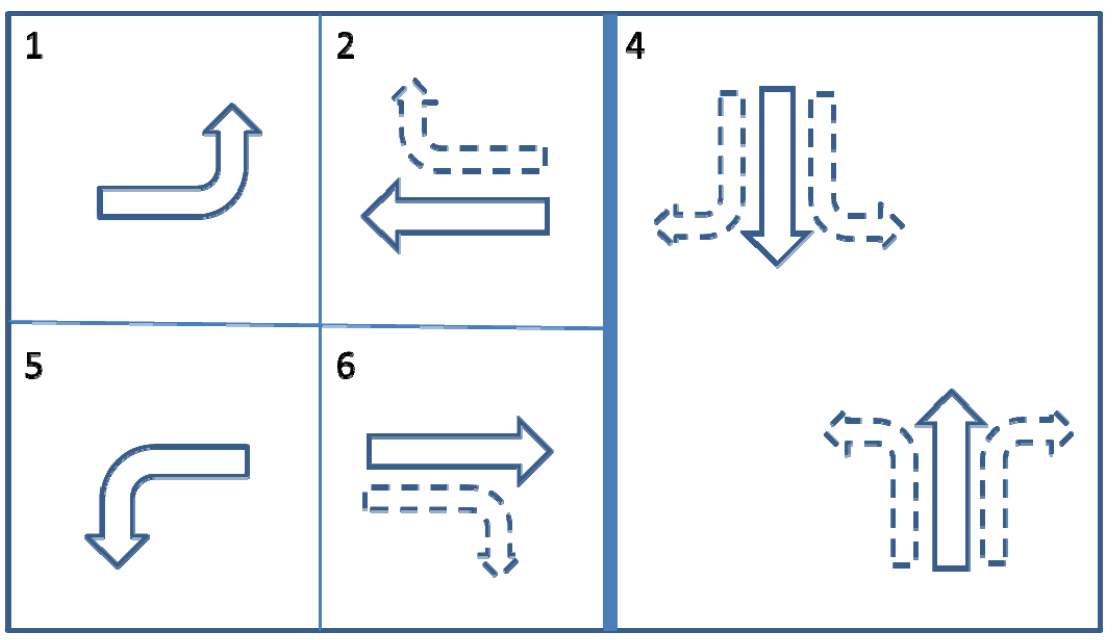

Figure 7. Ring and Barrier Diagram

\subsection{STATISTICAL ANALYSIS}

A detailed statistical analysis was conducted by first creating a database including the air pollutant concentrations, atmospheric factors, observed traffic, and traffic-signal timing variables. Each row in the database represents a five-second period. The final database has a sample size of 1,591. If the data measurement was taken per second then it was aggregated to five seconds to fit into the structure of the database. All of the air pollutant concentration levels were averaged over the five seconds. Particulate matter concentration levels were expressed in $\mu \mathrm{g} / \mathrm{m}^{3}$. In order to include wind direction, eight direction bins were created, including N, NE, E, SE, S, SW, W, and NW. The impact of both wind direction and wind speed on pollutant levels was incorporated by creating interaction terms. The eight wind-direction bins were multiplied by wind speed to create a new set of inputs in meters per second. The data dictionary is shown in Table 14 and includes descriptive statistics for particulate matter; atmospheric-related factors such as temperature, relative humidity, wind speed and direction; observed traffic and traffic-signal timing. 
Table 14. Data Dictionary

\begin{tabular}{|c|c|c|c|c|c|c|}
\hline Name & Description & Data Type & Units & Min & Mean & Max \\
\hline \multicolumn{7}{|c|}{ Air Pollutant Concentration } \\
\hline $\mathrm{PM}_{2.5}$ & Concentration & Numeric & $\mu \mathrm{g} / \mathrm{m}^{3}$ & 27.40 & 38.78 & 114.80 \\
\hline \multicolumn{7}{|c|}{ Atmospheric Factors } \\
\hline Temp & Temperature & Numeric & ${ }^{\circ} \mathrm{F}$ & 39.31 & 39.94 & 41.04 \\
\hline $\mathrm{RH}$ & Relative humidity & Numeric & $\%$ & 74.66 & 78.92 & 80.97 \\
\hline wsN & Wind speed in the north & Numeric & $\mathrm{m} / \mathrm{s}$ & 0 & 0.167 & 1.81 \\
\hline wsNE & Wind speed in the northeast & Numeric & $\mathrm{m} / \mathrm{s}$ & 0 & 0.052 & 1.12 \\
\hline wsE & Wind speed in the east & Numeric & $\mathrm{m} / \mathrm{s}$ & 0 & 0.027 & 1.42 \\
\hline wsSE & Wind speed in the southeast & Numeric & $\mathrm{m} / \mathrm{s}$ & 0 & 0.036 & 0.87 \\
\hline wsS & Wind speed in the south & Numeric & $\mathrm{m} / \mathrm{s}$ & 0 & 0.067 & 1.09 \\
\hline wsSW & Wind speed in the southwest & Numeric & $\mathrm{m} / \mathrm{s}$ & 0 & 0.050 & 1.13 \\
\hline wsW & Wind speed in the west & Numeric & $\mathrm{m} / \mathrm{s}$ & 0 & 0.053 & 1.48 \\
\hline wsNW & Wind speed in the northwest & Numeric & $\mathrm{m} / \mathrm{s}$ & 0 & 0.073 & 1.95 \\
\hline \multicolumn{7}{|l|}{ Observed Traffic } \\
\hline Bus & $\begin{array}{l}\text { If there was a bus present at the } \\
\text { westbound direction bus stop }\end{array}$ & Binary & $(0,1)$ & 0 & 0.074 & 1 \\
\hline Bus Red Light & $\begin{array}{l}\text { Amount of time bus is waiting at a } \\
\text { red light at the stop }\end{array}$ & Numeric & secs & 0 & 0.877 & 45 \\
\hline DPF & $\begin{array}{l}\text { If the bus has a diesel particulate } \\
\text { filter }\end{array}$ & Binary & $(0,1)$ & 0 & 0.049 & 1 \\
\hline EMP & $\begin{array}{l}\text { If the bus has an engine cooling } \\
\text { system }\end{array}$ & Binary & $(0,1)$ & 0 & 0.020 & 1 \\
\hline TP Angled & $\begin{array}{l}\text { If the bus tailpipe has an angled } \\
\text { orientation away from pedestrians }\end{array}$ & Binary & $(0,1)$ & 0 & 0.003 & 1 \\
\hline Heavy Vehicle & $\begin{array}{l}\text { If there was a heavy vehicle within } \\
\text { the first } 50 \text { feet of the westbound } \\
\text { queue }\end{array}$ & Binary & $(0,1)$ & 0 & 0.031 & 1 \\
\hline HV Time & $\begin{array}{l}\text { Amount of time the heavy vehicle } \\
\text { is waiting in the queue }\end{array}$ & Numeric & secs & 0 & 0.896 & 45 \\
\hline \multicolumn{7}{|l|}{ Traffic Volumes } \\
\hline WBTH & \multirow{2}{*}{$\begin{array}{l}\text { Number of vehicles during the } \\
\text { phase per } 5 \text { seconds }\end{array}$} & Numeric & vehs & 0 & 1.967 & 4.25 \\
\hline EBTH & & Numeric & vehs & 0 & 1.250 & 4.00 \\
\hline Powell Volume & $\begin{array}{l}\text { Sum of eastbound and westbound } \\
\text { through volume }\end{array}$ & Numeric & vehs & 0 & 3.212 & 7.00 \\
\hline SBTH & \multirow{2}{*}{$\begin{array}{l}\text { Number of vehicles during the } \\
\text { phase per } 5 \text { seconds }\end{array}$} & Numeric & vehs & 0 & 0.229 & 2.00 \\
\hline NBTH & & Numeric & vehs & 0 & 0.077 & 1.00 \\
\hline $\begin{array}{l}\text { Volume per } \\
\text { Cycle }\end{array}$ & Number of vehicles per cycle & Numeric & vehs & 50 & 95.94 & 137 \\
\hline \multicolumn{7}{|c|}{ Traffic Signal Timing } \\
\hline Phase A & Green time for EBTH \& WBTH & Numeric & secs & 56 & 72.05 & 120 \\
\hline Phase $\mathrm{C}$ & Green time for WBTH \& WBLT & Numeric & secs & 0 & 5.784 & 22 \\
\hline Phase E & Green time for EBTH \& EBLT & Numeric & secs & 0 & 1.841 & 15 \\
\hline Phase F & Green time for EBLT \& WBLT & Numeric & secs & 0 & 6.631 & 20 \\
\hline Phase D & Green time for SBTH \& NBTH & Numeric & secs & 12 & 29.05 & 33 \\
\hline Cycle Length & Cycle length & Numeric & secs & 80 & 115.29 & 168 \\
\hline
\end{tabular}


PM2.5 NE

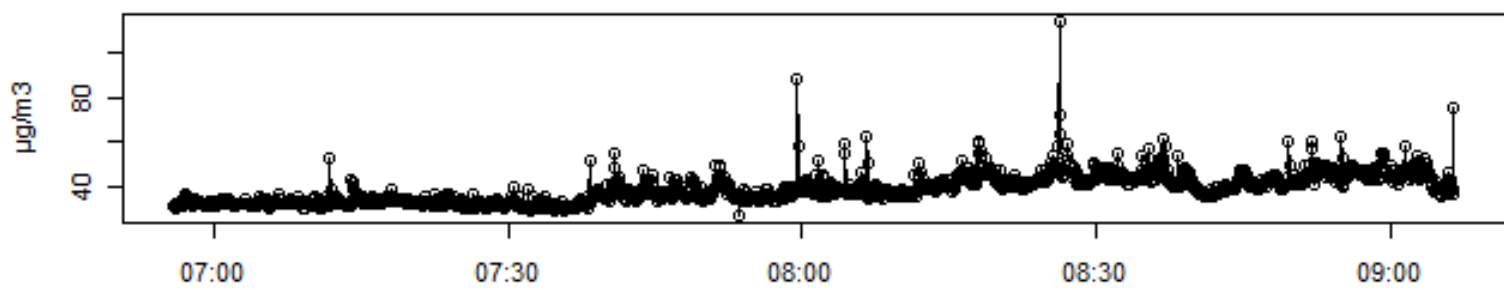

Wind Speed - South

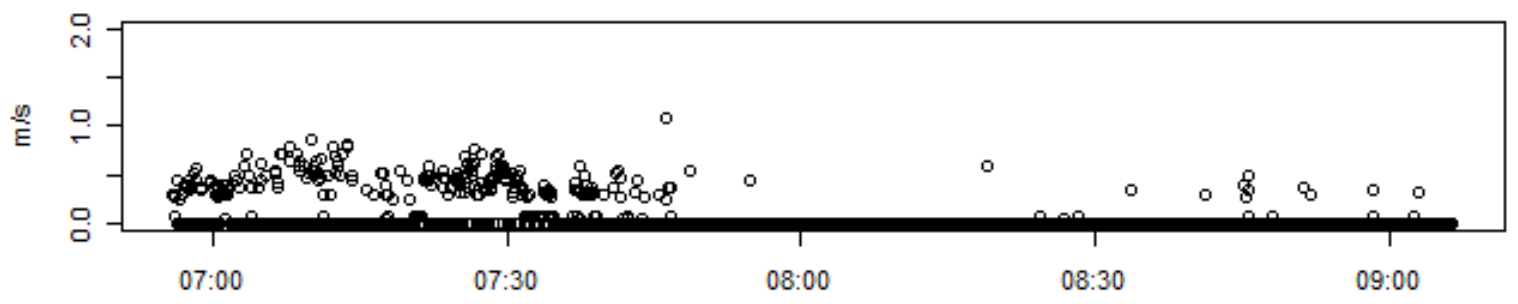

Wind Speed - North

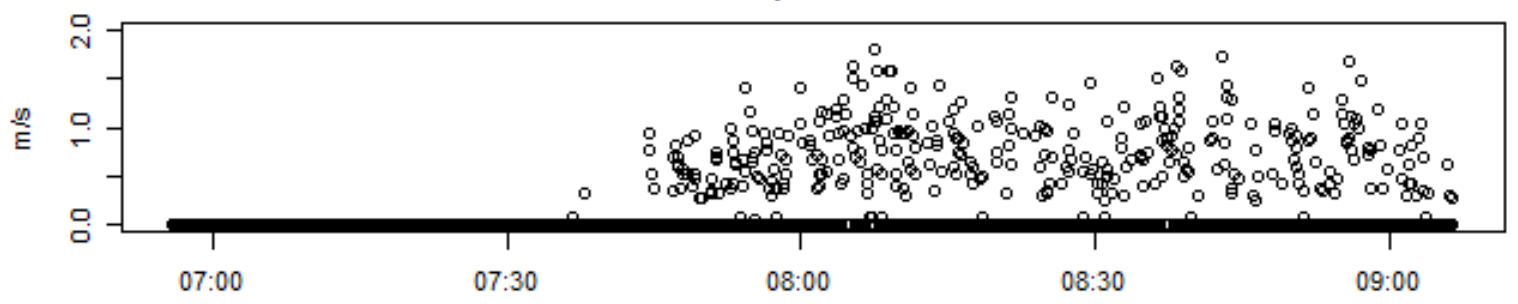

Volume per Cycle

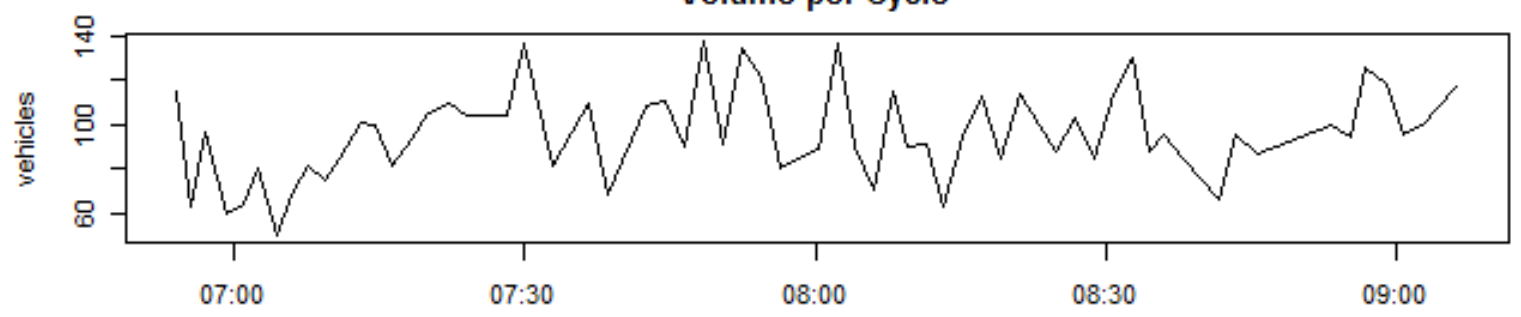

Figure 8. $\mathbf{P M}_{2.5}$ Concentration, Wind, and Volume Scatterplots

Scatterplots were made to examine trends in $\mathrm{M}_{2.5}$ levels, the predominant wind direction, and volume per cycle, as shown in Figure 8. These plots illustrate the importance of accounting for wind direction in particulate matter concentration levels. When the wind switched direction around 7:45 a.m., almost halfway through the data collection period, from the south to the north there is a noticeable increase in $\mathrm{PM}_{2.5}$ levels. There is no clear trend and significant variability on Powell volume per cycle (the cycle length itself is a variable that changes as determined by the SCATS adaptive traffic-control system). As customary in the air quality literature, to reduce skewness, the natural logarithm of $\mathrm{PM}_{2.5}$ levels were regressed against the independent variables (log-linear regression model).

\section{Autoregressive Log-linear Model Regression Results}

It is common with pollution data that the error terms of a regression model are not independent from one another. One of the assumptions of ordinary least squares (OLS) linear regression models is that the error 
terms are independent. If this assumption is violated there are problems with the estimation of coefficients and their standard errors. The Durbin Watson (DW) test determined there was significant positive correlation between contiguous error terms. Autocorrelation function plots confirmed that autocorrelation was a problem that was dealt with using an autoregressive (AR) model of order one.

Table 15 shows only the results where independent variables significant at the 0.05 level remained. In order to determine if the autocorrelation was properly addressed, autocorrelation plots and the Durbin Watson test were performed. The log linear model and the autoregressive of order one or AR(1) model are shown in Table 15, including the regression coefficients, standard error and significance for each predictor in the model.

Table 15. $\mathrm{PM}_{2.5}$ Log Linear \& AR1 Models

\begin{tabular}{|c|c|c|c|c|c|c|}
\hline & \multicolumn{3}{|c|}{ Linear Model } & \multicolumn{3}{|l|}{ AR1 } \\
\hline $\mathrm{R}^{2}$ & \multicolumn{3}{|l|}{$44.63 \%$} & \multicolumn{3}{|l|}{$76.38 \%$} \\
\hline Sigma $^{2}$ & & & & \multicolumn{3}{|l|}{0.00587} \\
\hline Log Likelihood & & & & \multicolumn{3}{|l|}{1803.34} \\
\hline AIC & & & & \multicolumn{3}{|l|}{-3576.68} \\
\hline \multirow[t]{2}{*}{ Durbin Watson } & \multicolumn{3}{|l|}{0.6426} & \multicolumn{3}{|l|}{2.2445} \\
\hline & $\mathrm{B}$ & $\mathrm{SE}_{\mathrm{B}}$ & P-Value & $\mathrm{B}$ & $\mathrm{SE}_{\mathrm{B}}$ & P-Value \\
\hline $\operatorname{AR}(1)$ & & & & 0.8238 & 0.0163 & 0.0000 \\
\hline Constant & 1.6358 & 0.4768 & 0.0006 & 6.4178 & 1.5291 & 0.0000 \\
\hline RH & 0.0069 & 0.0034 & 0.0447 & 0.0174 & 0.0092 & 0.0148 \\
\hline Temp & -0.1348 & 0.0092 & 0.0000 & -0.1045 & 0.0322 & 0.0003 \\
\hline wsSE & -0.1950 & 0.0268 & 0.0000 & -0.0260 & 0.0197 & 0.0466 \\
\hline wsS & -0.2482 & 0.0209 & 0.0000 & -0.0267 & 0.0155 & 0.0214 \\
\hline wsSW & -0.1405 & 0.0198 & 0.0000 & -0.0264 & 0.0135 & 0.0125 \\
\hline BusRedLight & 0.0050 & 0.0005 & 0.0000 & 0.0013 & 0.0009 & 0.0343 \\
\hline EMP & & & & -0.0395 & 0.0280 & 0.0396 \\
\hline HVNE & 0.0780 & 0.0174 & 0.0000 & & & \\
\hline PowellVol & & & & 0.0034 & 0.0015 & 0.0052 \\
\hline GreenA & -0.0028 & 0.0003 & 0.0000 & -0.0017 & 0.0007 & 0.0048 \\
\hline GreenE & 0.0049 & 0.0007 & 0.0000 & 0.0029 & 0.0015 & 0.0126 \\
\hline GreenF & & & & 0.0016 & 0.0010 & 0.0326 \\
\hline GreenD & 0.0025 & 0.0006 & 0.0000 & 0.0027 & 0.0011 & 0.0040 \\
\hline VolCycle & 0.0006 & 0.0002 & 0.0002 & 0.0005 & 0.0004 & 0.0359 \\
\hline
\end{tabular}

As expected, not all terms remained when the AR(1) term was added. More important is the fact that the variables that remained as significant in the autoregressive model differed slightly from the log linear regression model and signs did not change. This highlights the stability of the regression results. Loglinear models not only reduce the skewness of the dependent variable, but also facilitate the interpretation of the independent variables and their elasticity. Three methods of interpretation are included:

1. Percent change in the dependent variable per unit change in independent variable $X$;

2. Percent change in the dependent variable per $1 \%$ change in the independent variable $\mathrm{X}$ (elasticity for each independent variable evaluated at its mean value); and 
3. Percent contribution of each independent variable evaluated at its mean value (sign and \% contribution of each independent variable to the mean value of the dependent variable).

The following Table 16 is for $\mathrm{PM}_{2.5}$ using all three of the interpretation methods. The unit changes are very useful but can be somewhat misleading if the reader does not account for the fact that the independent variables have different units and scales. The second and third methods make interpretation more intuitive because the units of the model input do not affect the results. These two methods require the mean values for each model input for the calculations, as previously shown in the data dictionary.

In terms of the percent change in particulate matter per unit change for each predictor, the variable with the largest impact was temperature, where each additional degree Fahrenheit decreases $\mathrm{PM}_{2.5}$ by almost $10 \%$. Each increase in relative humidity of $1 \%$ increases $\mathrm{PM}_{2.5}$ by almost $2 \%$. Temperature and humidity signs are expected and reflect the fact that there is more pollution when the density of the air increases. Wind in the southeast, south, and southwest directions decreases $\mathrm{PM}_{2.5}$ by around $2.5 \%$ for each meter per second. This is intuitive because $\mathrm{PM}_{2.5}$ was measured in the NE corner. Weather has a large impact on particulate matter levels.

Table 16. $P M_{2.5}$ AR 1 Model Interpretation

\begin{tabular}{|l|l|l|l|}
\hline & $\begin{array}{l}\text { \% Change per Unit Change } \\
\text { in X }\end{array}$ & $\begin{array}{l}\% \text { Change per } 1 \% \\
\text { Change in X }\end{array}$ & $\begin{array}{l}\text { O } \\
\text { Contribution } \\
\text { Baseline* }\end{array}$ \\
\hline RH & $1.75 \%$ & $\mathbf{1 . 3 8 1 \%}$ & \\
wemp & $\mathbf{- 9 . 9 3 \%}$ & $-\mathbf{4 . 0 8 8 \%}$ & \\
wsS & $-2.56 \%$ & $-0.001 \%$ & $-0.09 \%$ \\
wsSW & $-2.63 \%$ & $-0.002 \%$ & $-0.18 \%$ \\
BusRedLight & $-2.61 \%$ & $-0.001 \%$ & $-0.13 \%$ \\
EMP & $0.13 \%$ & $0.001 \%$ & $0.11 \%$ \\
PowellVol & $-3.87 \%$ & $-0.001 \%$ & $-0.08 \%$ \\
GreenA & $0.34 \%$ & $0.011 \%$ & $1.09 \%$ \\
GreenE & $-0.17 \%$ & $-0.122 \%$ & $\mathbf{- 1 1 . 4 7 \%}$ \\
GreenF & $0.30 \%$ & $0.005 \%$ & $0.54 \%$ \\
GreenD & $0.16 \%$ & $0.010 \%$ & $1.04 \%$ \\
VolCycle & $0.27 \%$ & $0.079 \%$ & $\mathbf{8 . 2 5 \%}$ \\
\hline
\end{tabular}

*The baseline value is provided by the contribution of the constant, humidity and temperature variables evaluated at their mean value (background value given the average atmospheric conditions at the time of the study)

$\mathrm{PM}_{2.5}$ is increased by $0.13 \%$ for each additional second that the bus is waiting at a red light. If the bus has an engine cooling system, which increases engine efficiency, pollutant levels are decreased by about $4 \%$ compared to buses that are not equipped with this technology. For each additional vehicle per five seconds traveling through on Powell Boulevard, $\mathrm{PM}_{2.5}$ increases by $0.3 \%$, whereas for each additional vehicle per cycle (the average cycle length is approximately two minutes or 24 five-second intervals), $\mathrm{PM}_{2.5}$ increases by $0.05 \%$. These two volume variables cannot be directly compared due to differences in the units of the predictors.

In terms of traffic- signal timing parameters, each additional second of green time for Phase A decreases $\mathrm{PM}_{2.5}$ by $0.17 \%$, whereas additional green time for all other phases increases the concentration levels. This can be interpreted as the impact of queuing on the northeast corner: During Phase A vehicles are 
passing by the northeast corner; during the other phases vehicles are queuing at the northeast corner. These results seem to indicate that queuing increases $\mathrm{PM}_{2.5}$ levels.

For the mean contribution of the independent variables, all numbers are in reference to the baseline value provided by the sum of relative humidity, temperature, and the constant (background value given the average atmospheric conditions at the time of the study). The largest contribution is provided by the green time for Phase A with a value of $-11 \%$ followed by a $+8 \%$ for green time for Phase $\mathrm{D}$. This result highlights the importance of signal timing and queuing time on $\mathrm{PM}_{2.5}$ levels. Volume per cycle is the third variable, with a 5\% contribution. Using the mean contribution interpretation, it is clear that the impact from volume per cycle is larger than volume on Powell Boulevard, which is different from the unit change interpretation previously discussed.

\section{Lagged Autoregressive Log-linear Model Regression Results}

The AR model previously discussed examined cross sectional data (i.e., did not include the impact of previous periods, lagged variables, on the $\mathrm{PM}_{2.5}$ level at the present time). However, it is expected for emissions to have a delayed response that is caused by the time necessary to travel from the vehicle tailpipe to the measuring station. In order determine if there were lagged effects, cross correlation plots (CCFs) were made for each traffic-related variable and $\mathrm{PM}_{2.5}$ levels. The CCFs for vehicle movements, including eastbound, westbound, southbound and northbound through volumes, are shown for up to two minutes or 24 five-second lags before and after time zero in Figure 9.

database\$EBTH \& database\$PM2.5NEln

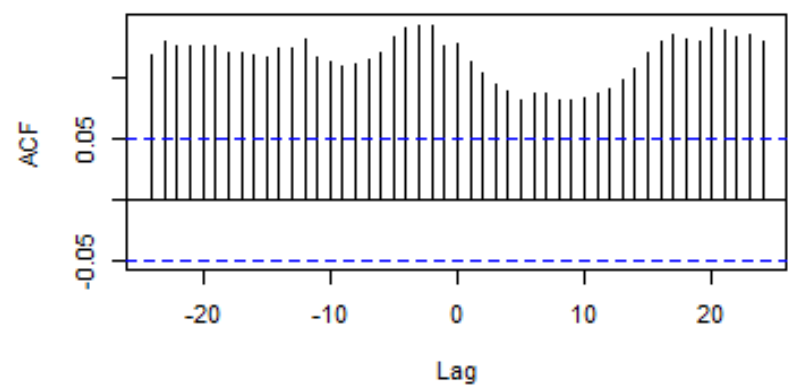

database\$SBTH \& database\$PM2.5NEIn

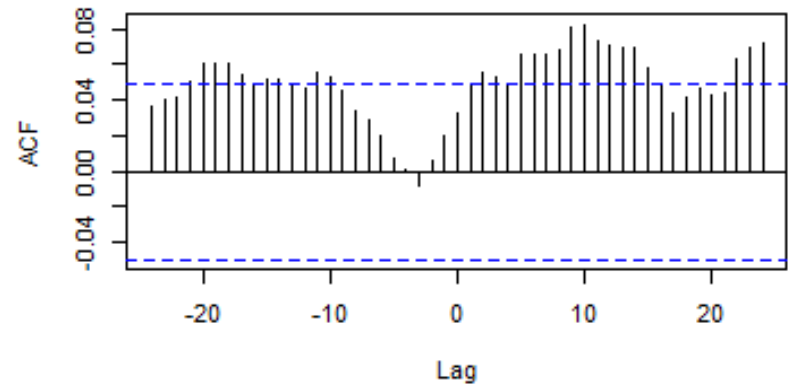

database\$WBTH \& database\$PM2.5NEIn

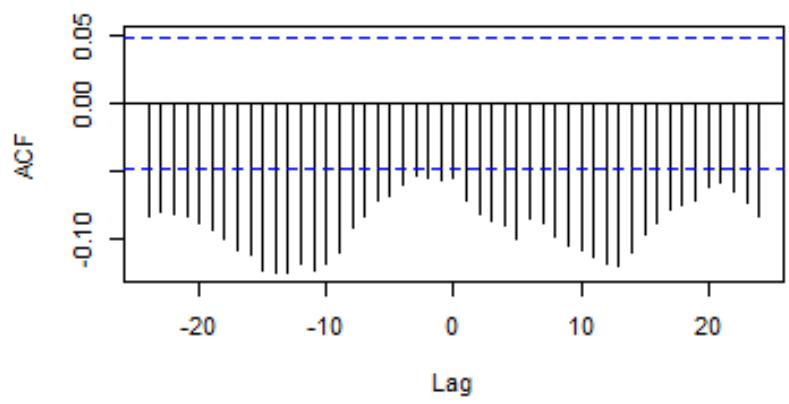

database\$NBTH \& database\$PM2.5NEln

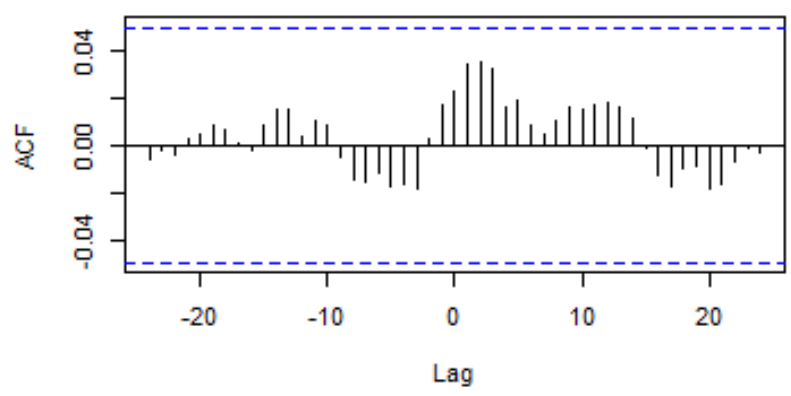

Figure 9. Cross Correlation Plots

The cross correlation plots shown in Figure 9 clearly demonstrate the cyclic impacts of vehicle movements on $\mathrm{PM}_{2.5}$ levels. A cycle is about two minutes long (or 24 five-second lags). The peaks and valleys of the graphs are roughly 12 periods or half a cycle. These plots confirm the cyclic nature of the 
relationship between vehicle movements, phases, and pollutant levels and the value of including lagged variables in the model.

The $\mathrm{R}^{2}$ value for the regression has improved as well as the AIC value and log likelihood. The lagged autoregressive model has an AR1 term of 0.7873, which is similar to the value from the non-lagged autoregressive model. The columns of Table 17 are similar to the columns in Table 16 and have the same interpretation. For variables that were significant at more than one lag, the weighted average lag time is included to facilitate its interpretation

Table 17. $P M_{2.5}$ Lagged AR 1 Model Interpretation

\begin{tabular}{|c|c|c|c|c|c|c|}
\hline & & & & \multicolumn{3}{|l|}{ AR1 } \\
\hline \multicolumn{4}{|l|}{$\mathrm{R}^{2}$} & \multicolumn{3}{|l|}{$78.45 \%$} \\
\hline \multicolumn{4}{|l|}{ Sigma $^{2}$} & \multicolumn{3}{|l|}{0.00555} \\
\hline \multicolumn{4}{|l|}{ Log Likelihood } & \multicolumn{3}{|l|}{1780.55} \\
\hline \multicolumn{4}{|l|}{ AIC } & \multicolumn{3}{|l|}{-3471.10} \\
\hline \multirow{2}{*}{\multicolumn{4}{|c|}{ Durbin Watson }} & \multicolumn{3}{|l|}{2.1838} \\
\hline & & & & $\begin{array}{l}\text { \% Change per } \\
\text { Unit Change in } \mathrm{X}\end{array}$ & $\begin{array}{l}\% \text { Change per } \\
1 \% \text { Change in } \\
\mathrm{X}\end{array}$ & $\begin{array}{l}\text { \% Average } \\
\text { Contribution to } \\
\text { Baseline* }\end{array}$ \\
\hline \multicolumn{4}{|l|}{$\mathrm{RH}$} & $1.65 \%$ & $1.299 \%$ & \\
\hline \multicolumn{4}{|l|}{ Temp } & $-13.28 \%$ & $-5.530 \%$ & \\
\hline \multicolumn{4}{|l|}{ wsSE } & $-3.08 \%$ & $-0.001 \%$ & $-0.11 \%$ \\
\hline \multicolumn{4}{|l|}{ wsS } & $-2.74 \%$ & $-0.002 \%$ & $-0.18 \%$ \\
\hline \multicolumn{4}{|l|}{ wsSW } & $-2.96 \%$ & $-0.002 \%$ & $-0.15 \%$ \\
\hline \multicolumn{4}{|l|}{ EMP } & $-4.00 \%$ & $-0.001 \%$ & $-0.08 \%$ \\
\hline \multicolumn{4}{|l|}{ PowellVol } & $0.44 \%$ & $0.014 \%$ & $1.41 \%$ \\
\hline \multicolumn{4}{|l|}{ GreenA } & $-0.20 \%$ & $-0.143 \%$ & $-13.31 \%$ \\
\hline \multicolumn{4}{|l|}{ GreenE } & $0.20 \%$ & $0.004 \%$ & $0.37 \%$ \\
\hline \multicolumn{4}{|l|}{ GreenD } & $0.33 \%$ & $0.097 \%$ & $10.20 \%$ \\
\hline & Avg. Lag & Secs. & Mins. & & & \\
\hline BusRedLight & 8.4 & 42 & 0.70 & $0.66 \%$ & $0.006 \%$ & $0.58 \%$ \\
\hline EMP & 8 & 40 & 0.67 & $-4.88 \%$ & $-0.001 \%$ & $-0.10 \%$ \\
\hline TPAngled & 14.9 & 75 & 1.24 & $-81.50 \%$ & $-0.002 \%$ & $-0.23 \%$ \\
\hline HVNETime & 18 & 90 & 1.50 & $0.13 \%$ & $0.001 \%$ & $0.11 \%$ \\
\hline EBTH & 13 & 65 & 1.09 & $7.13 \%$ & $0.089 \%$ & $8.92 \%$ \\
\hline WBTH & 15.4 & 77 & 1.28 & $-6.58 \%$ & $-0.130 \%$ & $-12.95 \%$ \\
\hline SBTH & 3 & 15 & 0.25 & $-1.71 \%$ & $-0.004 \%$ & $-0.39 \%$ \\
\hline VolCycle & 54.1 & 280 & 4.67 & $0.14 \%$ & $0.130 \%$ & $13.44 \%$ \\
\hline
\end{tabular}

*The baseline value is provided by the contribution of the constant, humidity and temperature variables evaluated at their mean value (background value given the average atmospheric conditions at the time of the study)

After adding the lagged variables, the non-lagged variable coefficients did not change in sign and many of their values and contributions are of similar magnitude (comparing Table 16 and Table 17); this shows the robustness of the model and its results. 
There are eight independent variables that show significant lagged effects. It takes, on average, 42 seconds for the impact of bus waiting time during a red light to be measured at the northeast corner where the instrument was located, and it provides a $0.66 \%$ increase in particulate matter per each second the bus is waiting (idling). As seen previously, buses with engine cooling systems reduce $\mathrm{PM}_{2.5}$ by $5 \%$ when compared to buses that do not have this technology (average lag effect is 40 seconds and very close to the bus-waiting-time variable). Buses that have an angled tailpipe (pointing away from the sidewalk or northeast corner) reduced $\mathrm{PM}_{2.5}$ levels by $82 \%$ compared to a backwards (parallel to the sidewalk) oriented tailpipe. Heavy vehicles queuing, on average, a minute and a half earlier contribute $0.13 \%$ to particulate matter per additional second.

Each additional vehicle per five seconds in the eastbound direction from a minute before (half a cycle in duration) increases pollutant levels by $7 \%$, while westbound decreases pollutant levels by $6.5 \%$. Southbound vehicles reduce $\mathrm{PM}_{2.5}$ by $2 \%$ per vehicle during a five-second period 25 seconds earlier. Each vehicle per cycle adds $0.14 \%$ to $\mathrm{PM}_{2.5}$ levels and the average lag is almost two traffic-signal timing cycles (four and a half minutes). The remaining lagged variables have elasticity values under $0.2 \%$, which shows a relatively small sensitivity. Only three of the lagged variables have an average contribution relative to the baseline over five: eastbound traffic, westbound traffic, and volume per cycle.

\subsection{SUMMARY}

This research aimed to link pedestrian and transit-user exposure levels along an urban arterial with traffic variables. The results of this research are novel; to the best of the authors' knowledge this is the first research work that has quantified the impacts of traffic-signal timing on particulate matter pollution levels. The level of granularity (five seconds) and the high number of traffic, signal variables, bus and atmospheric variables included in the analysis are also unique. Model results with and without lagged variables and/or autocorrelation terms have shown statistically significant results and a high degree of robustness and consistency. Although more research is needed in this area, some of the results are likely transferable to other congested corridors and urban areas.

To a high degree, this research has shown that pedestrian exposure can be considered as an outcome of traffic-signal timing decisions made by cities and counties. The statistical results have shown the high impact that signal timing and queuing have on pedestrian level exposure. Longer green times along the main corridor are able to significantly reduce particulate matter for transit users and pedestrians waiting at the sidewalk of the intersection, whereas time allocated to cross the street increases queuing and exposure along the main corridor. Future research can compare and quantify if delays and emissions predicted by traffic-simulation packages and emission models accurately predict sidewalk-level measurements of particulate matter.

The impact of heavy-duty diesel engines is also clear. Heavy vehicle volume was a significant variable as well as the presence of buses. The reduction of bus idling time through more efficient operations and transit signal priority is likely to reduce pedestrian and transit users' pollution exposure levels. Transit agencies can also reduce pollution significantly by improving the efficiency and cleanliness of their engines. TriMet initiatives to improve fuel efficiency by installing EMP engine cooling devices not only improve fuel efficiency, but also air quality. 


\subsection{AN EMPIRICAL ANALYSIS OF EXPOSURE TO PARTICULATE MATTER AT BUS-STOP SHELTERS}

\subsection{STUDY LOCATION}

Bus shelters selected for this study are located along Powell Boulevard. Powell Boulevard serves as a commuter thoroughfare for the outlying suburbs and is served by several high-frequency bus lines, with high inbound morning traffic volumes and high outbound evening traffic volumes. Land use along the corridor is primarily one- and two-story commercial buildings, apartment complexes, and other uses such as Cleveland High School and Powell Park.

There are 31 bus stops along the two-mile stretch of roadway selected for analysis. Of these 31 stops, 17 feature shelters. The shelters can be of four different configurations, determined by panel layout. Shelters are characterized according to the number of panels in their design, the depth of the shelter, and the orientation of the shelter.

To study the impact of bus-shelter design, three shelters were chosen for investigation. The first shelter ("Location 1") is oriented away from the roadway while other shelters ("Location 2" and "Location 3") are oriented towards the roadway. Characteristics of the shelters and roadway are summarized in

Table 18. Each shelter is located at a signalized intersection.

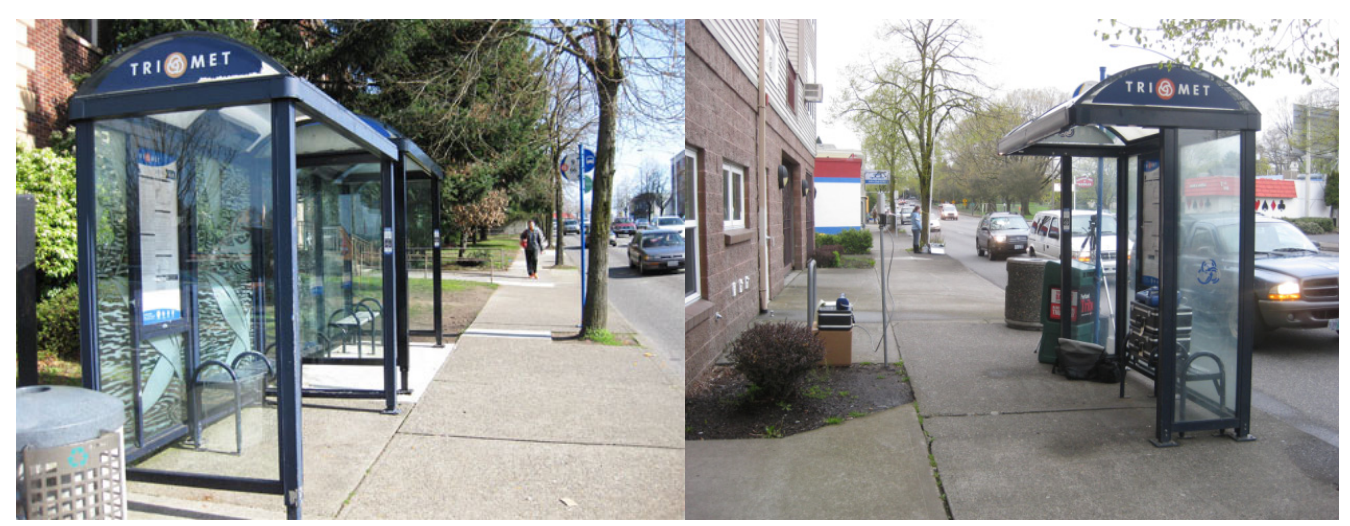

(a)

(b)

Figure 10. Shelter Orientation (a) Towards Roadway and (b) Away from Roadway 
Table 18. Study Location Details

\begin{tabular}{|c|c|c|c|}
\hline & Location 1 & Location 2 & Location 3 \\
\hline Shelter Orientation & Away from roadway & Towards roadway & Towards roadway \\
\hline $\begin{array}{l}\text { Eastbound/Westbound on } \\
\text { Powell Blvd }\end{array}$ & $\begin{array}{l}\text { Westbound } \\
\text { (Inbound) }\end{array}$ & $\begin{array}{l}\text { Westbound } \\
\text { (Inbound) }\end{array}$ & $\begin{array}{l}\text { Eastbound } \\
\text { (Outbound) }\end{array}$ \\
\hline Cross Street & $21^{\text {st }}$ Ave & $26^{\text {th }}$ Ave & $39^{\text {th }}$ Ave \\
\hline Cross Street Lanes & 2 & 2 & 4 \\
\hline Near-side/Far-side & Near-side & Near-side & Far-side \\
\hline Distance to Curb (m) & 0.6 & 2.7 & 3.8 \\
\hline $\begin{array}{lll}\begin{array}{l}\text { Powell } \\
\text { Average }\end{array} & \text { Blvd } & \text { Annualy } \\
(2009)^{*} & & \text { Traffic } \\
\end{array}$ & 35,300 & 31,500 & 34,100 \\
\hline $\begin{array}{l}\text { Percent } \\
\text { Morning** (Powell) }\end{array}$ & $12.4 \%$ & $18.6 \%$ & $4.5 \%$ \\
\hline $\begin{array}{l}\text { Percent } \\
\text { Evening** (Powell) }\end{array}$ & $9.7 \%$ & $17.1 \%$ & $5.5 \%$ \\
\hline $\begin{array}{l}\text { AverageBus Headway, } \\
\text { Morning }\end{array}$ & 8 minutes & 8 minutes & 20 minutes \\
\hline $\begin{array}{l}\text { AverageBus Headway, } \\
\text { Evening }\end{array}$ & 15 minutes & 15 minutes & 7 minutes \\
\hline $\begin{array}{l}\text { Average Boardings per } \\
\text { hour, Morning }\end{array}$ & 1.2 & 1.0 & 1.9 \\
\hline $\begin{array}{l}\text { Average Boardings per } \\
\text { hour, Evening }\end{array}$ & 1.6 & 1.9 & 2.8 \\
\hline
\end{tabular}

\subsection{DATA COLLECTION AND PROCESSING}

Particulate matter concentrations were monitored both inside and outside the shelter simultaneously to control for any changes in environmental conditions. Fine particulate $\left(\mathrm{PM}_{2.5}\right)$ measurements were made using two DustTrak DRX Aerosol Monitors (TSI Model 8533). UFP measurements were made using two P-Trak Ultrafine Particle Counters (TSI Model 8525). The equipment was started simultaneously and operated continuously at one-second resolutions for the entirety of the sampling period. Device intake points were set at 1.5 meters above the ground to simulate breathing height, following standard practice observed in similar studies. Inside the shelter, intake points were placed in the center of the shelter, approximately 15 centimeters from the rear panel (referenced as "inside location"). Outside the shelter, intake points were placed 0.9 meters from the shelter at the same distance from the curb as the monitors inside the shelter (referenced as "outside location").

Wind speed and direction in urban settings can have a significant effect on micro-measurements of air quality. To control for these effects, wind speed and direction were measured using an anemometer 
placed next to the outside location particulate monitors. Temperature and humidity data were collected from a nearby weather station.

Traffic data on Powell Boulevard were collected using an RTMS G4 unit (ISS Model K4-LV-CAM). The RTMS (Remote Traffic Microwave Sensor) unit is a radar sensor capable of providing per-lane presence as well as volume, occupancy, speed and classification information.

Data were collected during the morning peak (7-9 a.m.) and evening peak (4-6 p.m.) periods at each shelter. Data were collected on two different days at each shelter, yielding two morning and two evening sample sets for each location. Data collection occurred primarily on Fridays between late March and midMay, with one collection on a Tuesday at both Location 1 and Location 3.

All data were combined into one data frame and analyzed in the statistical software package R. All data were aggregated to one-minute intervals and all analysis was based on this level of resolution. One-sided paired t-tests were used to evaluate whether particulate levels inside the bus shelter were greater than particulate levels outside the shelter. Data were organized into dependent and independent variables for regression analysis, described in Table 19. Select vehicle and weather variables were lagged up to three periods to investigate delayed effects on particulate concentrations. Wind data are composed of wind speed and wind direction. Wind direction was split into four variables, each representative of a direction relative to the shelter and described in Table 19. Raw wind-direction data were output at one-second intervals. One-minute aggregations are composed of the percent of time the wind blew in one of the four directions over the previous minute.

\subsection{STATISTICAL ANALYSIS}

One-sided paired t-tests were used to evaluate whether particulate levels inside the bus shelter were greater than particulate levels outside the shelter. Particulate levels were found to be significantly greater inside the bus shelter when the shelter faces towards the roadway, and significantly greater outside the bus shelter when the shelter faces away from the roadway. Results are shown in Table 20. When the shelter faces the roadway, measurements inside the shelter were, on average, 29 percent more than measurements outside the shelter. In contrast, when the shelter faces away from the roadway, measurements inside the shelter were one percent less than measurements outside the shelter.

Peaks in concentration are of special interest when considering damaging health effects related to short, intense bursts of exposure. Chi-square tests of independence were used to evaluate whether concentration spikes were greater inside the shelter than outside the shelter. The magnitude of particulate concentration spikes was found to be statistically different inside and outside the bus shelters for all particulate sizes with the exception of UFP.

Figure 12 shows plots of observed concentrations of UFP and $\mathrm{PM}_{2.5}$ varying by wind speed and direction at each shelter location using polar plots for three dates: April 29, May 13, and March 22 for Locations 1, 2 , and 3, respectively. In these plots, the angular coordinate is given by wind direction and the radial coordinate is the wind speed. Wind speeds are denoted by concentric circles incremented to units of 0.5 $\mathrm{m} / \mathrm{s}$. At each of the coordinates in the two-dimensional plane, the third dimension is plotted based on a color-scale gradient. Higher concentrations are shown as red hues on the scale gradient and indicate concentration levels most affected by wind direction. Each vertical pair of plots represent inside (top) and outside (bottom). For instance, the UFP concentrations at Location 1 are clearly highest when the wind is from the east. Shelter orientation relative to cardinal directions is given in the figure descriptions. The plots in Figure 12 were created using the OpenAir package in the statistical software program R. 
Wind direction affects particulate concentrations differently in each shelter location and for each shelter orientation. Figure 12 (c) best illustrates discrepancies in particulate behavior: UFP concentrations inside and outside the shelter are equally affected by wind direction, as evidenced by the highest concentrations, which are always affected by westerly winds and increase with intensity. Conversely, $\mathrm{PM}_{2.5}$ concentrations appear to be unaffected by wind direction outside the shelter, indicated by uniform hues in all directions, while concentrations inside the shelter are minimally affected by easterly wind directions at very low wind speeds, evidenced by slightly higher color saturations.

Increasing wind speed generally results in lower concentrations, although this is not always the case. UFP concentrations inside the shelter in Figure 12 (a) increase with wind speed, indicating potential entrapment of particles within the shelter. $\mathrm{PM}_{2.5}$ concentrations inside the shelter at the same location are unaffected by wind speed, in contrast with concentrations outside the shelter which exhibit expected behavior. 
Table 19. Variable Definitions

\begin{tabular}{|c|c|c|}
\hline Variables & Definition & Unit \\
\hline \multicolumn{3}{|l|}{ DEPENDENT VARIABLES } \\
\hline UFP & Continuous variable describing concentration & $\mathrm{pt} / \mathrm{cc}$ \\
\hline $\mathrm{PM}_{2.5}$ & Continuous variable describing concentration & $\mu \mathrm{g} / \mathrm{m}^{3}$ \\
\hline \multicolumn{3}{|l|}{ INDEPENDENT VARIABLES } \\
\hline \multicolumn{3}{|l|}{ Location } \\
\hline Location & Dummy variables for location 1,2 , or 3 & - \\
\hline \multicolumn{3}{|l|}{ Vehicles } \\
\hline Vehicle Flow & $\begin{array}{l}\text { Total number of vehicles passing shelter; in-period and } \\
\text { lagged up to } 3 \text { periods }\end{array}$ & veh/hour \\
\hline Heavy Vehicle (Truck) Flow & $\begin{array}{l}\text { Number of heavy vehicles passing shelter(defined as } \\
\text { length }>6 \mathrm{~m} \text { ); in-period and lagged up to } 3 \text { periods }\end{array}$ & veh/hour \\
\hline Bus Presence & Dummy variable & - \\
\hline \multicolumn{3}{|l|}{ Weather } \\
\hline Wind Speed & $\begin{array}{l}\text { Average wind speed; in-period and lagged up to } 3 \\
\text { periods }\end{array}$ & $\mathrm{m} / \mathrm{s}$ \\
\hline $\begin{array}{l}\text { Wind Direction - Towards } \\
\text { Shelter }\end{array}$ & $\begin{array}{l}\text { Percent of time wind blows towards the shelter over a } \\
\text { one-minute interval; in-period and lagged up to } 3 \\
\text { periods }\end{array}$ & $\%$ \\
\hline $\begin{array}{l}\text { Wind Direction - Away from } \\
\text { Shelter (reference) }\end{array}$ & $\begin{array}{l}\text { Percent of time wind blows away from the shelter over } \\
\text { a one -minute interval; in-period and lagged up to } 3 \\
\text { periods }\end{array}$ & - \\
\hline $\begin{array}{l}\text { Wind Direction - With the } \\
\text { Direction of Traffic }\end{array}$ & $\begin{array}{l}\text { Percent of time wind blows in the direction of traffic } \\
\text { closest to the shelter over a one-minute interval; in- } \\
\text { period and lagged up to } 3 \text { periods }\end{array}$ & $\%$ \\
\hline $\begin{array}{l}\text { Wind Direction - Against the } \\
\text { Direction of Traffic }\end{array}$ & $\begin{array}{l}\text { Percent of time wind blows against the direction of } \\
\text { traffic closest to the shelter over a one-minute interval } \\
\text { in-period and lagged up to } 3 \text { periods }\end{array}$ & $\%$ \\
\hline Temperature & Temperature at nearby weather station & $\begin{array}{l}\text { degrees } \\
\text { Fahrenheit }\end{array}$ \\
\hline Relative Humidity & Relative humidity at nearby weather station & $\%$ \\
\hline
\end{tabular}


Table 20. Summary Statistics for Each Shelter Location

\begin{tabular}{|c|c|c|c|c|c|c|c|c|c|}
\hline & \multirow[b]{2}{*}{ Date } & \multirow[b]{2}{*}{$\begin{array}{l}\text { Particulate } \\
\text { Type }\end{array}$} & \multirow[b]{2}{*}{$\begin{array}{l}\text { Sample } \\
\text { Location }\end{array}$} & \multicolumn{3}{|c|}{ Morning } & \multicolumn{3}{|c|}{ Evening } \\
\hline & & & & $\begin{array}{l}\text { Mean } \\
\text { Concentration* }\end{array}$ & t-value & p-value & $\begin{array}{l}\text { Mean } \\
\text { Concentration* }\end{array}$ & t-value & p-value \\
\hline \multirow{8}{*}{ 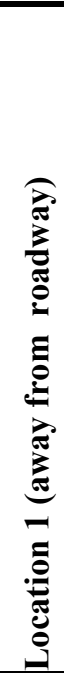 } & \multirow{4}{*}{ 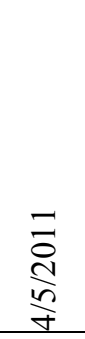 } & $\begin{array}{l}\text { UFP } \\
\text { (pt/cc) }\end{array}$ & $\begin{array}{l}\text { Inside } \\
\text { Outside }\end{array}$ & $\begin{array}{l}38,597 \\
\mathbf{5 4 , 9 1 5}\end{array}$ & -37.29 & $<0.001$ & \multirow{4}{*}{ NA } & NA & NA \\
\hline & & $\begin{array}{l}\mathrm{PM}_{1.0} \\
\left(\mu \mathrm{g} / \mathrm{m}^{3}\right)\end{array}$ & $\begin{array}{l}\text { Inside } \\
\text { Outside }\end{array}$ & $\begin{array}{l}21.99 \\
\mathbf{2 2 . 2 3}\end{array}$ & -1.26 & 0.2080 & & NA & NA \\
\hline & & $\mathrm{PM}_{2.5}$ & Inside & $\begin{array}{l}23.30 \\
23.56\end{array}$ & -1.38 & 0.1687 & & NA & NA \\
\hline & & $\begin{array}{l}\mathrm{PM}_{10} \\
\left(\mathrm{ug} / \mathrm{m}^{3}\right)\end{array}$ & $\begin{array}{l}\text { Inside } \\
\text { Outside }\end{array}$ & $\begin{array}{l}\mathbf{3 0 . 5 1} \\
2537\end{array}$ & 24.06 & $<0.001$ & & NA & NA \\
\hline & & $\begin{array}{l}\text { UFP } \\
(\mathrm{pt} / \mathrm{cc})\end{array}$ & $\begin{array}{l}\text { Inside } \\
\text { Outside }\end{array}$ & $\begin{array}{l}\mathbf{3 4 , 5 6 0} \\
33,137\end{array}$ & -0.77 & 0.4504 & $\begin{array}{l}17,153 \\
\mathbf{2 1 , 0 3 2}\end{array}$ & -53.75 & $<0.001$ \\
\hline & & $\begin{array}{l}\mathrm{PM}_{1.0} \\
\left(\mu \mathrm{g} / \mathrm{m}^{3}\right)\end{array}$ & $\begin{array}{l}\text { Inside } \\
\text { Outside }\end{array}$ & $\begin{array}{l}\mathbf{2 0 . 2 5} \\
15.14\end{array}$ & 13.99 & $<0.001$ & $\begin{array}{l}8.63 \\
\mathbf{1 1 . 7 9}\end{array}$ & -74.34 & $<0.001$ \\
\hline & $\bar{\sigma}$ & $\begin{array}{l}\mathrm{PM}_{2.5} \\
\left(\mu \mathrm{g} / \mathrm{m}^{3}\right)\end{array}$ & $\begin{array}{l}\text { Inside } \\
\text { Outside }\end{array}$ & $\begin{array}{l}\mathbf{2 0 . 4 8} \\
15.34\end{array}$ & 14.01 & $<0.001$ & $\begin{array}{l}8.72 \\
11.92\end{array}$ & -73.71 & $<0.001$ \\
\hline & $\stackrel{\frac{a}{9}}{\frac{2}{2}}$ & $\begin{array}{l}\mathrm{PM}_{10} \\
\left(\mu \mathrm{g} / \mathrm{m}^{3}\right)\end{array}$ & $\begin{array}{l}\text { Inside } \\
\text { Outside }\end{array}$ & $\begin{array}{l}\mathbf{2 1 . 1 6} \\
17.31 \\
\end{array}$ & 11.31 & $<0.001$ & $\begin{array}{l}10.36 \\
\mathbf{1 3 . 3 1}\end{array}$ & -54.83 & $<0.001$ \\
\hline \multirow{8}{*}{ 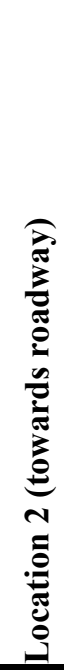 } & \multirow{4}{*}{ 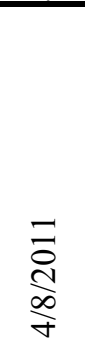 } & $\begin{array}{l}\text { UFP } \\
(\mathrm{pt} / \mathrm{cc})\end{array}$ & $\begin{array}{l}\text { Inside } \\
\text { Outside }\end{array}$ & $\begin{array}{l}50,427 \\
\mathbf{5 6 , 7 1 9}\end{array}$ & -18.05 & $<0.001$ & $\begin{array}{l}11,307 \\
\mathbf{1 1 , 4 9 6}\end{array}$ & -1.80 & 0.0708 \\
\hline & & $\begin{array}{l}\mathrm{PM}_{1.0} \\
\left(\mu \mathrm{g} / \mathrm{m}^{3}\right)\end{array}$ & $\begin{array}{l}\text { Inside } \\
\text { Outside }\end{array}$ & $\begin{array}{l}59.67 \\
\text { NA }\end{array}$ & NA & NA & $\begin{array}{l}\mathbf{8 . 6 1} \\
7.50\end{array}$ & 14.47 & $<0.001$ \\
\hline & & $\begin{array}{l}\mathrm{PM}_{2.5} \\
\left(\mu \mathrm{g} / \mathrm{m}^{3}\right)\end{array}$ & $\begin{array}{l}\text { Inside } \\
\text { Outside }\end{array}$ & $\begin{array}{l}60.14 \\
\text { NA }\end{array}$ & NA & NA & $\begin{array}{l}\mathbf{8 . 7 8} \\
7.61\end{array}$ & 15.06 & $<0.001$ \\
\hline & & $\begin{array}{l}\mathrm{PM}_{10} \\
\left(\mu \mathrm{g} / \mathrm{m}^{3}\right)\end{array}$ & $\begin{array}{l}\text { Inside } \\
\text { Outside }\end{array}$ & $\begin{array}{l}64.16 \\
\text { NA } \\
\end{array}$ & NA & NA & $\begin{array}{l}\mathbf{1 0 . 6 0} \\
9.98\end{array}$ & 5.77 & $<0.001$ \\
\hline & \multirow{4}{*}{ 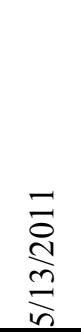 } & $\begin{array}{l}\text { UFP } \\
(\mathrm{pt} / \mathrm{cc})\end{array}$ & $\begin{array}{l}\text { Inside } \\
\text { Outside }\end{array}$ & $\begin{array}{l}\mathbf{3 6 , 0 2 0} \\
33,680\end{array}$ & 5.36 & $<0.001$ & $\begin{array}{l}\mathbf{1 4 , 2 0 1} \\
9,248\end{array}$ & 42.59 & $<0.001$ \\
\hline & & $\begin{array}{l}\mathrm{PM}_{1.0} \\
\left(\mu \mathrm{g} / \mathrm{m}^{3}\right)\end{array}$ & $\begin{array}{l}\text { Inside } \\
\text { Outside }\end{array}$ & $\begin{array}{l}\mathbf{1 7 . 9 3} \\
13.31\end{array}$ & 82.86 & $<0.001$ & $\begin{array}{l}12.46 \\
\mathbf{1 5 . 6 6}\end{array}$ & -32.59 & $<0.001$ \\
\hline & & $\begin{array}{l}\mathrm{PM}_{2.5} \\
\left(\mu \mathrm{g} / \mathrm{m}^{3}\right)\end{array}$ & $\begin{array}{l}\text { Inside } \\
\text { Outside }\end{array}$ & $\begin{array}{l}\mathbf{1 8 . 3 7} \\
13.61\end{array}$ & 85.00 & $<0.001$ & $\begin{array}{l}12.71 \\
\mathbf{1 5 . 8 3}\end{array}$ & -31.65 & $<0.001$ \\
\hline & & $\begin{array}{l}\mathrm{PM}_{10} \\
\left(\mu \mathrm{g} / \mathrm{m}^{3}\right) \\
\end{array}$ & $\begin{array}{l}\text { Inside } \\
\text { Outside } \\
\end{array}$ & $\begin{array}{l}\mathbf{2 1 . 1 9} \\
17.66 \\
\end{array}$ & 42.19 & $<0.001$ & $\begin{array}{l}15.86 \\
\mathbf{1 9 . 9 1} \\
\end{array}$ & -25.06 & $<0.001$ \\
\hline \multirow{8}{*}{ 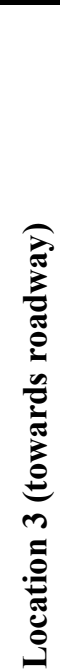 } & \multirow{4}{*}{ 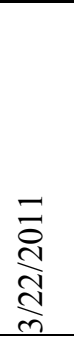 } & $\begin{array}{l}\text { UFP } \\
(\mathrm{pt} / \mathrm{cc})\end{array}$ & $\begin{array}{l}\text { Inside } \\
\text { Outside }\end{array}$ & $\begin{array}{l}\mathbf{5 3 , 5 4 5} \\
48,487\end{array}$ & 21.77 & $<0.001$ & $\begin{array}{l}\mathbf{3 1 , 3 6 2} \\
28,559\end{array}$ & 21.77 & $<0.001$ \\
\hline & & $\begin{array}{l}\mathrm{PM}_{1.0} \\
\left(\mu \mathrm{g} / \mathrm{m}^{3}\right)\end{array}$ & $\begin{array}{l}\text { Inside } \\
\text { Outside }\end{array}$ & $\begin{array}{l}\mathbf{2 3 . 3 0} \\
21.16\end{array}$ & 9.30 & $<0.001$ & $\begin{array}{l}\mathbf{1 1 . 2 7} \\
9.48\end{array}$ & 35.87 & $<0.001$ \\
\hline & & $\begin{array}{l}\mathrm{PM}_{2.5} \\
\left(\mu \mathrm{g} / \mathrm{m}^{3}\right)\end{array}$ & $\begin{array}{l}\text { Inside } \\
\text { Outside }\end{array}$ & $\begin{array}{l}\mathbf{2 4 . 0 7} \\
21.71\end{array}$ & 9.97 & $<0.001$ & $\begin{array}{l}\mathbf{1 1 . 7 2} \\
9.83\end{array}$ & 37.91 & $<0.001$ \\
\hline & & $\begin{array}{l}\mathrm{PM}_{10} \\
\left(\mu \mathrm{g} / \mathrm{m}^{3}\right)\end{array}$ & $\begin{array}{l}\text { Inside } \\
\text { Outside }\end{array}$ & $\begin{array}{l}\mathbf{2 5 . 9 3} \\
25.04 \\
\end{array}$ & 3.79 & $<0.001$ & $\begin{array}{l}14.13 \\
\mathbf{1 4 . 6 7}\end{array}$ & -3.33 & $<0.001$ \\
\hline & \multirow{4}{*}{$\begin{array}{l}\vec{\Xi} \\
\stackrel{N}{a} \\
\stackrel{n}{\sigma}\end{array}$} & $\begin{array}{l}\text { UFP } \\
(\mathrm{pt} / \mathrm{cc})\end{array}$ & $\begin{array}{l}\text { Inside } \\
\text { Outside }\end{array}$ & $\begin{array}{l}\mathbf{5 3 , 7 9 0} \\
40,457\end{array}$ & 31.35 & $<0.001$ & $\begin{array}{l}\mathbf{5 6 , 5 9 0} \\
35,994\end{array}$ & 22.35 & $<0.001$ \\
\hline & & $\begin{array}{l}\mathrm{PM}_{1.0} \\
\left(\mu \mathrm{g} / \mathrm{m}^{3}\right)\end{array}$ & $\begin{array}{l}\text { Inside } \\
\text { Outside }\end{array}$ & $\begin{array}{l}66.46 \\
60.35\end{array}$ & 0.00 & 0.9987 & $\begin{array}{l}9.72 \\
8.92\end{array}$ & 12.44 & $<0.001$ \\
\hline & & $\begin{array}{l}\mathrm{PM}_{2.5} \\
\left(\mu \mathrm{g} / \mathrm{m}^{3}\right)\end{array}$ & $\begin{array}{l}\text { Inside } \\
\text { Outside }\end{array}$ & $\begin{array}{l}\mathbf{6 8 . 5 3} \\
60.62\end{array}$ & 1.29 & 0.2102 & $\begin{array}{l}9.89 \\
9.07\end{array}$ & 12.62 & $<0.001$ \\
\hline & & $\begin{array}{l}\mathrm{PM}_{10} \\
\left(\mu \mathrm{g} / \mathrm{m}^{3}\right)\end{array}$ & $\begin{array}{l}\text { Inside } \\
\text { Outside }\end{array}$ & $\begin{array}{l}\mathbf{7 6 . 2 3} \\
62.40\end{array}$ & 1.78 & 0.0892 & $\begin{array}{l}\mathbf{1 0 . 4 0} \\
10.09\end{array}$ & 8.23 & $<0.001$ \\
\hline
\end{tabular}



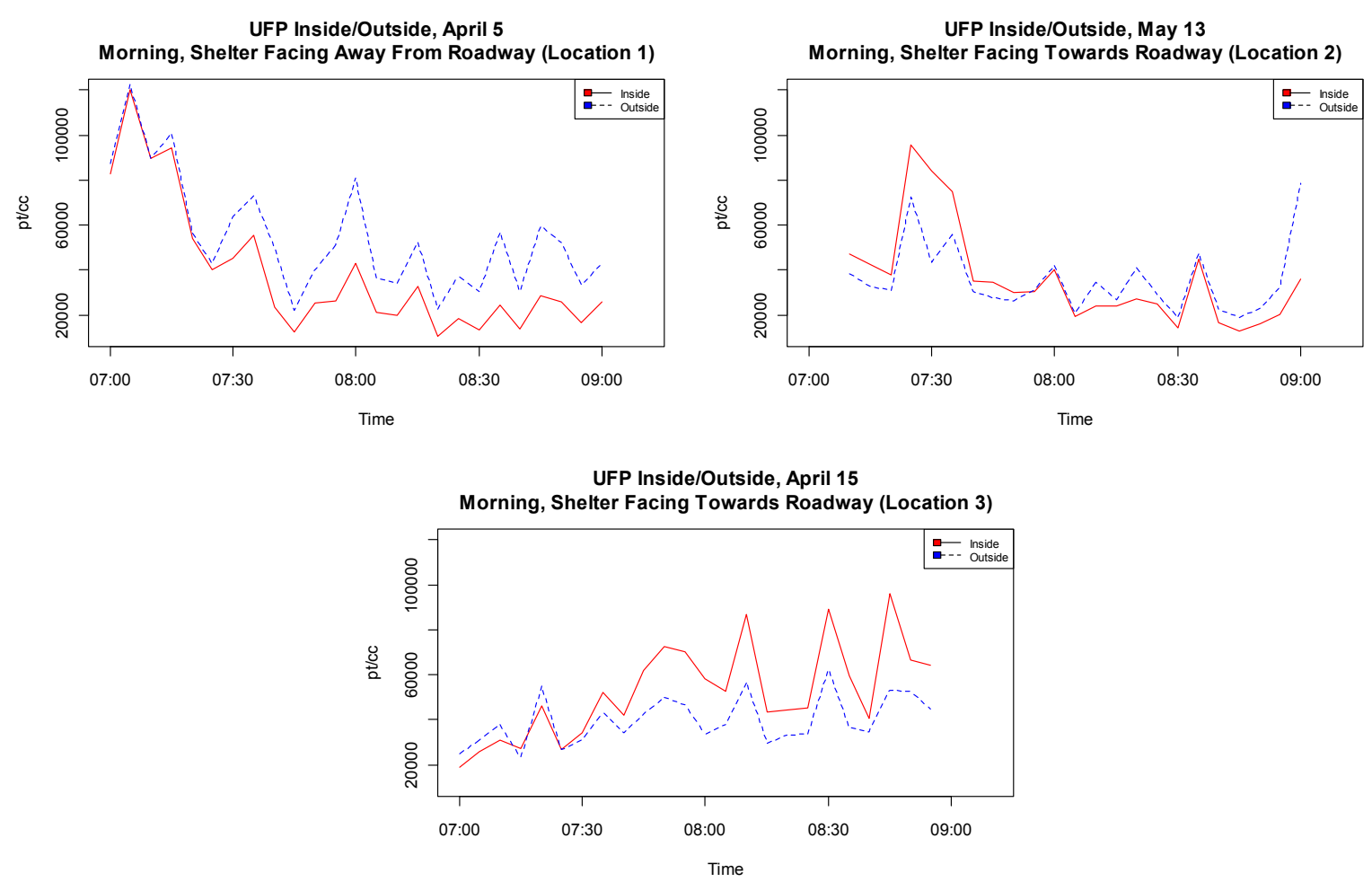

(a)
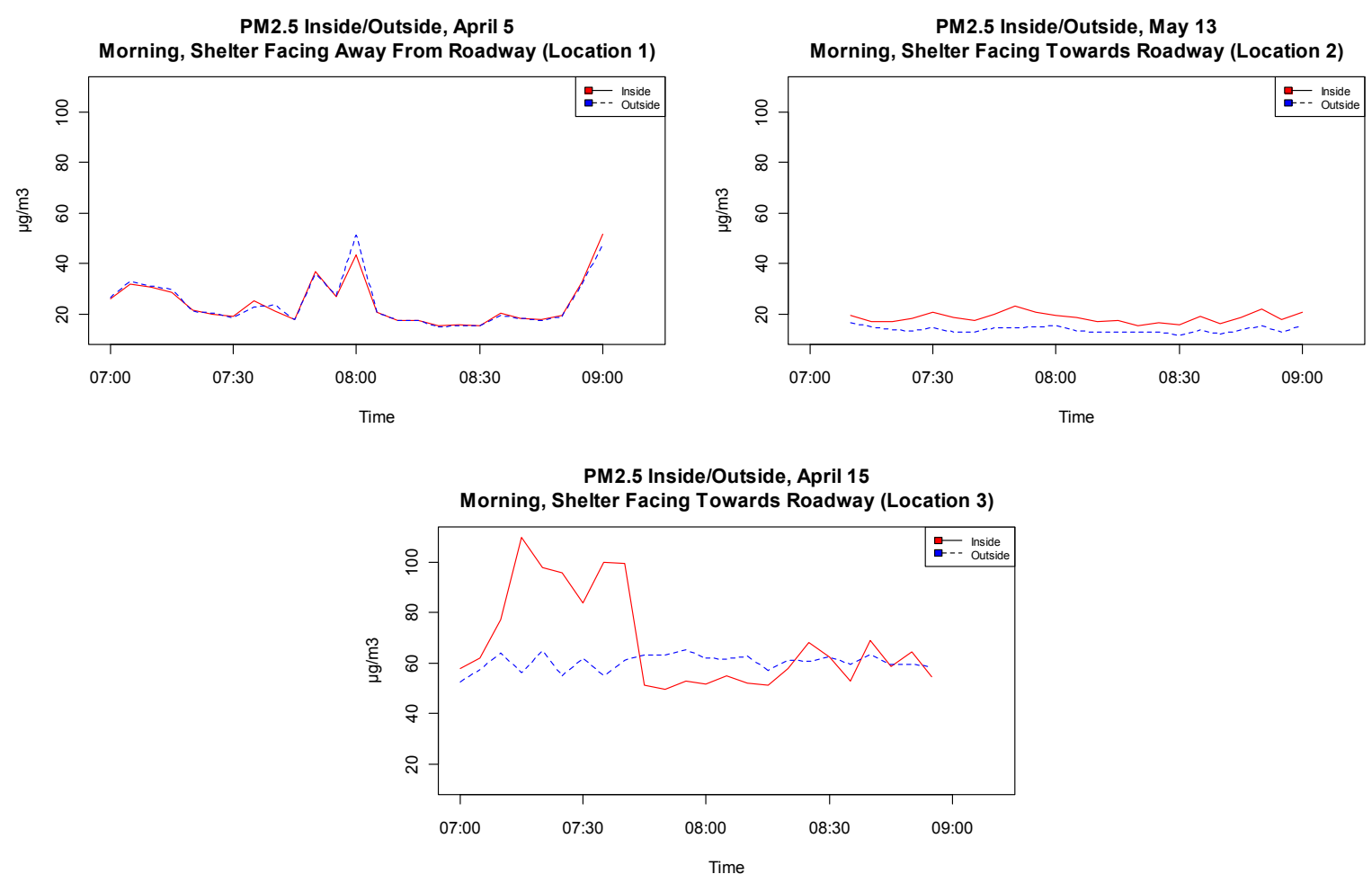

(b)

Figure 11. Morning (a) UFP and (b) $\mathbf{P M}_{2.5}$ Concentrations Inside and Outside the Bus Shelter 
UFP Inside/Outside Shelter Facing Away From Roadway (Morning)

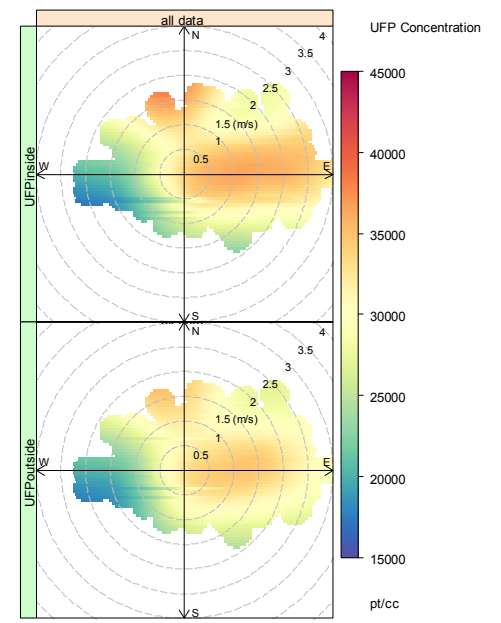

(a) Location 1, shelter facing north

UFP Inside/Outside Shelter Facing Towards Roadway (Evening)

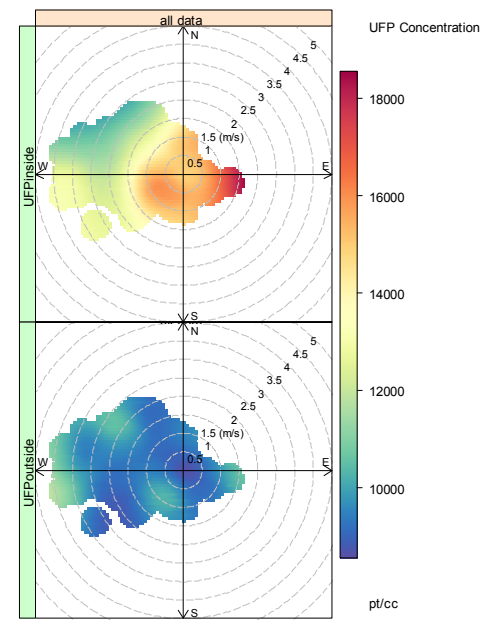

(b) Location 2, shelter facing south

UFP Inside/Outside Shelter Facing Towards Roadway (Evening)

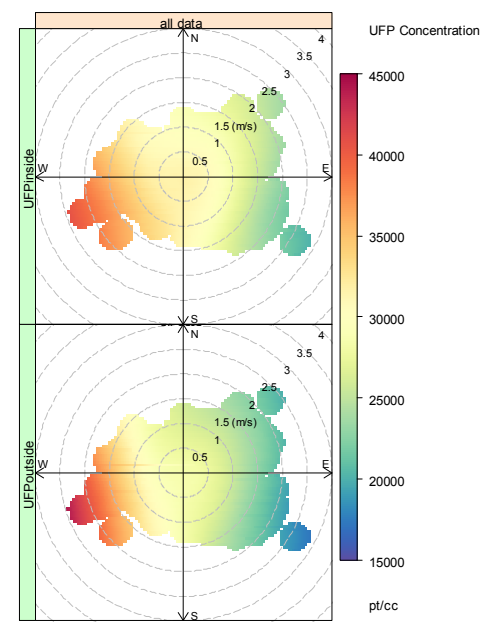

$\mathrm{PM}_{2.5}$ Inside/Outside Shelter Facing Away From Roadway (Morning)

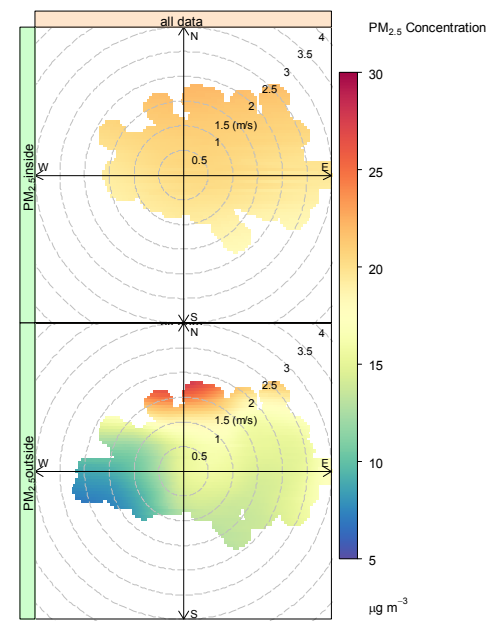

$\mathrm{PM}_{25}$ Inside/Outside Shelter Towards From Roadway (Evening)

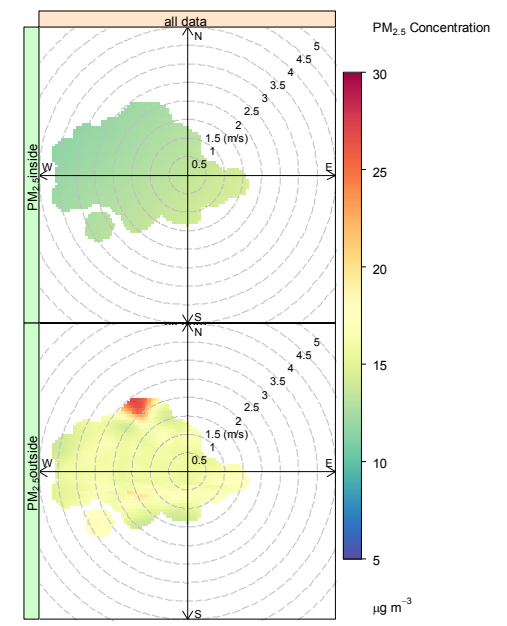

$\mathrm{PM}_{25}$ Inside/Outside Shelter Towards From Roadway (Evening)

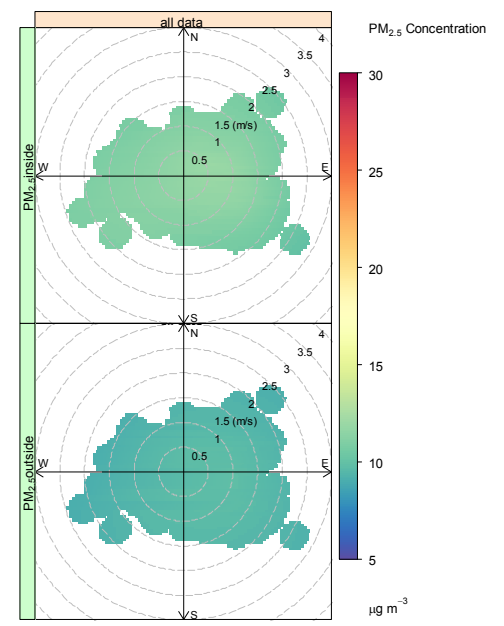

(c) Location 3, shelter facing north

Figure 12. Bivariate Polar Plots Illustrating Wind Speed and Direction Effects on UFP and PM 2.5 
To prepare for regression analysis, the dependent data were checked for normality using quantile-quantile (Q-Q) plots and both variables were found to be skewed. As in previous research efforts, dependent variables were log-transformed to compensate for skewness. Testing again for normality after $\log$ transformation, Q-Q plots for both variables suggested normal distributions. The logarithm of the dependent variables are thus utilized in this section. To investigate pairwise correlations between each particulate size and the independent variables, a Pearson test for association $(\alpha=0.05)$ was performed between each vehicle and weather variable and each logged particulate variable. Results are presented in Table 21 .

Table 21. Association Correlation Test

\begin{tabular}{|c|c|c|c|c|c|c|c|c|c|}
\hline \multirow{3}{*}{\multicolumn{2}{|c|}{ Variable }} & \multicolumn{4}{|l|}{ Inside } & \multicolumn{4}{|c|}{ Outside } \\
\hline & & \multicolumn{2}{|c|}{$\operatorname{logUFP}$} & \multicolumn{2}{|c|}{$\log \mathrm{PM}_{2.5}$} & \multicolumn{2}{|c|}{$\operatorname{logUFP}$} & \multicolumn{2}{|c|}{$\log \mathrm{PM}_{2.5}$} \\
\hline & & $\mathrm{r}$ & $\mathrm{p}$ & $\mathrm{r}$ & $\mathrm{p}$ & $\mathrm{r}$ & $\mathrm{p}$ & $\mathrm{r}$ & $\mathrm{p}$ \\
\hline \multicolumn{10}{|c|}{ Location 1 (Shelter facing away from roadway) } \\
\hline \multicolumn{2}{|c|}{ Vehicles } & -0.04 & 0.464 & -0.13 & 0.040 & -0.03 & 0.591 & -0.03 & 0.591 \\
\hline \multicolumn{2}{|c|}{ Heavy Veh } & -0.15 & 0.008 & -0.15 & 0.022 & -0.14 & 0.018 & -0.06 & 0.310 \\
\hline \multicolumn{2}{|c|}{ Wind Speed } & -0.04 & 0.660 & -0.08 & 0.549 & -0.04 & 0.708 & 0.01 & 0.949 \\
\hline \multirow{4}{*}{ 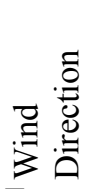 } & $\mathrm{TS}$ & -0.07 & 0.457 & 0.07 & 0.609 & -0.04 & 0.653 & -0.05 & 0.614 \\
\hline & AS & -0.04 & 0.682 & 0.00 & 0.991 & -0.01 & 0.895 & 0.21 & 0.041 \\
\hline & WT & 0.19 & 0.055 & -0.03 & 0.844 & 0.15 & 0.123 & 0.09 & 0.406 \\
\hline & $\mathrm{AT}$ & -0.15 & 0.130 & 0.00 & 0.988 & -0.14 & 0.165 & -0.27 & 0.007 \\
\hline \multicolumn{2}{|c|}{ Temperature } & -0.43 & $<0.001$ & -0.69 & $<0.001$ & -0.46 & $<0.001$ & -0.41 & $<0.001$ \\
\hline \multicolumn{2}{|c|}{ Rel. Humidity } & 0.43 & $<0.001$ & 0.69 & $<0.001$ & 0.47 & $<0.001$ & 0.43 & $<0.001$ \\
\hline \multicolumn{10}{|c|}{ Location 2 (Shelter facing towards roadway) } \\
\hline \multicolumn{2}{|c|}{ Vehicles } & 0.03 & 0.476 & 0.13 & 0.006 & 0.03 & 0.478 & 0.27 & $<0.001$ \\
\hline \multicolumn{2}{|c|}{ Heavy Veh } & 0.00 & 0.928 & 0.06 & 0.183 & 0.03 & 0.461 & 0.02 & 0.688 \\
\hline \multicolumn{2}{|c|}{ Wind Speed } & -0.29 & $<0.001$ & -0.42 & $<0.001$ & -0.32 & $<0.001$ & 0.02 & 0.787 \\
\hline \multirow{4}{*}{ 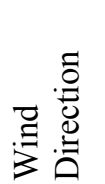 } & TS & 0.10 & 0.133 & $\mathbf{0 . 3 3}$ & $<0.001$ & 0.23 & $<0.001$ & 0.08 & 0.375 \\
\hline & AS & -0.07 & 0.301 & -0.16 & 0.012 & -0.10 & 0.112 & -0.03 & 0.782 \\
\hline & WT & 0.08 & 0.219 & 0.29 & $<0.001$ & 0.18 & 0.006 & 0.23 & 0.013 \\
\hline & AT & -0.05 & 0.412 & -0.26 & $<0.001$ & -0.18 & 0.007 & -0.03 & 0.736 \\
\hline \multicolumn{2}{|c|}{ Temperature } & -0.61 & $<0.001$ & -0.84 & $<0.001$ & -0.80 & $<0.001$ & 0.23 & $<0.001$ \\
\hline \multicolumn{2}{|c|}{ Rel. Humidity } & 0.64 & $<0.001$ & 0.82 & $<0.001$ & 0.79 & $<0.001$ & 0.31 & $<0.001$ \\
\hline \multicolumn{10}{|c|}{ Location 3 (Shelter facing towards roadway) } \\
\hline \multicolumn{2}{|c|}{ Vehicles } & -0.09 & 0.064 & 0.04 & 0.460 & -0.16 & 0.001 & 0.07 & 0.148 \\
\hline \multicolumn{2}{|c|}{ Heavy Veh } & 0.01 & 0.827 & 0.13 & 0.005 & -0.03 & 0.493 & 0.17 & $<0.001$ \\
\hline \multicolumn{2}{|c|}{ Wind Speed } & -0.11 & 0.252 & -0.03 & 0.730 & -0.05 & 0.601 & -0.02 & 0.813 \\
\hline \multirow{4}{*}{ 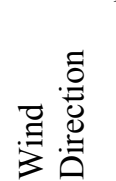 } & TS & 0.04 & 0.722 & 0.09 & 0.353 & -0.02 & 0.863 & -0.03 & 0.741 \\
\hline & $\mathrm{AS}$ & -0.07 & 0.511 & -0.03 & 0.771 & -0.11 & 0.270 & -0.02 & 0.819 \\
\hline & WT & 0.05 & 0.636 & -0.12 & 0.238 & 0.07 & 0.488 & -0.14 & 0.157 \\
\hline & AT & -0.01 & 0.931 & 0.06 & 0.518 & -0.05 & 0.635 & 0.16 & 0.108 \\
\hline \multicolumn{2}{|c|}{ Temperature } & -0.24 & $<0.001$ & -0.42 & $<0.001$ & -0.37 & $<0.001$ & -0.49 & $<0.001$ \\
\hline \multicolumn{2}{|c|}{ Rel. Humidity } & 0.38 & $<0.001$ & 0.40 & $<0.001$ & 0.24 & $<0.001$ & 0.47 & $<0.001$ \\
\hline
\end{tabular}

$r=$ Pearson correlation coefficient, $p=$ observed significance level

Bold $r$-values indicate significance at $\mathrm{p}=0.05$ level

"TS" = Towards Shelter, "AS" = Away from Shelter, "WT" = With Traffic, "AT" = Against Traffic

The strongest predictors in the correlation analysis, temperature and humidity, are also the most global. More local variables (i.e. vehicles and wind) are less correlated. Significant correlations were consistently observed for temperature and relative humidity for both UFP and $\mathrm{PM}_{2.5}$. In most instances, temperature is negatively correlated. Relative humidity was consistently observed to have a significant positive 
correlation with both particulate sizes. Vehicles, heavy vehicles, and wind speed and direction are inconsistently correlated, and few conclusions can be drawn regarding shelter design.

The inconsistencies in these results indicate the complexity of the environment surrounding the bus-stop shelters. Correlations alone are not enough to explain the relationship between multiple independent variables and particulate concentrations. Linear regression models were thus estimated to further analyze the relationships between location, traffic and meteorological variables.

Models were specified for both particulate sizes inside and outside the shelter, for a total of four models. The models presented in this section present variables significant at $\alpha=0.05$. The final model specifications are presented in Table 22 and Table 23.

The final models were estimated in two steps. First, all variables, including lagged variables and interactions between groups of variables, were included in the model. Vehicle flow was tested for interaction with both wind speed and wind direction to compare particulate levels when wind blows towards the shelter as vehicle volume varies. The location variables were tested for interaction with windrelated variables to compare wind effects for a shelter facing away from the roadway versus towards the roadway. For the second step of the estimation process, variables that were non-significant (at $\alpha=0.05$ ) were removed sequentially. In several instances during model specification, temperature and relative humidity were both significant, but the coefficient sign of one was the opposite of expected. For example, temperature and relative humidity both had negative coefficients in the model for UFP inside the shelter, indicative of high correlation and near multicolinearity. To correct the issue, one of the two variables was removed - whichever had the least effect on the overall model.

UFP levels inside the shelter are expected to decrease by $3 \%$ on average per degree Fahrenheit increase in temperature, holding constant all other variables. $\mathrm{PM}_{2.5}$ levels inside the shelter are expected to decrease an average of $2 \%$ per degree Fahrenheit increase in temperature, holding constant all other variables. Wind speed and direction are irregularly significant. Wind speed is only significant in the model for UFP inside the shelter. The coefficient sign is consistent with expectations, and UFP levels are expected to decrease an average of $19 \%$ with a one $\mathrm{m} / \mathrm{s}$ increase in wind speed, holding constant all other variables.

$\mathrm{PM}_{2.5}$ levels inside the shelter are expected to decrease an average of $20 \%$ two minutes after wind blows toward the shelter.PM $\mathrm{P}_{2.5}$ levels are expected to decrease when inside the shelter at Location 1, with Location 2 as the reference. Weather is a consistently significant descriptor in the models. Temperature and/or relative humidity are significant in every model.

Heavy vehicle flow is not significant in any model. Total vehicle flow, however, is significant in the UFP inside model. Lagged total vehicle flow is significant in the $\mathrm{PM}_{2.5}$ outside model. Lagged significance explains the time it takes vehicle-based pollution to reach the shelter from the roadway.

Interactions between wind characteristics and the location dummy variables do not yield significance. UFP concentrations are expected to be lower on average when wind speed at Location 1 increases, and higher on average when wind blows in the direction of traffic at Location 1. Finally, the joint effect of vehicle flow, wind speed, and wind direction is estimated to increase UFP concentrations inside the shelter, $\mathrm{PM}_{2.5}$ concentrations inside the shelter, and $\mathrm{PM}_{2.5}$ concentrations outside the shelter. 
Table 22. Log-Linear UFP Regression Model

\begin{tabular}{|c|c|c|c|}
\hline $\mathrm{N}=1,231$ & Inside & & \\
\hline Variable & Coefficient & SE & $\mathrm{p}$ \\
\hline Intercept & 12.0800 & 0.0846 & $<0.001$ \\
\hline Location 3 & 0.2188 & 0.0506 & $<0.001$ \\
\hline Bus Presence & 0.1272 & 0.0549 & 0.021 \\
\hline Wind Speed & -0.1722 & 0.0679 & 0.012 \\
\hline $\begin{array}{lr}\text { Wind } & \text { Direction } \\
\text { Towards } & \text { Shelter, } \\
\text { Lagged } 3 \text { Periods }\end{array}$ & -0.4534 & 0.1376 & $<0.001$ \\
\hline $\begin{array}{l}\text { Wind Direction With } \\
\text { the flow of traffic, } \\
\text { Lagged } 3 \text { Periods }\end{array}$ & -0.4138 & 0.0933 & $<0.001$ \\
\hline Temperature & -0.0336 & 0.0014 & $<0.001$ \\
\hline $\begin{array}{l}\text { Vehicle Flow : Wind } \\
\text { Speed : Wind } \\
\text { Direction with the } \\
\text { flow of traffic }\end{array}$ & 0.0002 & 0.0001 & $<0.001$ \\
\hline $\mathrm{R}^{2}$ & 0.6812 & & \\
\hline Adjusted $\mathrm{R}^{2}$ & 0.6754 & & \\
\hline $\mathrm{N}=1,231$ & Outside & & \\
\hline Variable & Coefficient & SE & $\mathrm{p}$ \\
\hline Intercept & 12.4194 & 0.0674 & $<0.001$ \\
\hline Location 3 & 0.2454 & 0.0398 & $<0.001$ \\
\hline Bus Presence & 0.1933 & 0.0496 & $<0.001$ \\
\hline $\begin{array}{l}\text { Wind Direction With } \\
\text { the Flow of Traffic, } \\
\text { Lagged } 3 \text { Periods }\end{array}$ & -0.3945 & 0.0769 & $<0.001$ \\
\hline Temperature & -0.0469 & 0.0012 & $<0.001$ \\
\hline $\mathrm{R}^{2}$ & 0.7895 & & \\
\hline Adjusted $\mathrm{R}^{2}$ & 0.7876 & & \\
\hline
\end{tabular}


Table 23. Log-Linear $\mathbf{P M}_{2.5}$ Regression Model

\begin{tabular}{|c|c|c|c|}
\hline $\mathrm{N}=1,231$ & \multicolumn{3}{|l|}{ Inside } \\
\hline Variable & Coefficient & SE & $\mathrm{p}$ \\
\hline Intercept & 3.3350 & 0.6434 & $<0.001$ \\
\hline Location 1 & -0.8616 & 0.0611 & $<0.001$ \\
\hline Location 3 & -0.7377 & 0.0377 & $<0.001$ \\
\hline Bus Presence & 0.0632 & 0.0287 & 0.028 \\
\hline $\begin{array}{l}\text { Wind Direction Towards Shelter, } \\
\text { Lagged } 2\end{array}$ & -0.1830 & 0.0700 & 0.009 \\
\hline Temperature & -0.0184 & 0.0070 & 0.009 \\
\hline $\begin{array}{l}\text { Vehicle Flow, Lagged 2Periods: } \\
\text { Wind Speed, Lagged } 2 \text { Periods: } \\
\text { Wind Direction Towards Shelter, } \\
\text { Lagged } 2 \text { Periods }\end{array}$ & 0.0002 & 0.0001 & $<0.001$ \\
\hline $\mathrm{R}^{2}$ & \multicolumn{3}{|l|}{0.9547} \\
\hline Adjusted $\mathrm{R}^{2}$ & \multicolumn{3}{|l|}{0.9538} \\
\hline $\mathrm{N}=1,015$ & \multicolumn{3}{|l|}{ Outside } \\
\hline Variable & Coefficient & SE & $\mathrm{p}$ \\
\hline Intercept & 1.6820 & 0.1481 & $<0.001$ \\
\hline Location 3 & -1.0780 & 0.0922 & $<0.001$ \\
\hline Vehicle Flow, Lagged 2 Periods & 0.00005 & 0.00002 & 0.005 \\
\hline Vehicle Flow, Lagged 3 Periods & 0.00005 & 0.00002 & 0.003 \\
\hline Wind Speed, Lagged 2 Periods & 0.0720 & 0.0292 & 0.014 \\
\hline Humidity & 0.0261 & 0.0040 & $<0.001$ \\
\hline $\begin{array}{l}\text { Vehicle Flow, Lagged 2Periods : } \\
\text { Wind Speed, Lagged } 2 \text { Periods: } \\
\text { Wind Direction Towards Shelter, } \\
\text { Lagged } 2 \text { Periods }\end{array}$ & 0.0002 & 0.0000 & $<0.001$ \\
\hline $\mathrm{R}^{2}$ & 0.8273 & & \\
\hline Adjusted $\mathrm{R}^{2}$ & 0.8225 & & \\
\hline
\end{tabular}

Following specification of the initial model for each particulate, models were tested for serial correlation, a common occurrence in time-series data sets. Time-series models are prone to serial correlation because the error term from one time period depends in some systematic way on the value of the error term in other time periods. The classical assumptions of linear regression state that the error terms of successive periods must be uncorrelated. The Durbin-Watson and Ljung-Box Q-statistic were used to test the specified models in Table 22 and Table 23; all models had significant positive serial correlation.

In the presence of serial correlation standard errors tend to be underestimated, which leads to the inclusion of non-significant variables in the model. Serial correlation for the models in Table 22 and Table 23 was corrected using an autoregressive model AR(1). After application of the AR(1) term, insignificant variables were removed and the models rerun until all variables were significant at $\alpha=0.05$. No interactive or lagged terms were significant. The final model specifications are presented in Table 24 and 
Table 25. Location 3 is statistically significant in all four models. Bus presence and temperature are significant in three models. Of the variables listed in Table 19, only vehicle flow is not significant in any model. The signs of the variables are in line with expectations, based on literature findings. The coefficients of the models indicate percentage changes in the dependent variable per unit change of the independent variable, all else equal.

Table 24. Log-Linear AR(1) UFP Regression Models

\begin{tabular}{l|l|l|l}
\hline $\mathrm{N}=445$ & \multicolumn{3}{l}{ Inside } \\
\hline Variable & Coefficient & $\mathrm{SE}$ & $\mathrm{p}$ \\
\hline $\mathrm{AR}(1)$ & 0.7326 & 0.0328 & $<0.001$ \\
Intercept & 11.7040 & 0.1559 & $<0.001$ \\
Location 3 & 0.2603 & 0.1047 & 0.003 \\
Bus Presence & 0.0986 & 0.0336 & 0.001 \\
Wind Speed & -0.0663 & 0.0456 & 0.037 \\
Temperature & -0.0304 & 0.0030 & 0.000 \\
\hline $\mathrm{R}^{2}$ & 0.5714 & \\
\hline Adjusted $\mathrm{R}^{2}$ & 0.5665 & & \\
\hline $\mathrm{N}=1,231$ & \multicolumn{3}{|l}{} \\
\hline Variable & Outside & $\mathrm{p}$ \\
\hline AR(1) & 0.7573 & 0.0191 & $<0.001$ \\
Intercept & 12.5268 & 0.1535 & $<0.001$ \\
Location 3 & 0.2761 & 0.0676 & $<0.001$ \\
Bus Presence & 0.0544 & 0.0218 & 0.003 \\
Temperature & -0.0499 & 0.0030 & 0.003 \\
\hline $\mathrm{R}^{2}$ & 0.6303 & & \\
\hline Adjusted $\mathrm{R}^{2}$ & 0.6294 & & \\
\hline
\end{tabular}


Table 25. Log-Linear AR(1) PM $_{2.5}$ Regression Models

\begin{tabular}{|c|c|c|c|}
\hline $\mathrm{N}=1,185$ & \multicolumn{3}{|l|}{ Inside } \\
\hline Variable & Coefficient & SE & $\mathrm{p}$ \\
\hline $\operatorname{AR}(1)$ & 0.9524 & 0.0096 & $<0.001$ \\
\hline Intercept & 6.0064 & 0.2476 & $<0.001$ \\
\hline Location 3 & 0.2805 & 0.1081 & 0.002 \\
\hline Bus Presence & 0.0320 & 0.0142 & 0.006 \\
\hline Temperature & -0.0657 & 0.0044 & 0.000 \\
\hline $\mathrm{R}^{2}$ & \multicolumn{3}{|l|}{0.8877} \\
\hline Adjusted $\mathrm{R}^{2}$ & \multicolumn{3}{|l|}{0.8873} \\
\hline $\mathrm{N}=223$ & \multicolumn{3}{|l|}{ Outside } \\
\hline Variable & Coefficient & SE & $\mathrm{p}$ \\
\hline $\operatorname{AR}(1)$ & 0.6851 & 0.0498 & $<0.001$ \\
\hline Intercept & 1.8402 & 0.2480 & $<0.001$ \\
\hline Location 3 & -1.0516 & 0.1822 & $<0.001$ \\
\hline Wind Speed Lag 2 & 0.0626 & 0.0234 & 0.002 \\
\hline Relative Humidity & 0.0263 & 0.0076 & $<0.001$ \\
\hline $\mathrm{R}^{2}$ & 0.7209 & & \\
\hline Adjusted $\mathrm{R}^{2}$ & 0.7158 & & \\
\hline
\end{tabular}

Wind speed variables were significant inside the shelter for UFP and outside the shelter for $\mathrm{PM}_{2.5}$. Increased wind speed inside the shelter is expected to lower UFP concentrations, indicating wind is clearing out pollutants that would otherwise collect in the confined space. Wind outside the shelter brings higher $\mathrm{PM}_{2.5}$ levels after a two-minute lag period. As temperature rises inside the shelter, we expect to see lower particulate concentrations. This temperature effect was apparent in substantially different morning and evening particulate concentrations. While the temperature range observed in this study is narrow, the temperature variable may be acting as a proxy for unspecified variables. Notably, temperature is positively correlated with the time of day (morning versus evening). Additionally, temperature can also be correlated to other weather-related phenomena, such as changing inversion layers.

Significant traffic-related variables in the autoregressive models are limited to bus presence. The routine presence of a diesel engine in close proximity to the shelters increases exposure to both UFP and PM $\mathrm{P}_{2.5}$ for passengers waiting inside the shelter, and outside the shelter for $\mathrm{PM}_{2.5}$. An unexpected outcome was the insignificance of all vehicle and heavy-vehicle-flow variables in the final AR(1) models, given the considerable body of literature showing higher pollutant levels near roadways, in which vehicles are the primary polluters. It is very likely that the joint effect of lagged vehicle pollution and wind are now captured by the serial correlation term, suggesting the importance of a period $t$ pollution level in explaining the pollution level at period $t+1$.

\subsection{SUMMARY}

This study used a comparative approach to determine the impacts of shelter design on particulate matter concentrations inside and outside bus shelters along a busy urban corridor. To the best of the authors' knowledge this was the first study that analyzes the impact of shelter orientation on transit users' 
exposure at bus stops. Bus-stop orientation is shown to play a statistically significant role in particulate matter levels and, consequently, exposure.

This study utilized a log-linear regression model with lagged variables to determine the effects of several categories of environmental influences on exposure in bus-stop shelters along busy urban corridors. Understanding how each variable differently affects particulate concentrations inside and outside a shelter is crucial for minimizing exposure for waiting transit passengers. Transit agencies do not intend for passengers to be exposed to greater particulate concentrations, though air quality considerations are not included in any known guidelines. An increasing body of research demonstrates differences in particulate concentrations in and around bus-stop shelters.

Among the traffic-related variables studied here, bus presence was the most significant and persistent variables. This result highlights the importance of reduced idling at the bus stops to improve air quality for transit riders that remain in the shelter waiting for a bus. Any operational improvement, such as Transit Signal Priority (TSP) or Automatic Fare Payment (AFP), that reduces unnecessary bus idling at bus shelters will improve air quality for transit riders. Meteorological variables (temperature and humidity) also have a significant impact on exposure. Regression results indicated that to reduce unnecessary exposure to PM and UFP pollution it is particularly important to reduce passenger waiting time inside bus shelters on colder days. 


\subsection{CONCLUSIONS AND RECOMMENDATIONS}

This report combines three different areas of research of the SCATS system: The relationship between SCATS and Transit Signal Priority (TSP), between TSP and bus driver behavior, and the correlation between signal timing and air quality, in particular, human exposure to the air pollutant $\mathrm{PM}_{2.5}$ along transit corridors. All three studies present the results of statistical tests and regressions to determine SCATS impacts.

Overall, the traffic conditions before and after SCATS were significantly different in terms of speed and volume. SCATS did show statistically significant improvements regarding traffic speeds at one minor intersection, even when traffic volumes showed a statistically significant improvement. At a major intersection results were mixed and not conclusive.

TSP was not affected by SCATS. Overall, it was determined that the improvements available through SCATS vary depending on the time of day and the direction of travel. Travel times were reduced in both directions during the off-peak period, which covers most of the day. However, the peak periods are when bus demand is the highest. During the peak periods, improvements in travel time for the entire study corridor segment were observed in the eastbound direction, while there were no improvements in the westbound direction. From the traffic evaluation it seems that after SCATS transit buses may be dealing with the same congested conditions at major intersections, but with improved conditions at a minor intersections.

The second topic of this research was an empirical analysis of TriMet's Route 9 in Southeast Portland that was performed to determine the joint effects TSP, traffic and operator behavior have on travel time and if those effects could be distinguished from each other. This study focused on the stop-to-stop travel segment in order to determine if TSP benefits at certain locations may be masked by poor performance at the corridor or route level. Traffic conditions and driver behavior were approximated by maximum speed, and predicted travel-time reductions as much as nine and 12 seconds when maximum speeds were in the upper $3^{\text {rd }}$ and $4^{\text {th }}$ quartile, respectively. Priority requests at the previous stop were shown to have only slight reductions in travel (less than one second), but the coefficients of the signalized intersection type variables proved the advantages of priority enabled signals. Non-priority signals had a much greater impact on travel time than priority signals (11.0 and 0.6 seconds for the corridor model, respectively). In controlling for both priority and operator behavior, each were shown to have a distinguished and significant impact on travel time.

All signals provided significant effects on travel time. When these coefficients were combined with the other variable coefficients describing the characteristics of the stop, contributions to travel time for each intersection were calculated. This produced an intuitive ranking of the intersections that meets expectations of Albright and Figliozzi (2012), where major intersections with high traffic volumes on cross streets are likely to not experience TSP benefits. This verification of the previous study is especially reassuring as different approaches were used for each study.

The third part of this research aimed to link pedestrian and transit-user exposure levels along an urban arterial with traffic variables. The results of this research are novel; to the best of the authors' knowledge this is the first research work that has quantified the impacts of traffic-signal timing on particulate matter pollution levels. To a high degree, this research has shown that pedestrian exposure can be considered as an outcome of traffic-signal timing decisions made by cities and counties. The statistical results have 
shown the high impact that signal timing and queuing have on pedestrian level exposure. Longer green times along the main corridor are able to significantly reduce particulate matter for transit users and pedestrians waiting at the sidewalk of the intersection, whereas time allocated to cross the street increase queuing and exposure along the main corridor. Future research can compare and quantify if delays and emissions predicted by traffic-simulation packages and emission models accurately predict sidewalk level measurements of particulate matter.

The impact of heavy-duty diesel engines is also clear. Heavy vehicle volume was a significant variable as well as the presence of buses. The reduction of bus idling time through more efficient operations and transit signal priority is likely to reduce pedestrian and transit-users' pollution exposure levels. Transit agencies can also reduce pollution significantly by improving the efficiency and cleanliness of their engines. TriMet initiatives to improve fuel efficiency by installing EMP engine cooling devices not only improve fuel efficiency but also air quality. Also, significant reductions in transit users' exposure to traffic-related pollution can be made at bus stops by properly orienting the shelter and by reducing bus idling. Any operational improvement, such as Transit Signal Priority (TSP) or Automatic Fare Payment (AFP), which can help reduce unnecessary bus idling at bus shelters will improve air quality for transit riders. 


\subsection{REFERENCES}

Albright, Eric, and Miguel Figliozzi. 2012. “A Study of the Factors That Influence Transit Signal Priority Effectiveness and Late Bus Recovery at the Signalized Intersection Level." Forthcoming in Transportation Research Record: Journal of the Transportation Research Board.

Bedada, G., Heinrich,J., Gotschi, T., Downs, S., Forsberg, B., Jarvis, D., Luczynska, C., Soon, A., Torenh, K., and Künzli, N. 2007. "Urban background particulate matter and allergic sensitization in adults of ECRHS II," vol. 210, no. 6, 2007.

Bigazzi, A. and Figliozzi, M. 2012. "The Impact of Freeway Traffic Conditions on in-Vehicle Exposure to Ultrafine Particulate Matter," Atmospheric Environment.

Byrne, Neil, Peter Koonce, Robert Bertini, Chris Pangilinan, and Matt Lasky. 2005. "Using Hardware-in-the-Loop Simulation to Evaluate Signal Control Strategies for Transit Signal Priority." Transportation Research Record: Journal of the Transportation Research Board 1925 (-1) (January 1): 227-234. doi:10.3141/1925-23.

City of Portland. Transportation Operations Innovation \& Demonstration Program 2008-2011 STIP Application - US 26 Adaptive Signal System.”

City of Portland, 2008. "Oregon Department of Transportation: Transportation Operations Innovation \& Demonstration Program".

Cools, M., Moons, E., Wets, G. 2009. "Assessing the Impact of Weather on Traffic Intensity" Transportation Research Institute, Hasselt University, Diepenbeek, Belgium.

Dickens, M., and J. Neff. APTA 2011 Public Transportation Fact Book. 2011.

Dion, Francois, Hesham Rakha, and Yihua Zhang. 2004. "Evaluation of Potential Transit Signal Priority Benefits Along a Fixed-Time Signalized Arterial." Journal of Transportation Engineering 130 (3): 294-303. doi:10.1061/(ASCE)0733-947X(2004)130:3(294).

EPA, "Particulate Matter: Air \& Radiation," [Online]. Available: http://www.epa.gov/oar/particlepollution/. [Accessed 2 July 2011].

EPA, "National Ambient Air Quality Standards," EPA, 8 November 2011. [Online]. Available: http://www.epa.gov/air/criteria.html. [Accessed 29 December 2011].

EPA, "Federal Register Proposed Rules," 29 June 2012. [Online]. Available: http://www.gpo.gov/fdsys/pkg/FR-2012-06-29/pdf/2012-15017.pdf.

FHWA."Traffic Congestion and Reliability: Trends and Advanced Strategies for Congestion Mitigation."

Furth, Peter, and Theo H. Muller. 2000. "Conditional Bus Priority at Signalized Intersections: Better Service with Less Traffic Disruption.” Transportation Research Record: Journal of the Transportation Research Board 1731 (-1) (January 1): 23-30. doi:10.3141/173104.

HCM. "Highway Capacity Manual: Chapter 16 - Signalized Intersections."

Janos, Melanie, and Peter Furth. 2002. "Bus Priority with Highly Interruptible Traffic Signal Control: Simulation of San Juan's Avenida Ponce De Leon." Transportation Research Record: Journal of the Transportation Research Board 1811 (-1) (January 1): 157-165. doi:10.3141/1811-19.

Kergaye, C., Stevanovic, A.Z., and P.T., Martin (2010). Comparative Evaluation of Adaptive 16 Traffic Control System Assessments through Field and Microsimulation. In Journal of 17 Intelligent Transportation Systems, Vol. 14, No. 2, 2010, pp. 109-114. 
Kimpel, T.J., J. Strathman, R.L. Bertini, and S. Callas. 2005. "Analysis of Transit Signal Priority Using Archived TriMet Bus Dispatch System Data." Transportation Research Record: Journal of the Transportation Research Board 1925 (-1): 156-166.

Kittelson \& Associates, Inc., KFH Group, Inc., Parsons Brinckerhoff Quade \& Douglas Inc., and K. Hunter-Zaworski. Transit Capacity and Quality of Service Manual, 2nd ed. Publication 100. Transportation Research Board, p. 572.

Kittelson and Associates, Quality Counts, and Portland State University. "Powell Blvd, Oregon Video Results.".

Kittelson \& Associates, Inc. 2008. "Traffic Signal Timing Manual," US Department of Transportation Federal Highway Administration.

Kloos, W.C., A.R. Danaher, and KM Hunter-Zaworski. 1995. "Bus Priority at Traffic Signals in Portland: The Powell Boulevard Pilot Project." In Intelligent Transportation: Serving the User Through Deployment. Proceedings of the 1995 Annual Meeting of ITS America.

Kyte, M., Khatib, Z., Shannon, P., Kitchener, F. 2000. "Environmental Factors on Free-Flow Speed" Proceedings: Fourth International Symposium on Highway Capacity, Transportation Research Circular E-C018.

Li, J.-Q., Wu, G, and Zou, N. 2011. "Investigation of the impacts of signal timing on vehicle emissions at an isolated intersection," Transportation Research Part D, vol. 16, pp. 409414.

Li, X., Li, G., Pang, S.-S., Yang, X. and Tian, J. 2004. "Signal timing of intersections using integrated optimization of traffic quality, emissions and fuel consumption: a note," Transportation Research, vol. Part D, no. 9, pp. 401-407.

Ngan, V., T. Sayed, and A. Abdelfatah. 2004. "Impacts of Various Traffic Parameters on Transit Signal Priority Effectiveness." Journal of Public Transportation 7 (3). http://trid.trb.org/view.aspx?id=741608.

ODOT. "2009 Traffic Volumes on State Highways."

Papson, A., Hartley, S. and Kuo, K.-L. 2011. "Analysis of Emissions at Congested and Uncongested Intersections using MOVES2010," in Transportation Research Board, Washington DC.

Parikh, R. I. 2006. "Effectiveness of Signal Coordination as an Emission Reduction Measure for Vehicles," University of Texas at Arlington - Masters Thesis Dissertation.

Peters, J., P. O’Brien, and J. Pachman. "Memorandum: Farmington Road Adaptive Traffic Control Benefits Analysis."

Peters, J., McCourt, R., and Hurtado, R. 2009. "Reducing Carbon Emissions and Congestion by Coordinating Traffic Signals," ITE Journal, vol. 79, no. 4, pp. 25-29.

Skabardonis, Alexander. 2000. "Control Strategies for Transit Priority." Transportation Research Record: Journal of the Transportation Research Board 1727 (-1) (January 1): 20-26. doi:10.3141/1727-03.

Soyke, N., D. Bullock, and D. Gettman. 2006. "A Systematic Approach to Evaluate Adaptive Traffic Control Methods". London.

Stevanovic, A., Stevanovic, J., and Kergaye, C., 2012. "Environmental Benefits of Adaptive Traffic Control System: Assessment of Fuel Consumption and Vehicular Emissions." Proceedings TRB Annual Conference, Washington DC, January 2012.

Strathman, James G., Thomas J. Kimpel, Kenneth J. Dueker, Richard L. Gerhart, and Steve Callas. 2002. "Evaluation of Transit Operations: Data Applications of Tri-Met's 
Automated Bus Dispatching System.” Transportation 29 (3): 321-345. doi:10.1023/A:1015633408953.

Sunkari, S. 2004. "The Benefits of Retiming Traffic Signals," ITE Journal, vol. 74, no. 4, pp. 2629.

Tao, F., Shi, Q., and Yu, L. 2011. "Evaluation of Effectiveness of Coordinated Signal Control on Reducing Vehicle Emissions during Peak Hours vs. Non-peak Hours," in Transportation Research Board, Washington DC.

TransCore. "SCATS Adaptive Traffic Control System."

TriMet. 2012. "Transit Investment Plan FY 2012." http://www.trimet.org/tip/index.htm.

Unal, A., Rouphail, N. M. and Frey, H. C. 2003. "Effect of Arterial Signalization and Level of Service on Measured Vehicle Emissions," Transportation Research Record, vol. 1842, pp. 47-56.

Vallero, D. 2008. "Fundamentals of air pollution". Academic press,. 



\section{GOTREC \\ AND EDUCATION CONSORTIUM}

P.O. Box 751

Portland, OR 97207

OTREC is dedicated to stimulating and conducting collaborative multi-disciplinary research on multi-modal surface transportation issues, educating a diverse array of current practitioners and future leaders in the transportation field, and encouraging implementation of relevant research results. 